\title{
DISCLAIMER
}

This report was prepared as an account of work sponsored by an agency of the United States Government. Neither the United States Government nor any agency thereof, nor any of their employees, makes any warranty, express or implied, or assumes any legal liability or responsibility for the accuracy, completeness, or usefulness of any information, apparatus, product, or process disclosed, or represents that its use would not infringe privately owned rights. Reference herein to any specific commercial product, process, or service by trade name, trademark, manufacturer, or otherwise does not necessarily constitute or imply its endorsement, recommendation, or favoring by the United States Government or any agency thereof. The views and opinions of authors expressed herein do not necessarily state or reflect those of the United States Government or any agency thereof.

\section{MODELING OF THERMODYNAMIC AND CHEMICAL CHANGES IN LOW-TEMPERATURE GEOTHERMAL SYSTEMS}

\author{
Amanda L. Spencer \\ Earth Sciences Division \\ Lawrence Berkeley Laboratory \\ University of California \\ Berkeley, California 94720
}

M.S. Thesis

December 1986

This work was supported by the Assistant Secretary for Energy Research, Office of Basic Energy Sciences, Division of Engineering and Geosciences, through the U.S. Department of Energy under Contract No. DE-AC03-76SF00098. 


\section{DISCLAIMER}

This report was prepared as an account of work sponsored by an agency of the United States Government. Neither the United States Government nor any agency Thereof, nor any of their employees, makes any warranty, express or implied, or assumes any legal liability or responsibility for the accuracy, completeness, or usefulness of any information, apparatus, product, or process disclosed, or represents that its use would not infringe privately owned rights. Reference herein to any specific commercial product, process, or service by trade name, trademark, manufacturer, or otherwise does not necessarily constitute or imply its endorsement, recommendation, or favoring by the United States Government or any agency thereof. The views and opinions of authors expressed herein do not necessarily state or reflect those of the United States Government or any agency thereof. 


\section{DISCLAIMER}

Portions of this document may be illegible in electronic image products. Images are produced from the best available original document. 


\section{Table of Contents}

LST OF FIGURES ………...................................................................................... i

LIST OF TABLES ………........................................................................................

NOMENCLATURE …............................................................................................. vii

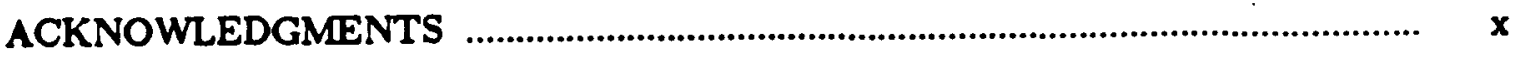

1.0 INTRODUCTION ............................................................................................

2.0 BACKGROUND ……................................................................................

2.1 Literature Review .........................................................................................

2.2 Chemistry of Low-Temperature Systems .................................................... 14

3.0 DEVELOPMENT OF THE NUMERICAL CODE ........................................... 26

3.1 Governing Equations …........................................................................... 26

3.2 Numerical Formulation ............................................................................ 30

3.3 Code Modification ........................................................................................... 35

3.4 Performance of the Code .............................................................................. 37

4.0 APPLICATION OF THE CODE .................................................................... 43

4.1 Sensitivity Studies ...................................................................................... 43

4.1.1 Approsch ...................................................................................... 43

4.1.2 Study of Kinetic Reactions ................................................................ 46

4.1.3 Study of Convective Transport ........................................................... 59

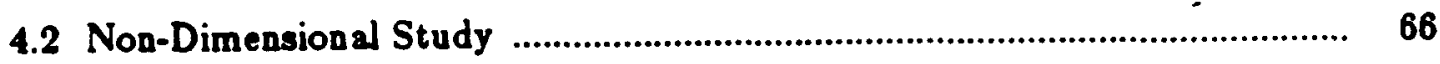

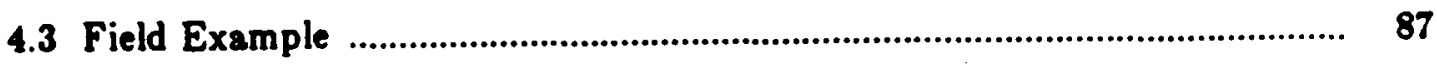

4.4 Theoretical Study .................................................................................... 114

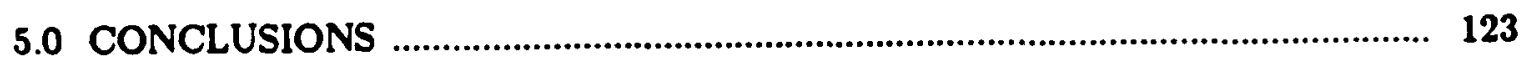

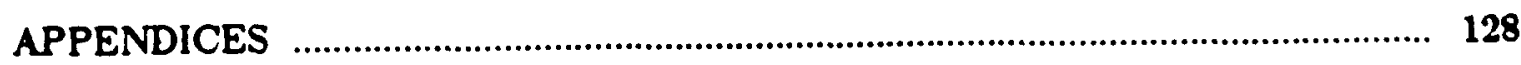

Appendix A: Equation of State for Liquid Water ........................................... 128 
Appendix B: Subroutine incorporated into the code PTCC to calculate the kinetic reactions of oxy gen-18. 


\section{LIST OF FIGURES}

Figure 1. Chlorine concentration versus time from Selfoes, Iceland

(Tomaseon and Halldorsson, 1981).

Figure 2. Chemical data from the Wairakei geothermal feld in New Zealand (Henley and Stewart, 1984)

Figure 3. Chemical data from the La Primervera geothermal field in

Figure 4. Equilibrium curves for oxygen-18 for (a) quartz/water (Clayton et al., 1972); (b) basalt/water, felaic rock/water (after Cole et al., 1983) (c) dolomite/water (A), calcite/water (B); (Northrop and Clayton, 1966).

Figure 5. Sketch showing region $R$, with subregion $V$, and unit normal î (after Lai, 1985).

Figure 6. Sketch of mesh structure with node n connected to m surrounding nodes separated by a distances of $D_{\mathrm{a}, m}$ and $D_{m, n}$ respectively, and interface ares of A (Bodvarsion, 1982).

Figure 7. Three node mesh used in testing transport of the nonreactive chemical components.

Figure 8. Analytical and numerical solutions to kinetic transport problem for oxygen-18.

Figure 9. Sketch of three-node mesh used in sensitivity studies.

Figure 10. The influence of the rock/fuid system on the kinetic reactions of oxygen-18.

Figure 11. Comparing the effects of $\delta_{R}^{181}$ on the kinetics of oxygen-18 in a dolomite/water system at a temperature of $125^{\circ} \mathrm{C}$.

Figure 12. Significance of the average grain radius on the kinetic reactions of oxygen-18.

Figure 13. Significance of porcasity on kinetic reactions of oxygen-18. 53

Figure 14. Significance of temperature on the kinetic reactions of 55 oxygen-18.

Figure 15. Significance of temperature on the kinetic reactions of silica. Initial silica is 25 ppm.

Figure 16. Significance of temperature on the kinetic reactions of silica. Initial silice is $\mathbf{5 0 0} \mathbf{~ p p m}$.

Figure 17. Significance of $A / V$ on the kinetic reactions of silica. 60

Figure 18. Significance of porcaity on silica transport by convection 62 only. 
Figure 19. Comparison between the convective transport of silices with and without kinetic reactions.

Figure 20. Significance of volume on silica transport by convection . . only.

Figure 21. Tempersture versus time for various field volumes flow rates.

Figure 22. Fitting a linear temperature function to the kinetic rateconstant for silica.

Figure 23. Equilibrium solubilities for silica (from Robinson, 1982). A linear function of temperature is assumed over the temperature range $80^{\circ} \mathrm{C}$ to $150^{\circ} \mathrm{C}$, for a-cristobolite.

Figure 24. Fitting a linear temperature function to the kinetic rateconstant for oxy gen-18.

Figure 25. Teating the uniqueneas of the nondimensional parameters for, (a) silice and (b) oxygen-18.

Figure 26. Type curves for different values of the dimensionlesi :s . parameters, $D_{1}$ and $D_{2}$, by varying $q / x$.

Figure 27. Simple croas-sectional sketch of the Ellidaar geothermal gystem (Lai, 1885).

Figure 28. Field data from the Ellidasr geothermal field (Hettling, 1984) for silica plotted non-dimensionally against dimensionless time.

Figure 29. Type curves of range in dimensionless parameter $D_{3}$, showing effect of relative recharge in from the top and side. The curves are identified in the legend by the variations made in the ratio of $\alpha$ to $\beta$ multiplied by 100 (where $100 x$ $\bar{\alpha}=\%$ tux from the top; $100 \times \bar{\beta}=\%$ flux from the side).

Figure 30. Type curves of range in dimensionless parameter $D_{3} \ldots$ Porosity has been raised to from $5 \%$ to $10 \%$. The curves are identified in the legend by the variations made in the ratio of $\bar{\alpha}$ to $\bar{\beta}$ multiplied by 100 (where $100 \times \bar{\alpha}=\%$ fux from the top; $100 \times \vec{\beta}=\%$ flux from the side).

Figure 31. Type curves of range in dimensionless parameter $D_{3}$. The $q / x$ has been decreased by an order of magnitude. The curves are identified in the legend by the variations made in the ratio of $\bar{\alpha}$ to $\beta$ multiplied by 100 (where $100 \times \bar{\alpha}=$ \% fux from the top; $100 \times \vec{\beta}=\%$ fux from the side).

Figure 32. Type curves of range in dimensionless parameter $D_{3}$. The $q / x$ has been increased by an order of magnitude. The curves are identified in the legend by the variations made in the ratio of $\bar{\alpha}$ to $\bar{\beta}$ multiplied by 100 (where $100 \times \bar{\alpha}=$ $\%$ tux from the top; $100 x \beta=\%$ fux from the side). 
Figure 33. Type curves of range in dimensionless parameter $D_{3}$. The value of $A / V$ has been increased from 5.5 to 25.0. The curves are identified in the legend by the variations made in the ratio of $\alpha$ to $\beta$ multiplied by 100 (where $100 \times \bar{\alpha}=$ \% liux from the top; $100 \times \beta=\%$ tux from the side).

Figure 34. Plot of temperature versus time showing match between numerical model and field data from the Ellidaar field.

Figure 35. Plot of fluoride versus time showing the match between the numerical model and field data from the Ellidaar field.

Figure 36. Plot of sodium versus time showing the match between the numerical model and field data from the Ellidaar field.

Figure 37. Plot of silica versus time showing the match between the numerical model and field data from the Ellidaar field.

Figure 38. Plot of oxygen-18 versus time showing the match between the numerical model and field data from the Ellidas field.

Figure 39. Map of Seltjarnarnes geothermal feld, Iceland showing layout of wells and main production area (Kristmannsdottir, 1986).

Figure 40. Two-layer mesh used to model the Seltjarnarnes geothermal area Iceland, including the initial conditions and values of field parameters.

Figure 41. Plot of silics versus time showing the match between the numerical model and feld data from the Seltjarnarnes geothermal area, Iceland.

Figure 42. Plot of chloride versus time showing the match between the numerical model and field data from the Seltjarnarnes geothermal area, Iceland.

Figure 43. Plot of sodium versus time showing the match between the numerical model and field data from the Seltjarnarnes geothermal area, Iceland.

Figure 44. Plot of oxygen-18 versus time showing the match between the numerical model and field data from the Seltjarnarnes geothermal area, Iceland.

Figure 45. Plot of temperature versus time showing the match 103 between the numerical model and field data from the Seltjarnarnes geothermal field, Iceland.

Figure 46. Silica versus time with and without kinetic transport using the best model for Seltjarnarnes.

Figure 47. The central section of the two-dimensional mesh designed to model the Seltjarnarnes geothermal field, Iceland (Tulinius et al., 1987). Small dots mark the well sites. 
Figure 48. The chlorine transport match between the numerical model and field data for the Seltjarnarnes geothermal system for (a) well SN-01; (b) well SN-02; (c) well SN-03; (d) well SN04; (e) well SN-05; (I) well SN-06.

Figure 49. The sodium transport match between the numerical model and field data for the Seltjarnarnes geothermal system for (a) well SN-01; (b) well SN-02; (c) well SN-03; (d) well SN04; (e) well SN-05; (f) well SN-06.

Figure 50. The silica transport match between the numerical model and field data for the Seltjarnarnes geothermal system for (a) well SN-01; (b) well SN-02; (c) well SN-03; (d) well SN04; (e) well SN-05; (f) well SN-06.

Figure 51. The oxygen-18 transport match between the numerical model and field data for the Seltjarnarnes geotbermal system for (a) well SN-01; (b) well SN-02; (c) well SN-03; (d) well SN-04; (e) well SN-05; (I) well SN-06.

Figure 52. Sketch ohowing the ouggeated boundary between seawater and meteoric water at the Seltjarnarnes geothermal field, lceland.

Figure 53. A simple hypothetical model of a typical geotbermal system.

Figure 54. Temperature contours for the syatem evolving under the infuence of a heat source for 100,000 years. Contour units are in $\mathrm{C}$.

Figure 55. The pattern of fuid tow and of the silica precipitation/diseolution for the system evolving under the influence of a beat source. The relative sizes of the arrows corresponds to the amount of luid low. The light shading represents the area of precipitation; the dark shading corresponds to the ares of dissolution.

Figure 56. Oxy gen-18 contours for the evolving system after 100,000 of heating. Contour units are in per mil. 


\section{LIST OF TABLES}

TABLE 1. Equations describing the equilibrium constant for each

. form of silica

TABLE 2. Temperature dependent functions for the rate and equilibrium constants of oxygen-18 for each rock/fluid system.

TABLE 3. Oxygen-18 contents of the rock types included in the present work. (Source: Henley, Truesdell and Barton, 1984)

TABLE 4. Performance test of conservative species transport using the code PTCC.

TABLE 5. Performance test on the kinetic reactions of oxygen-18 using the code PTCC.

TABLE 6. Comparison of the times to reach chemical equilibrium at various temperatures obtained by the code PTCC and those obtained using the analytical solution developed by Cole (1983).

TABLE 7. (a) Values of the parameters used in the single element model for the sensitivity studies of the kinetic reactions. (b) Values of the parameters used in the model for the convective sensitivity studies.

TABLE 8. Comparison of the equilibrium and rate constants between rock/Buid systems at $125^{\circ} \mathrm{C}$.

TABLE 9. Values of the dimensionless parameters held constant in Figures 29 through 33. 
TABLE 10. Values for the concentrations of the chemical species for the different fluids used in modeling the Seltjarnarnes Geothermal field. 
-vii-

NOMENCLATURE

A Ares $\left[\mathrm{m}^{2}\right]$

A/V . . Surface area of silica per volume $\left[\mathrm{m}^{-1}\right]$

C Concentration of silica [ppm]

C* Dimensionless concentration

CS Concentration of chemical species [ppm]

c Heat capacity $\left[\mathrm{J} / \mathrm{kg}^{\bullet} \mathrm{C}\right]$

D Coefficient of dispersion

E Total energy [J]

$\mathrm{G}_{\mathrm{f}} \quad$ Mass source $/ \mathrm{sink}\left[\mathrm{kg} / \mathrm{m}^{3} \cdot \mathrm{s}\right]$

$\mathrm{G}_{\mathrm{H}} \quad$ Heat source/ sink $\left[\mathrm{J} / \mathrm{m}^{3} \cdot \mathrm{s}\right]$

g Acceleration of gravity $\left[\mathrm{m} / \mathrm{s}^{2}\right]$

$K_{t} \quad$ Effective thermal conductivity $\left[\mathrm{kgm}^{2} / \cdot \mathrm{C}\left(\mathrm{s}^{2}\right)\right]$

k Absolute permeability $\left[\mathrm{m}^{2}\right]$

$k_{1} \quad$ Rate constant for kinetic reactions of silica $[\mathrm{m} / \mathrm{s}]$

M $\quad$ Mass $[\mathbf{k g}]$

no Direction cosine

${ }^{16} \mathrm{O} \quad$ Oxyger-16

${ }^{18} \mathrm{O} \quad$ Oxygen -18

P Pressure

$9 \quad$ Flow rate $[\mathrm{kg} / \mathrm{s}]$

$r_{1} \quad$ Rate constant for kinetic reactions of oxygen -18 $\left[\mathrm{mol} / \mathrm{m}^{2} \cdot \mathrm{s}^{1}\right]$

S Moles of oxygen in solid

SA Surface area $\left[\mathrm{m}^{2}\right]$ 


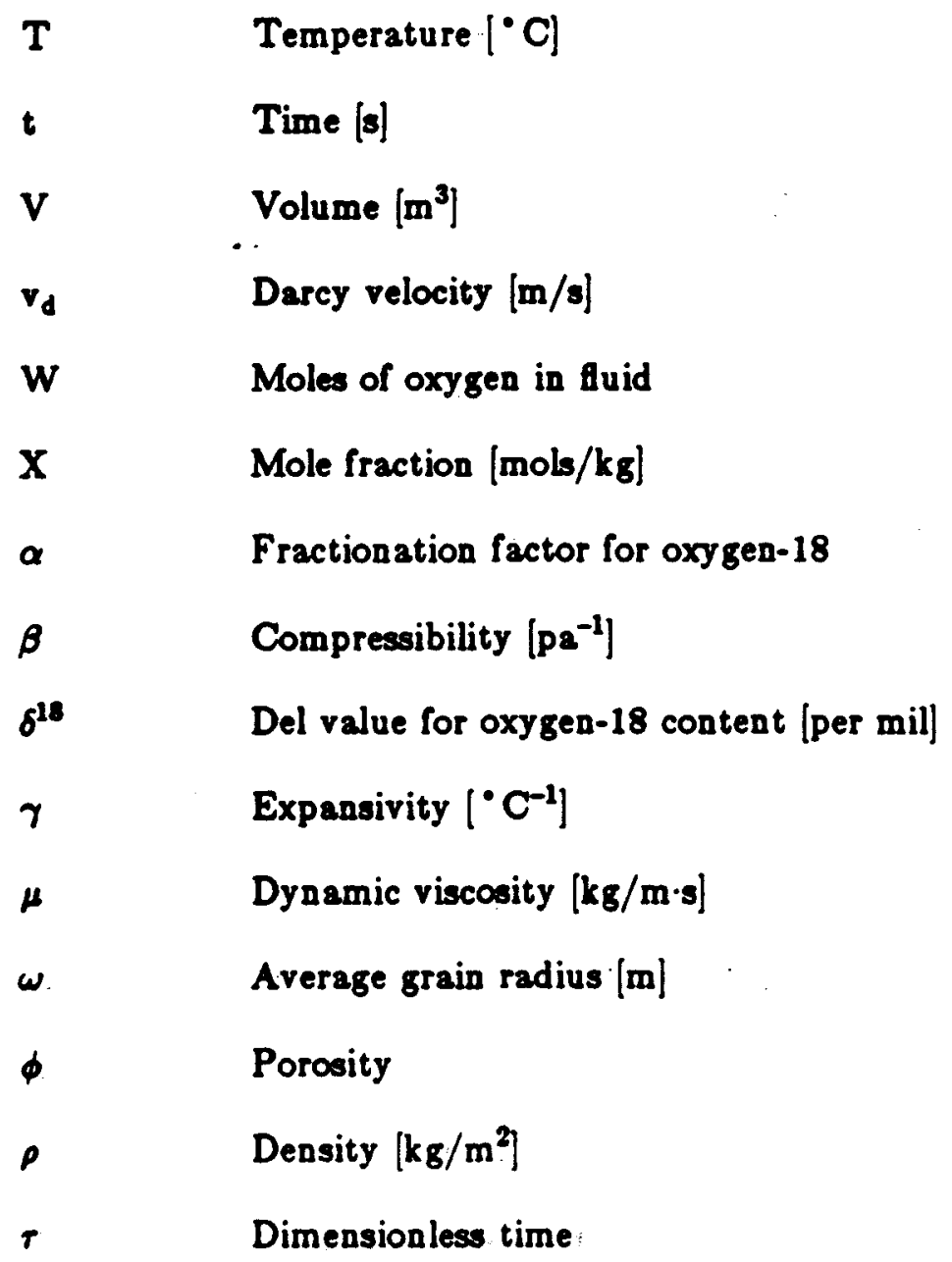


-ix-

Superscripts

eq

f

i
Equilibrium value

Final

Initial 


\section{ACKNOWLEDGEMENTS}

First, I would like to thank Dr. P.A. Witherspoon for for his support and guidance during my work on this thesis. His critical review of this work, as well as his encouragement and enthusiasm, were most appreciated. I would also like to express my deepest gratitude to Dr. G.S. Bodvarseon. His helpful suggeations contributed significantly to this project. He has greatly aided in my technical writing skills and has provided me with many fundamental techniques in approaching numerical modeling.

I would like to thank Dr. K.S. Udell for his helpful discussions and critical review of my thesis work. Very special thanks are due to Mary Bodvarsoon. Without ber help in typing and editing, this thesis would have been greatly delayed.

Finally, without the encouragement and support of Robert Prucha this work might not have been completed. His help and patience were greatly appreciated. 


\subsection{INTRODUCTION}

In recent years, study of geothermal systems as a means for energy production has significantly increased. However, the majority of this research has focused on high temperature systems, while exploration and study of low-temperature systems for direct use has received much less attention in the United States. Use of lowtemperature systems for direct use is common in many other countries, including the Soviet Union, Japan, China, and Iceland. These countries provide good examples of the benefits of utilizing low-temperature geothermal systems as an alternate means of energy.

A potential problem with the development of low-temperature geothermal systems is the risk of a rapid decline in the temperature of the system as a result of exploitation. This cooling directly affects the economic viabilities of a geothermal project and it is of great importance to be able to determine the cold water recharge zones and predict the long term rate of the temperature decline. Most previous studies of geothermal systems have consisted of developing a hydrological model of the region from existing geological and geophysical data. Mass and heat transport equations are then employed to estimate the permeability of the field, and the field volume. The role of geochemistry has been predominantly qualitative, for tracing the paths of fluid flow with tracers or indicate the temperature of the system using empirical relations between the chemical component and temperature (geothermometry).

In the present work, a method is developed to incorporate the transport of several chemical components into a model of the transport of fluid mass and heat within a geothermal system. Utilizing as much data from the geothermal system as possible would permit a more detailed understanding of the geothermal system under investigation. By incorporating the chemical transport into a mass/heat transport model, more of the available data on the geothermal field would be employed and consequently more information can be extracted from the analysis. It will be demonstrated that the use of coupled hydrological, thermal and chemical data will allow for the determination of field porosities, amounts and regions of cool recharge in to the system as well as field 
permeabilities and the hot reservoir volume. With the additional information a reliable prediction of the long-term cooling rate can be made. The economical potential of a geothermal project can then be forecasted in the early stages of the project.

\section{OBJECTIVE AND ORGANIZATION OF PRESENT WORK}

The objective of the present study is to develop a method of modeling the chemistry of low-temperature systems to aid in determining the zones and amounts of cool recharge into a system, and in eatimating the properties of a system. The study is presented in three main parts:

(1) A background on topics pertinent to the present work;

(2) Development of a numerical code incorporating chemical transport.

(3) Applications of the modified code to both theoretical and field examples.

The first part includes a literature review covering different methods of modeling geothermal systems and previous work done using these methods. Following the literature review, a short chapter is given on the behavior of chemical components common to bw-temperature geothermal systems. Several chemical components are chosen as strong candidates to be included in a modeling scheme and are discussed in more detail.

The second part involves a review of the governing equations for mass, heat and chemical transport. The numerical code, PT (Bodvarson, 1982), capable of modeling pressure and temperature, is then described. Next, modifications to PT to incorporate silica transport, performed previous to the present work by Lai (1985), are discussed. The modifications to incorporate multi-component chemical transport into the existing code are developed, and the performance of the new code tested.

In the third part of this work, the code is applied to test the sensitivity of the chemical transport to various field parameters. The chemical transport equation is non-dimensionalized, and sensitivity studies applied to dimensionless groups that are 
introduced. Next, the code is applied to two field examples, utilizing pressure, temperature and chemical data from the Ellidaar and Seltjarnarnes geothermal areas in Iceland. And a theoretical study of the evolution of low-temperature systems in terms of a circulation that is influenced by a heat source at depth and cool rainwater infiltrating at the surface is presented.

Before developing a background on the methods of modeling geothermal systems, it is helpful to define the characteristics common to the systems. Geothermal systems are classified as either high-temperature or low-temperature. High-temperature fields are above $150^{\circ} \mathrm{C}$, and are usually two phase, consisting of liquid water and steam. Low temperature fields have auid temperatures less than $150^{\circ} \mathrm{C}$ and the fluid is entirely in the liquid phase.

The majority of geothermal systems are comprised of a heat source at depth, overlain by a permeable zone saturated with fluids and recharged from waters infiltrating from the surface. Warm surface springs are common to many systems, providing a conduit for Auid to escape as the pressure within the system rises due to the incoming heat. Also, many low-temperature fields may develop due to high local thermal gradients (e.g. the Laugarnes field in Iceland). The present work is focussed on low-temperature fields and studies of both types of systems: those which developed due to a high thermal gradient and those which developed due to a beat source at depth are presented. 


\subsection{BACKGROUND}

\subsection{LITERATURE REVIEW}

Developing potentially economic geothermal oystems for direct use and for electrical power generation where possible will ease the dependance on oil and coal in the future. Creating methods to reliably study system will belp to promote the development of low-temperature systems:- According to a world survey of low-temperature geothermal utilization taken in 1980,4 countries have low-temperature geothermal resources. Of these countries, 24 are involved in exploration, 12 are utilizing the lowtemperature geothermal energy and 9 countries have conducted appraisals of the energy potentials for possible exploitation (Gudmundseon and Palmason, 1982). A report by Howard (1975a) indicates that by 1975, $400 \mathrm{MW}$-thermal were being used for residential and commercial applications, $5500 \mathrm{MW}$-thermal were being used for agriculture and $200 \mathrm{MW}$-thermal were being used for industrial applications (most of the latter from bigh temperature fields).

Residential and commercial applications consist primarily of space beating. Gertsch and Juncal (1984), have reviewed four case histories of direct use space heating projects currently in progress in Northern California at Wendel in Lassen County, Greenville in Plumas County, Big Bend in Shasta County, and Cederville in Modoc County. Space heating by these thermal systems bas significantly lowered the consumption of oil and natural gas generally required for these heating purposes. Eighty. percent of the homes and commercial buildings in Iceland utilize low-temperature geothermal energy for space heating. A survey by Hettling (1984) documents over a decade of field data making up detailed case studies for three low-temperature Gelds near Rekjavik. Tomasson (1966) and Tomasson and Halldorsson (1981) reviewed the history of the Selfoss low-temperature geothermal area in Iceland, a field which has been used for domestic heating since 1948. These examples demonstrate that utilizing low temperature thermal energy can indeed lower a region's oil dependance on 
electrical power.

Another important use of bw temperature thermal energy for the future is in agriculture. The Soviet Union has made extensive use of low-temperature geothermal energy in large acreage green bouses in areas not normally considered farmable. (The stated amount of use of $5500 \mathrm{MW}$-thermal by Howard (1975a) may be too high according to Gudmundseon and Palmason (1981)).

There are a number of ways to model geothermal systems. These methods can be split into four basic groups: (a) hydrological methods, (b) geochemical methods, (c) numerical methods involving presoure and temperature data, and (d) integrated preasure-temperature-chemiatry numerical methods. The method developed in this paper falls in the last category. However, before describing this code, it is belpiul to review the previous work doae within all of the above mentioned categories.

Hydrological methods utilize all the available data on the geology of the region, well-test analysis, and geophysical and lithological well logs, to piece together a hydrological model of the given aystem. Hydrological methods have been practiced longer than any of the other methods, and numerous examples of its application are available. A few examples of various ways to use this type of modeling on liquid dominated felds are described.

Halfman et al (1982) developed a model for the fluid flow path of the liquiddominated geothermal system at Cerro Prieto based on geophysical and lithological data, well completion data and downhole temperatures. Zais and Bodvarsson (1980) analyzed pressure and production data from geothermal systems at Wairakei, the Geysers, Larderello, and Cerro Prieto using the exponential and hyperbolic production decline type curres developed by Arp $(1045,1956)$, along with the historical data from the felds, to model the production decline of each system. Hulen and Niebon (1982) utilized surface and borebole drilling data to formulate a reservoir model of distinct thin stratigraphic aquifers in the Bacs Geothermal area. With the aid of this model, stratigraphic permeability was eatimated, and thermal fiuid flow paths traced. Benson (1982) analyzed well production data from a well near Wendel, California to eatablish a 
model in which fractures provide the main component of the revervoir permeability. Hydrological methods can be very useful, but extensive data about fié feld; often not available, in necesasy to develop an accurate model.

sranast $\leq$ seces

The second method of developing a reservoir model consists of utititing 6 Ge chemical data on a geothermal aystem. Severa approsches have been tiated to atidyzit the geochemical data. One approsch is using the documented chemicaleóncentrations as geothermometers, by applying empirical equations to describe the given chemical species concentration as a function of temperature. Several authórs (Fóurnier; 1977; Fouillac and Michard, 1981; Fournier and Truesdell, 1973; Fournier and Potter, 1982) have deacribed experimentally developed empirical equations có qứrirtz, alpha cristobalite, betercriatobalite, chalcedony, (Na/K), Na-K-Ca, Nâ/Ei, and oxygen-18. Most often, seothermometry in combined with chemical analyses tóteterifine chemical characteristic of certain bocations and to describe flow paths as wellisis aubourface temperatures. Thompaon, Grunder and Hildreth (1983) used-Na-K-Ci; Na-li relations to eatimate the near-surface and deeper reservoir temperatures combined with a detailed water chemistry analysis to determine the probable fluid low paths and sources of recharge in the liquid-dominated Calabozos Caldera Field in Central Chile. Capuano (1981) used this approsch to eatimate the eubsurface temperatures at a lowtemperature system near Arteaian City Area, Idaho, and to predict the How paths and recharge zones of the system.

The fluid chemistry of the Wendel-Amedee geothermal system in Northern California was analyzed using the above approach and the economic potential of the system for electrical and/or direct use was eatimated by studying projected temperatures and cool recharge zones (Adams, 1984). Na-K, Ca-Na, Ca-K and silica geothermometers were used in Nicaragua on a number of sites to select the most probable economically exploitable region (Tonani and Teilman, 1980). Hilfilker et al. (1980) compared silica geothermometers with temperature gradients in the central Western region of New York State to detect areas of elevated temperature, helpful in locating potential geothermally active regions. Michels (1977) developed a aimilar approach to geothermometry in which he applies an empirically derived equation relating salt 
concentrations to saturation pressures and temperatures to describe the thermodynamic behevior of low-temperature geothermal brines.

Another approsch to utilizing geochemical data for reservoir modeling is to develop ways to trace the transport of a chemical species. Konikow (1977) developed a solute-transport model to predict the morement of dissolved chloride from industrial wastes discharged into unlined ponds. He combined a finite-difference solution to the Auid bow equation with the method-of-characteristics solution to the solute-transport equation (both methods are described in detail in his paper). Many studies have utilized the concentration of the stable inotope oxygen-18, which often is characteristic to a secific region, to study the flow patterns of the fluid in a system (e.g. Giggenbach et al., 1983; Payne and Yurteever, 1974; Panichi et al., 1974; Stahl and Aust, 1974).

Other studies have concentrated on the effects of heat on the precipitation/diseolution of a chemical species within a geothermal oystem. Kandarpa and Vetter (1981) developed semi-empirical model which can predict sulfate precipitation due to injection of cool water into a geothermal system. Several studies which used simulated experimental models coupling transient flow behavior and kinetic reactions discuss the effects of silics precipitation and permeability reduction (Keith et al., 1983; Moore et al., 1981; Itoi et al., 1984). Itoi et al. (1985) developed a mathematical model of permeability reduction due to exploitation of a geothermal system using fluid flow equations, silica concentrations and equations for the kinetic reactions of silica, combined with the Kozeny-Stein equation (Camp, 1964) for permeability.

The third approach to studying and modeling geothermal systems is by numerical solutions to fuid and heat fow equations, enabling the pressure and temperature to be documented as functions of time. Most commonly a hydrological model of the system being studied is developed by utilizing available geological and geophysical data. Boundary conditions, discretization schemes and initial input parameters are determined from the hydrological model and applied to the numerical code. Several numerical codes have been developed in the past decade, and used to predict geothermal reservoir behavior under various types of conditions. Sorey (1975) developed a three- 
dimensional single-phase fnite-difference code for luid and heat transport; be applied this to the Long Valley, Californis geothermal region to study the natural convection within the system. Mercer et al. (1975) developed a single-phase finite-element code which was then applied to the Wairakei, New Zealand geothermal region and a match between field date and the calculated data achieved. Bodvarsoon (1082) developed a single phase, integrated finitedifierence method to solve the beat and mase transport equations, including the preasure and temperature dependancy of density and the temperature dependancy of viscosity, expansivity and compressibility. He applied the code to the geothermal system at Krafla, Iceland by simulating individual wells to find a match with the wellteat date. Lippmen and Bodvarmon (1085) combined a detailed hydrological review, a numerical model of the natural atate of the aystem and numerical solutions to various production atates uaing the code deacribed above to develop a comprehensive model of the Heber geothermal system in Southern California. Several studies bave utilized single-phase numerical codes to study free convection in geothermal systems (Cheng, Yeung and Lu, 1976; Elder, 1966; Rana, Horne and Cheng, 1978) Numerical simulators for two-phase flow in: high-temperature, vapor dominated systems have also been developed (eg: Costs, 1977; Toronyi and Farouq Ali, 1975; Faust and Mercer, 1979; Gars et a., 1975; Laseter et al., 1975, Pruese, 1979). These simulators have been used to model the behavior of two-phase and rapor dominated fields (eg. Moench, 1976) as well as to predict the convective heat transfer near plutons (Kang and Ahern, 1984; Catbles 1977; Norton and Knight, 1977). These will not be reviewed in detail, as the present work is mostly intereated with single-phase systems.

The fourth approsch to modeling the behavior of geothermal systems combines all three of the above approaches, utilizing every aspect of systems modeling to achieve the most comprehensive representation of the system as is possible. This involves developing a detailed bydrological model of a system from all available geological, geophysical and lithological data. Numerical solutions to the heat and mass transport equations, as well as solute transport equations are developed. Boundary conditions for the chemical species, pressure and temperature are set by the conceptual model. The behavior of the geothermal system is modeled by matching well-test data, 
downhole temperatures and pressures. The reservoir volume, permeability and possibly the amount and zones of recharge can then be eatablished. As numerical codes have become more complex and solution techniques upgraded, the integrated hydrologicak-pressure-temperature- chemistry approach has become more credible and probably the most reliable method for assessing the potential of geothermal systems. accurate solutions to geothermal models is logical.

Athough not as common, a few studies have been completed utilizing an integrated pressure-temperature-chemiatry approach to modeling hydrological systems. Norton and Taylor (1979) combined chemical and isotopic transport equations with man and heat transport in a Gnite difference code. Presoure and temperature were colved se the dependent variables and were used in turn, to solve the oxygen-18 varia tions in plagioclase. The density wa abo calculated as a function of temperature and pressure. They applied the model to the Sksergased intrusion after developing an extensive geological and geophysical background from which the initial and boundary conditions were formulated. The calculated oxygen-18 and the measured oxygen-18 were in excellent agreement for all three of the major rock units. $\mathrm{Li}$ et al. (1982) developed a mathematical model which deacribes the behavior of a hot water geothermal system eccompanied by disoolution/precipitation of silica. The luid flow, thermal energy and solute transport equations were solved using a Galerkin finite-element method for spacial derivatives and implicit fnite difference method is used for the time derivatives. Parmentier (1981) developed a finite-diference code solving mass, heat and oxygen-18 transport in a porous medium. Density was treated as a function of temperature and pressure. Oxygen-18 transport included convective transport as well as kinetic reactions between the rock and water, and oxygen diffusivity in feldspars. Parmentier used the model to study oxygen-18 depletion near igneous intrusions being cooled by groundwater convection.

Until recently, a large problem with integrated solute transport equations was the numerical diffusion introduced in the frst order fnite-difference modeling. Higher order modeling would reduce the error but could also cause large oscillations near fronts. Lai (1985) developed an integrated method which utilizes a second order Godunov scheme 
with monotonized upwind central differencing and operator splitting. By use of operator splitting; the convection terms are solved by an explicit upwind central difference method modeled after Van Leer (1977) and the diffusion terms are solved by an implicit central difference method. Lai reports negligible numerical difiusion nor oseillations, and obtained an excellent match between calculated and observed data for field data from Ellidaar, Iceland.

Or all the work reviewed, silica and oxygen-18 were the only chemical components included in an integrated pressure-temperature-chemical numerical model. But for many geothermal systems being studied, data is abo available on several other chemieal components. For example, chloride concentrations were recorded at the Selfows geothermal area from 1965 to 1080 (Figure 1). At the Laugarnes geothermal ares in Iceland, silica, chloride, eulfatea, fuoride, carbon dioxide, and total disoolved solids were recorded over a period of ten years (Hettling, 1984). Chloride concentrations from the Wairekei geothermal field in New Zeahand have been recorded (Figure 2). At the La Primavera geothermal field, in Mexico, a chemical history of the lluids including the silica, boron, and sulfate concentrations, were recorded from 1980 through 1982 (Figure 3). To best utilize all the available data on a geothermal system, an integrated hydrological-pressure-temperature-chemistry numerical code which can handle several different chemical species needs to be developed. As a first step towards this goal, a review on the chemistry of pure liquid geothermal systems is necessary. 


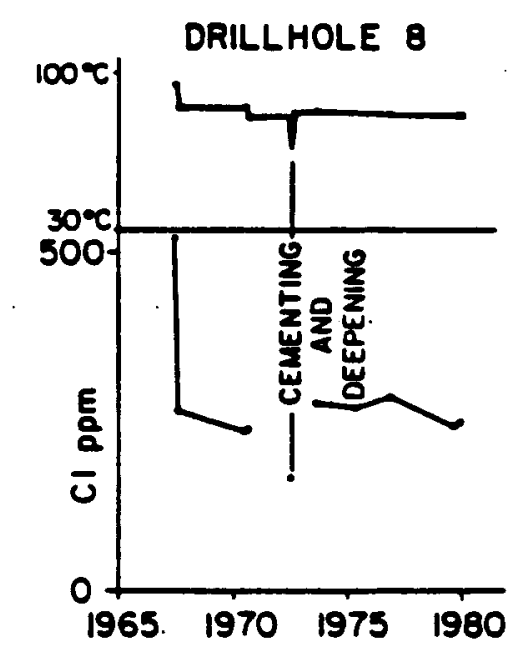

Figure 1. Chlorine concentration versus time from Selfoss, Iceland (Tomasson and Halldorsson, 1981). 


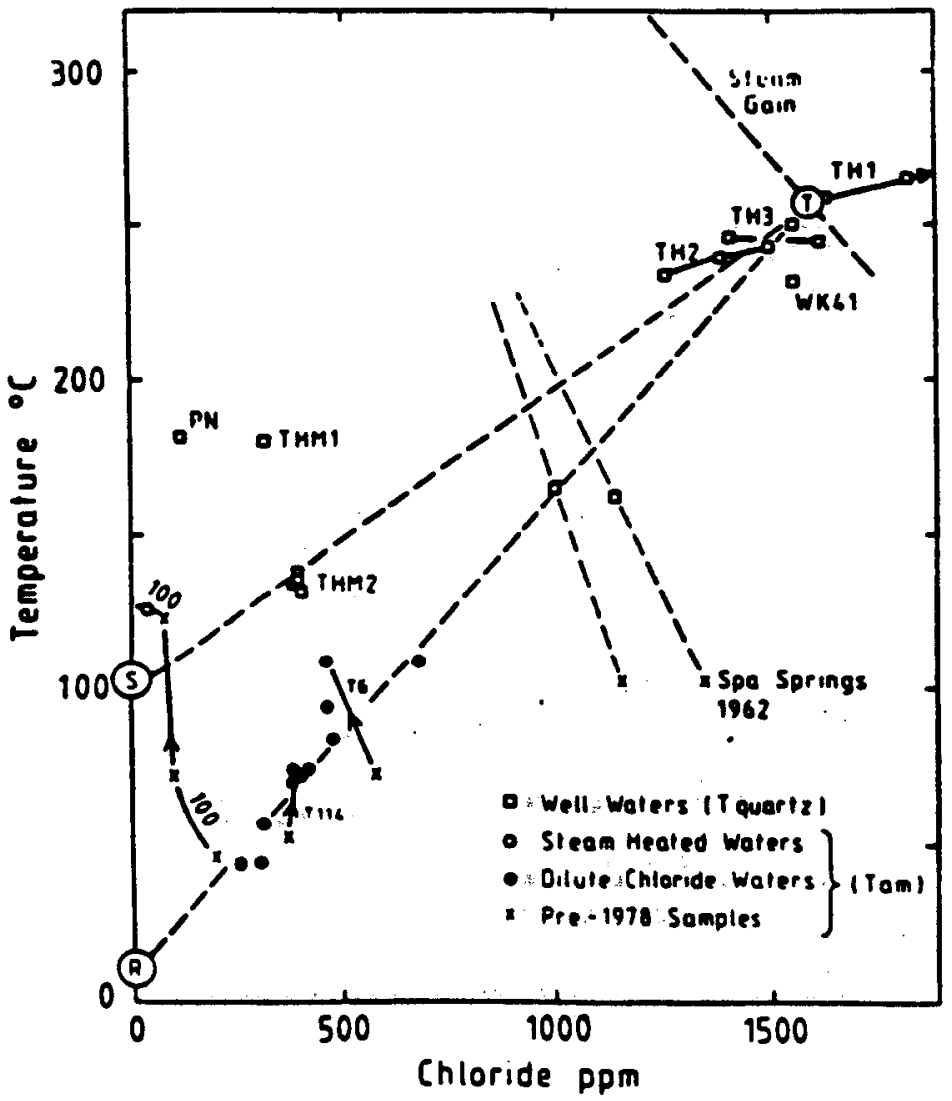

Figure 2. Chemical data from the Wairakei geothermal field in New Zealand (Henley and Stewart, 1984) 


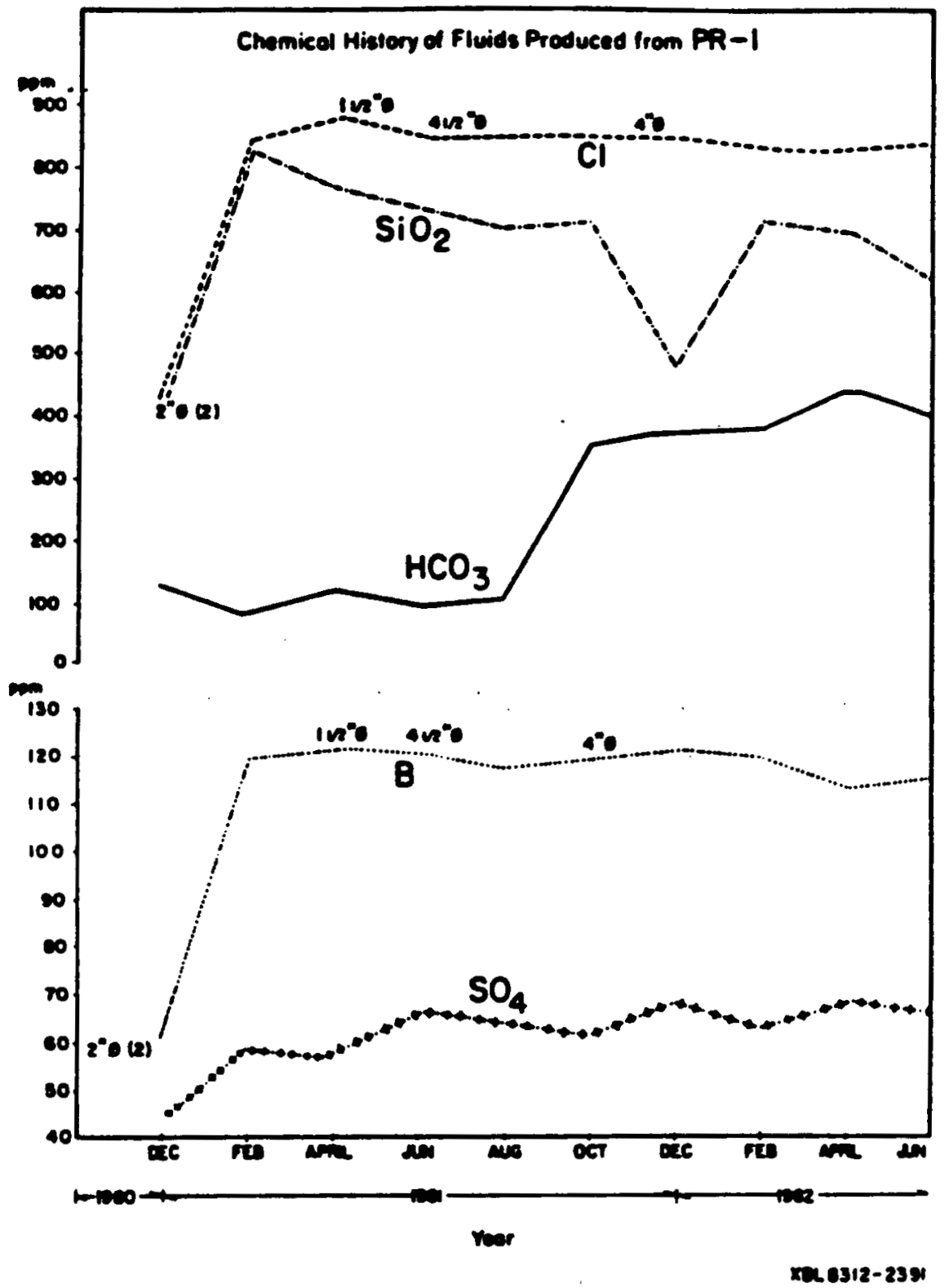

Figure 3. Chemical data from the La Primervera geothermal field in Mexico (Domingues and Lippmann, 1983). 


\subsection{CHEMITRY OF LOW-TEMPERATURE GEOTHIERMAL SYSTEMS}

The main purpose of a review of the chemistry of liquid geotbermal systems is to gain insight into the best chemical species to include in a modeling scheme. For best results a background on the behavior of the common chemical species found in liquiddominated fields is necessary before choosing which apecies to model. Once the chemical species are chosen, an indepth review of their behavior is essential.

Due to the different geologic settings of geothermal oystems; each system will have an asemblage of chemical components unique to its history and setting. Some gyatems contain only groundwaters of meteoric origin, while others near the cosat may be fed by ceawater or a mixture of meteoric water and seawater. Still other aystems may contain connate water (foosil marine water). The heat source, if magmatic, can add fuids containing a wide assortment of chemical components. The bot geothermal waters may react with their hoat rocks; diboolving components such as silica and altering primary minerals to form new mineral suites:

Although the range of chemical components in a fuid may be very complex, certain components are common to moat systems. These include: oxygen-18; silica; chloride, deuterium, calcium and sodium; less abundant but atill common to many systems are potasoium, magnesium, boron, fuoride carbonates, and sulfate. Kinetic reactions and rate constants as functions of temperature and pressure are not wellknown for any of the components listed above, except for silica and oxygen-18. This makes it difficult to determine whether or not a component is in chemical equilibrium. However, if the solubilities of the minerals containing a chemical component are low and equilibrium rates are very slow, the kinetic reactions of the species will not be: significant over small time ranges (i.e. $<100 \mathrm{yrs}$ ). Abo, if the species is not chemically active with other chemical components in solution or in the surrounding rock, and the oxidation/reaction reactions in a medium range of $\mathrm{pH}(4.0-9.0)$ are not strong, the component may be considered "non-reactive" or conservative. For the purposes of modeling the behavior of these components, kinetic/difusion effects can be ignored. $A$ 
mixing model to simulate the non-reactive chemical components can be assumed, accounting for convective transport only.

Hem (1970) reviews the behavior of all the chemical components characteristic to natural wsters. From this review it was possible to choose which components could be considered non-reactive, and included in a mixing model scheme. The stable isotope deuterium, when in solution, does not interset significantly with the surrounding country rock and is chemically atable in solution at low temperatures $\left(<200^{\circ} \mathrm{C}\right)$. With these characteriatica, it is a good candidate for a conservative model. Chloride ions do not enter significantly into oxidation/reduction reactions; they also do not form important solute complexes with other ions and are not significantly adsorbed onto mineral surfaces. Circulation of chloride ions in largely through phyaical proceseses, making it an excellant choice for a mixing model scheme. Boron and sulfate are slightly more chemically active but abo appear to be good candidates for a mixing model. Sulfate ions require specific biological factors to be present before entering into oxidation/reduction reactions and are chemically stable in aerated water. Boron is generally found in minerals resistant to chemical attack and is chemically stable in natural waters. Fluoride is generally stable in natural waters, but can form strong solute complexes with many ionic and is contained by some rery soluble minerals. Some error might incur if it is asumed a conservative apecies, but the error is likely to be insignificant.

The cations of calcium $\left(\mathrm{Ca}^{2+}\right)$, magnesium $\left(\mathrm{Mg}^{2+}\right)$, and sodium $\left(\mathrm{Na}^{+}\right)$are all subject to cation-exchange (calcium the moat, magnesium the least), which can have considerable affect on the concentration of the species in water. Calcium is very pH sensitive, precipitating a $\mathrm{CaCO}_{3}$ readily at higher values of $\mathrm{pH}$. Magnesium is much less likely to precipitate out of solution, and sodium will only precipitate at very high concentrations (>100,000 ppm). Therefore, although not completely conservative, the cations $\mathrm{Mg}^{2+}$ and $\mathrm{Na}^{+}$can be modeled in a non-reactive scheme, given the poosibility that slight error may result. Calcium is likely not to be a dependable choice for a conservative species since it is so chemically active. Potassium ions are also not a good candidate for a conservative model, as they are difficult to liberate from silicate 
minerals, and are readily rosadsorbed. Abo, the narrow range in concentration of potansium found in natural systems suggests a significant chemical control mechanism, but not enough in known for any calculations to be made.

The kinetic and diffusion reactions for oxy gen-18 between water and host rock have been studied by several authors. Oxygen-18 exchange between feldspar and water was analyzed by Yund and Anderson (1974, 1979), and O'Neil and Taylor (1967). O'Neil et al. (1969), and Northrop and Clayton (1966) have studied fractionation of oxygen-18 in carbonate-water systems. O'Neil and Taylor, (1969) covered kinetic exchange between muscovite and water; O'Neil and Kharaka (1976) studied exchange between clays and water. Oxygen-18 exchange in quartz-water aystems has been otudied by Clayton et al. (1972). Gilleti et al. (1978) and Gilleti and Andermon (1075) studied oxygen-18 diffusion in feldspar/water and mica/water systems. In most of the studies mentioned above the authors have developed temperature and/or pressure dependent equations to describe the kinetic and difusive reactions from the experimental results.

Kinetic and diffusive reactions have also been studied for silica: Rimstidt and Barnes (1980) and Boblman et al (1980) have studied the kinetics of silica-water reactions and developed temperature/preasure dependent relationships to describe the results. Fournier and Potter (1982) and Fournier et al. (1982) studied the solubility of quartz in water and sodium chloride solutions. Robinson (1982) has reviewed both the kinetic and diffusive behavior of silica, as well as providing a detailed overview of similar studies.

Due to the availability of information on silica and oxygen-18 it is possible to design more detailed model to simulate their behavior in geothermal system: The model could include transport due to convection, diepersion, kinetic reactions and sources/sinks. To pave the way for the development of this model, an in depth review of the behavior of silica and oxygen-18 are provided. 


\section{Behavior of Silica}

Silicon (Si) is the second most abundant element in the earth's crust. It is the primary building unit for most of the minerals comprising igneous and metamorphic rocks. It is present in almost all rocks and most natural waters. Silica is primarily deposited in four different forms: quartz (crystalline silica), $\alpha$-crystobalite, $\beta$-crystobalite, and amorphous or microcrystalline silics (eg., chert, flint, chalcedony, jasper). Quartz is the primary form found in igneous rocks and usually constitutes the majority of the grains in most sandstones. It is the most resistant form of silica, crystallizes at lower temperatures and remains stable through a wider temperature and pressure range. The criatobalites and microcryatalline forms are less stable and more soluble in water.

The rate law deacribing the deposition/discolution of silice is dependent on which form of silica is deposited/dissolved. It is a.function of temperature and pressure, but according to Fournier and Potter (1982), the pressure effects are small relative to the temperature effects and may be neglected without significantly affecting the results. Therefore, the rate law deacribing the kinetic reactions of silica may be written (Robinson, 1982):

$$
\frac{d C}{d t}=k_{1}\left[\frac{A}{V}\right]\left(C^{\infty q}-C\right)
$$

where $C$ is the silica concentration, $k_{1}$ is the rate constant, and $A / V$ is the surface area open to reaction per volume of syatem. The rate constant, $k_{1}$, is a function of temperature and can be written (Rimstidt and Barnes, 1982):

$$
k_{1}=\exp \left[\frac{\overline{-A}}{T}+\bar{B}\right]
$$

where $\bar{A}=9410.7, \bar{B}=0.90261$, and $T$ is the temperature in $\bullet K$.

The equilibrium constant, $\mathrm{C}^{\circ}$, for silica is predominently a function of temperature, slightly of pressure (which, as discussed above, will be neglected). Fournier and Potter (1982) developed a series of equations for the equilibrium silica concentration 
over a wide range of temperatures and pressures based on experimental data. The equations descriptive for the temperature range of $25^{\circ}$ to $300^{\circ} \mathrm{C}$ (liquid-fluid systems) are listed for each form of silica in Table 1.

TABLE 1. Equations describing the equilibrium constant for each form of silica (Temperature, $T$, is in degrees Kelvin).

Form of ailice:

Equation for $C^{\infty 9}$

Amorphous silica

$$
6 \times 10^{4}\left(\frac{\left.10^{(0.2000}-7 \operatorname{sen} \times 10^{-4} \mathrm{~T}-200.1 / \mathrm{T}\right)}{p}\right)
$$

Quartz

$$
6 \times 10^{4}\left(\frac{10^{\left(1.201-2.0200 \times 10^{-4} \mathrm{~T}-1600.0 / \mathrm{T}\right)}}{\rho_{p}}\right)
$$

a-cristobolite

$$
6 \times 10^{4}\left(\frac{10^{(-0.0021-008.2 / T)}}{\operatorname{Pr}}\right)
$$

R-cristobolite

$$
6 \times 10^{4}\left(\frac{10^{(-0.250-703.6 / T)}}{\rho_{f}}\right)
$$

Silica transport may also occur by chemical diffusion, described by:

$$
\frac{d C}{d t}=\rho_{p} D \nabla C
$$

where $D$ is the coefficient of dispersion and $\rho_{p}$ is the density of the fluid. 


\section{Behavior of Oxygen-18}

Oxygen-18 $\left({ }^{18} \mathrm{O}\right)$ and oxygen-16 $\left({ }^{16} \mathrm{O}\right)$ are both isotopes of oxygen; ${ }^{10} \mathrm{O}$ is much more common, constituting approximately $99.76 \%$ of all oxygen. Craig (1963) noted that the ratio of ${ }^{18} \mathrm{O} /{ }^{16} \mathrm{O}$ of the water in aystem is dependent on many factors, including fluid phase (gaseous, liquid or solid), latitude and elevation, siting a trend of progressive depletion of the heavy isotope $\left({ }^{18} \mathrm{O}\right)$ with distance from the tropical seas. These dependancies are primarily due to the temperature and pressure effects on the fractionation of the isotopes. The heavy isotope will preferentially enter into the condensed forms of water (rain and anow) with enrichment of ${ }^{10} \mathrm{O}$ in the remining vapor. Thus, as water in ovaporated from the sea and moves inland, it becomes steadily enriched in ${ }^{10} \mathrm{O}$ a the ${ }^{18} \mathrm{O}$ leaves with the precipitation. Becsuse of this, a fuid's oxygen-18 content will be characterintic of its cource and may be useful in determining flow paths within a system.

Oxygen-18 is usually measured in terms of its "del value," defined by:

$$
\delta^{18} O_{f}=\left[\frac{\left(\frac{18}{{ }^{16} 0}\right)_{\text {mea }}-\left(\frac{18 O}{16}\right)_{\text {SMOW }}}{\left(\frac{18 \mathrm{O}}{{ }^{16} \mathrm{O}}\right)_{\text {SMOW }}}\right] \times 10^{3} \%_{0} \text { (permil) }
$$

where $\left({ }^{18} \mathrm{O} /{ }^{16} \mathrm{O}\right)_{\text {men }}$ is the measured value, and $\left({ }^{18} \mathrm{O} /{ }^{16} \mathrm{O}\right)_{\text {smow }}$ is the value for standard mean ocean water. The SMOW standard is based on a hypothetical water sample with an isotopic ratio of oxygen similar to an average sample of ocean water with a value of 0.0 per mil. Thus, the per mil value of the oxygen-18 becomes more negative with distance inland from the sea and ranges between -7.0 and -11.0 in most regions.

Like silica, oxygen-18 within the fluid will react with the oxygen of the bost rock by intersurface reactions. The rate law for the interface reactions is predominantly dependent upon temperature (A.H. Trueadell, personal communication, March 1986). It also depends upon the crystallinity of the system, the rock type, and the average grain size of the rocks. Thus, an understanding of the lithology of the system is neces sary to describe the rate of kinetic reactions. According to Cole (1983), the rate law 
for the kinetic reactions of oxygen-18 in water may be written:

$$
\frac{d W_{2}}{d t}=\left(\frac{A}{S W}\right) r_{1}\left(W_{2}+W_{2}-W_{2}\right)\left(W_{1}+\alpha S_{1}\right)
$$

where $r_{1}$ is the rate constant, $W$ is moles of oxygen in water, $S$ is moles of oxygen in solid, $A$ is the total surface area of reaction, $\alpha$ is the fractionation factor, subscript 1 is oxygen-16, subscript 2 is oxygen 18, and superseript eq is the equilibrium value. Finally, since oxygen-18 makes up a very small part of the total amount of oxygen in the fluid and $\alpha$ is generally near unity, the following approximation will be used in the present study:

$$
\left(W_{1}+\alpha S_{1}\right) \approx(W+S)=\text { totalmolesofoxy genin thesystem. }
$$

As mentioned earlier, oxygen-18 in mont often meseured an a del value; therefore, it would most useful to get the rate law in the "del" form. In terms of the parameters $W, S, S_{1}, W_{1}, W_{2} ; S_{2}$; the del value is:

$$
\delta^{18} \mathrm{O}_{\mathrm{f}}=\left[\frac{\left(\frac{\mathrm{W}_{2}}{\mathrm{~W}_{1}}\right)_{\text {moes }}-\left(\frac{\mathrm{W}_{2}}{\mathrm{~W}_{1}}\right)_{\text {SMOW }}}{\left(\frac{\mathrm{W}_{2}}{\mathrm{~W}_{1}}\right)_{\text {SMOW }}}\right] \times 10^{3} \% 0
$$

Therefore,

$$
\begin{aligned}
& w_{2}=\left[\left(\frac{\left(\delta_{18} O_{f}\right)}{10^{3} \%}+1\right)\left(\frac{W_{2}}{W_{1}}\right)_{\text {SMOW }}\right] \cdot W_{1} \\
& W_{2}^{9 q}=\left[\left(\frac{\left(\delta^{18} O_{f}^{+9 q}\right)}{10^{30 \%}}+1\right)\left(\frac{W_{2}}{W_{1}}\right)_{\text {SMOW }}\right] \cdot W_{1}
\end{aligned}
$$

and

$$
\frac{d W_{2}}{d t}=\left(\frac{W_{1}}{10^{3} \%}\right)\left(\frac{W_{2}}{W_{1}}\right)_{\text {SMOW }} \cdot\left(\frac{d \delta^{18} O_{p}}{d t}\right)
$$


We also have

$$
\frac{d \delta^{18} O_{f}}{d t}=\left(\frac{S+W}{S W}\right) A \cdot r_{1}\left(\delta^{18} O_{f}-9-\delta^{18} O_{f}\right)
$$

The rate constant is defined by (Cole et al., 1985):

$$
r_{1}=\exp \left[\frac{-A^{\prime}}{T}+B^{\prime}\right]
$$

where $A^{\prime}$ and $B^{\prime}$ are constants dependent on the type of rock/fluid system (see Table 2 for the values of the constants for each rock/fluid system included in the present study).

TABLE 2. Temperature dependant functions for the rate and equilibrium conatents of oxysen-18 of each rock/Guid system.

\begin{tabular}{ccccc}
\hline Rock & $\begin{array}{c}\text { log } \mathrm{r}_{1} \\
(\mathrm{~T} \text { in } \mathrm{K})\end{array}$ & Source & $\begin{array}{c}\Delta_{\mathrm{R} W}^{\mathrm{eq}} \\
(\mathrm{T} \text { in } \cdot \mathrm{C})\end{array}$ & Source \\
\hline Basalt/seawater & $-2520 / \mathrm{T}-4.80$ & 1 & $-0.01463 \mathrm{~T}+7.85$ & 1 \\
Basalt/water & $-2520 / \mathrm{T}-4.80$ & 2 & $-0.052 \mathrm{~T}+15.2$ & 2 \\
Granite/seawater & $-2000 / \mathrm{T}-4.15$ & 2 & $-0.075 \mathrm{~T}+23.5$ & 2 \\
Granite/water & $-1300 / \mathrm{T}-5.73$ & 2 & $-0.070 \mathrm{~T}+23.5$ & 2 \\
Quartz/water & $-1250 / \mathrm{T}-6.55$ & 2 & $-0.05 \mathrm{~T}+22.0$ & 3 \\
Calcite/water & $-2250 / \mathrm{T}-3.35$ & 2 & $-0.038 \mathrm{~T}+18.1$ & 4 \\
Dolomite/water & $-2500 / \mathrm{T}-2.75$ & 2 & $-0.046 \mathrm{~T}+21.4$ & 5 \\
\hline
\end{tabular}




\section{Sources}

(1) Cole et al., 1986

(2) Cole, 1983

(3) Clayton et al., 1972

(4) O'Neil, 1963

(5) Northrop and Clayton, 1975

The total surface area of reaction, $A$, varies slightly between rock types due to the different grain geometries characteriatic of the rock type. According to Cole et al. (1983), for rock types with predominantly spherical grains (basslts, granites, quartz), the surface ares of reaction is (in meters):

$$
A=4 \pi \omega^{2}\left[\frac{M_{R}}{\rho_{R} 1.33 \pi \omega^{3}}\right]=\frac{3 V(1-\phi)}{\omega}
$$

and for carbonates:

$$
A=(b h)\left[\frac{M_{R}}{\rho_{R} b h(2 \omega)}\right]=\frac{3 V(1-\phi)}{\omega} ;
$$

where $M^{R}$ is the mass of the solid, $p^{R}$ is the density of the solid, $V$ is the total volume of the sample, and $\omega$ is the average grain radius (or one half the average grain width in the case of the carbonates).

The equilibrium value can be expressed by

$$
\delta^{18} O_{i}^{19}=\frac{\left(\delta^{18} O_{R}^{i}-\Delta_{R}^{e q}+\frac{W}{S} \cdot \delta^{18} O_{i}^{i}\right)}{1+\frac{W}{S}}
$$

where $\Delta_{R}{ }^{*} W$ is the equilibrium isotopic fractionation value, $\delta^{18} \mathrm{O}_{\mathrm{f}}^{i}$ is the initial oxygen18 measurement in rock, and $\delta^{18} \mathrm{O}_{f}^{i}$ is the initial oxygen-18 measurement of the fluid.

In a most geothermal system, the value for $W / S$ is less than 0.1 and equation $12 a$ may be simplified to: 


$$
\delta^{18} O_{f}^{e q}=\delta^{18} O_{R}^{i}-\Delta_{R W}^{e q}
$$

without significant error. From equation 12b, the importance of the amount of oxygen-18 within the rock on the equilibrium oxygen-18 content is apparent. The $\delta^{18} O_{R}$ content varies greatly between different rock types. Table 3 lists the typical range of $\delta^{18} \mathrm{O}_{R}$ for each rock type included in the presented study.

TABLE 3. Oxygen-18 contents of the rock types included in the present work. (Source: Henley, Trueadell and Barton, 1984)

Rock Type

\begin{tabular}{lc}
\hline Granite & $10-25$ \\
Carbonates & $10-20$ \\
Basalts & $5-10$ \\
Quartz & $10-25$. \\
\hline
\end{tabular}

The equilibrium rock/Guid fractionation value is a function of temperature and is dependent upon the rock/fluid system. In most studies on oxygen-18 fractionation, the results are not expreased in terms of the $\Delta_{R w}$ value, but as the isotopic fractionation factor. The "per mil" fractionation, or $10^{3} \ln \alpha$, is often a linear or approximate linear function of temperature over small temperature ranges. According to Friedman and O'Neil (1977), the "per mil" fractionation can be approximated by the rock/fuid fractionation:

$$
10^{3} \ln \alpha \approx \Delta_{\mathrm{RW}}
$$

or

$$
10^{3} \ln \alpha^{\bullet 9} \approx \Delta_{\mathrm{R} W}
$$


Therefore, the results of studies on the equilibrium curves between the "per mil" fractionation value and temperature were used in this study to expreas the equilibrium rock/fluid fractionation value as a linear function of temperature. Figure 4 shows the equilibrium curve for each rock/fluid system and, referring back to Table 2, the linear temperature functions assumed in this study are listed. Inspecting the curves in Figure 4, indicates that the use of a linear temperature function over small temperature ranges should not introduce a significant amount of error. However, most of the studies on the fractionation of oxygen were performed at high temperatures; it is assumed in the present work that the curves can be extrapolated to bwer temperatures. Also, due to the lack of information svailable on several of the rock/fluid systems, some approximations were neceasy. Specifically, for baalt/water the temperature function of the kinetic rate constant was not available, therefore the same function a for the basalt/seawater rate constant was sesumed. Information on the equilibrium rock/water fractionation value, $\Delta_{R}{ }^{\circ}$, for a granite/seawater system, was not availablë. As a substitute, the function for a felsic rock/water system was incorporated into the kinetic transport equations. As a result of these approximations, modeling the kinetic transport within a basalt/water or granite/seawater system will not be as accurate as in the other rock/luid systems. 

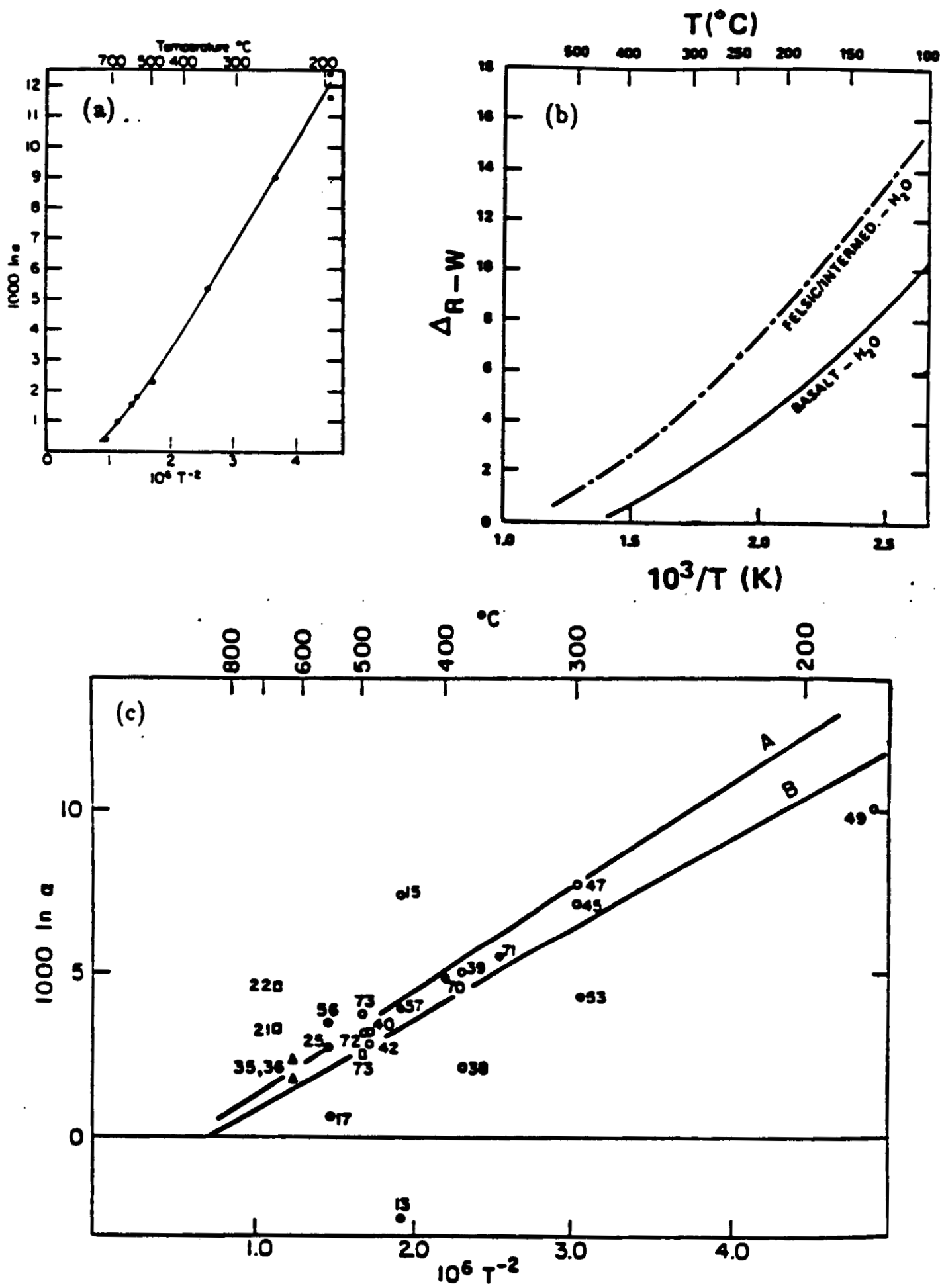

Figure 4. Equilibrium curves for oxygen-18 for (a) quartz/water (Clayton et al., 1972); (b) basalt/water, felsic rock/water (after Cole et al., 1983) (c) dolomite/water (A), calcite/water (B) (Northrop and Clayton, 1966). 


\subsection{DEVELOPMENT OF NUMERICAL CODE}

To develop the numerical method used in this paper, the code PTC (Lai, 1985) was expanded to include transport modeling of non-reactive chemical components and the transport of oxygen-18. PTC is an integrated pressure-temperature-chemistry numerical code capable of modeling two-dimensional fuid, heat and silica transport in fractured porous media. A combination of the second order Godunov method and operator splitting is utilized to solve the convection-diffusion-type equations. The code

PTC was originally developed from PT (Bodvarseon, 1982), a numerical code for modeling three-dimensional transport of tuid and beat.

The newly expanded code PTCC utilizes the method developed by Lai to simulate the transport of oxygen-18 and the non-reactive species. To describe the development of PTCC, the governing equations for fluid, heat, and chemical transport are . presented. A review of the numerical formulation of the governing equations for fluid and heat transport used in PT, and the modifications of PT introduced by Lai (1985) in developing PTC follow. Finally; a section on the additions made to PTC in developing PTCC, as well as an account of the performance of the expanded code are presented.

\subsection{GOVERNING EQUATIONS}

To model the heat, fluid and chemical transport for a single-phase geothermal system, the basic laws of conservation need to be introduced.

\section{Conservation of Mase}

Consider a region, $R$, of a geologic formation, saturated with a liquid fluid and containing a fixed subregion, $V$ (Figure 5). The rate of change of the mass of fluid within $V$ can be expressed as

$$
\frac{d M_{f}}{d t}=\int_{V} \frac{\delta\left(\phi \rho_{t}\right)}{\delta t} d V+\int_{V} G_{r} d V
$$




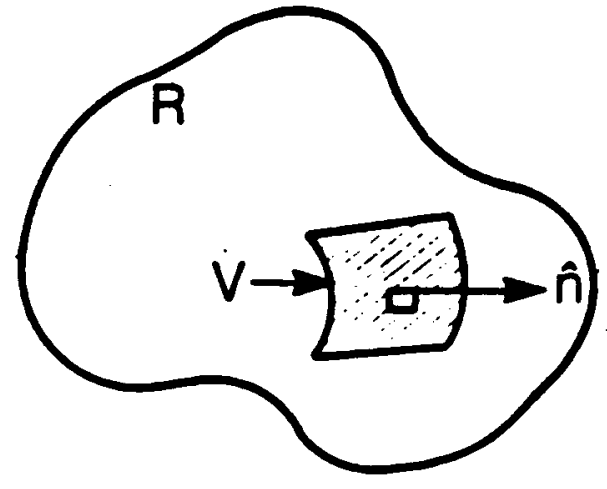

Figure 5. Sketch showing region $R$, with subregion $V$, and unit normal $\hat{n}$ (after Lai, 1985). 
where $M$ is the total mass of fluid within $V, \phi$ is the porosity, $G_{p}$ is the mass generation rate per unit volume within $V$ and $t$ is time. The left hand term in Eq. 14 is the total mase flow rate acroes the boundaries of $V$ and can be expressed as a surface integral by

$$
\frac{d M_{f}}{d t}=\int_{A} \rho_{f} \vec{\nabla}_{d} \cdot \hat{\mathbf{b}} d \Lambda
$$

where $\hat{\mathbf{n}}$ is the outward unit normal vector, $\mathbf{d A}$ is the elemental surface area and $\vec{\nabla}_{d}$ is the fluid relocity. The fuid velocity can be calculated by Darcy's Law:

$$
\nabla_{d}=\frac{-k}{\mu}\left(\nabla P+\rho_{\bar{B}}\right)
$$

where $k$ is the intrinaic permeability, $\mu$ is the dynamic visconity, $\mathbf{P}$ is the preasure and $\bar{Z}$ is the acceleration due to gravity. Subatituting (15) into Eq. 14 and rearranging, we have.

$$
\int_{v} \frac{\delta\left(\phi \rho_{f}\right)}{\delta t} d V=-\int_{A} \rho_{i} \nabla_{d} \cdot \hat{\mathbf{n}} d A+\int_{V} G_{i} d V
$$

According to the divergence theorem, the first term on the right-hand side may be written 2

$$
\int_{A} \rho_{r} \vec{\nabla}_{d} \cdot \hat{n} d A=\int v \nabla \cdot \rho_{f} \vec{\nabla}_{d} d V
$$

Substituting this back into (17), we have the integral form of the continuity equation:

$$
\int_{v} \frac{\delta\left(\phi p_{f}\right)}{\delta t} d V=-\int_{v} \nabla \cdot \rho_{p} \vec{\nabla}_{d} d V+\int_{v} G_{p} d V
$$

\section{Concervation of Energy}

Considering the same region $R$, with subregion, $V$, the rate of change of energy within $V$ may be written as

$$
\frac{d E}{d t}=\int v\left[\frac{\delta\left(\phi \rho_{r} c_{f}\right)}{\delta t}+\frac{\left.\delta(1-\phi) \rho_{r} c_{r}\right)}{\delta t}\right] T d V+\int_{v} G_{H} d V
$$


where subscripts $f$ and $\mathrm{r}$ refer to fluid and rock respectively, $c$ is the specific heat, $T$ is the temperature and $E$ is the total amount of energy within subregion V. The total energy flow rate, (dE/dt), acroos the boundaries of $V$, is composed of the heat flux due to convection and the heat flux due to conduction. By Fourier's Law for hoat flow, the conductive fux term can be described by

$$
\vec{q}_{\text {cood }}=-K_{\imath} \nabla T
$$

where $K_{t}$ is the effective thermal conductivity of the subregion $V$. The convective flux is described by

$$
q_{\text {eoser }}=\rho_{p} \nabla_{d} c_{f} T
$$

Subatituting (21) and (22) into Eq. 20 gives

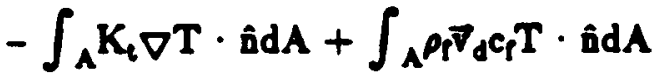

$$
\begin{aligned}
& =\int_{V}\left[\frac{\delta\left(\phi \rho_{P_{f}}\right)}{\delta t}+\frac{\delta\left((1-\phi) \rho_{r} c_{r}\right)}{\delta t}\right] \cdot T d V+\int_{V} G_{F t} d V
\end{aligned}
$$

Once again, the divergence theorem may be used to transform the surface integrals in to volume integrala. Applying the theorem and rearranging terms gives the energy equation in integral form:

$$
\begin{aligned}
& \int v\left[\frac{\delta\left(\phi \rho_{r_{f}}\right)}{\delta t}+\frac{\delta\left((1-\phi) \rho_{r} c_{r}\right)}{\delta t}\right] \mathrm{TdV} \\
& =-\int_{V} \nabla \cdot K_{i} \nabla T d V+\int_{V} \nabla \cdot \rho_{r} \nabla_{d} c_{f} T d V+\int_{V} G_{H} d V
\end{aligned}
$$

\section{Conservation of Chemical Specie.}

To develop the solute equation, a similar method as was taken for the mass and energy equation can be applied. A mass balance of the chemical species over subregion $V$ can be expressed as

$$
\frac{d C S}{d t}=\int v \frac{\delta\left(\phi_{\rho} C S\right)}{\delta t} d V+\int v G_{r} C S_{r} d V
$$


where CS is the concentration of the solute, CS the concentration of the solute within the fluid being generated. The rate of change in concentration of the chemical species, (dCS/dt), consists of chemical fux due to dispersion and fux due to convection. These inay be expresed as

$$
\overrightarrow{\mathrm{q}}_{\text {disp }}=\rho_{\mathrm{f}} \mathrm{D} \nabla \mathrm{CS}
$$

and

$$
q_{\text {conv }}=-\rho_{p} \vec{\nabla}_{d} C S
$$

where $D$ is the coeficient of dispersion.

As was done for the energy equation, we first take the total tux acrose the boundaries of $V$, and apply the divergence theorem to tranoform the surface integrals into volume integrals. After substituting these back into the original equation, we have the integral form of the solute transport equation:

$$
\begin{aligned}
\int_{v} \frac{\delta\left(\phi_{\rho} C S\right)}{\delta t} d V= & \int_{v}\left(\nabla \cdot \rho_{p} D_{i j} \nabla C S\right) d V-\int_{v}\left(\nabla \cdot \rho_{p} \nabla_{d} C S\right) d V+ \\
& \int_{v} G_{p} C S_{p} d V
\end{aligned}
$$

where $D_{i j}$ is the dispersion tensor necessary for the two-dimensional system.

\subsection{NUMERICAL FORMULATION}

Well-test data on geothermal systems usually provide the temperature, pressure and chemical concentrations within the system. In the governing equations developed above; these will be considered the primary dependant variables. In developing PT, Bodvarsoon (1982) took into account the temperature and/or pressure dependance of the density, viscosity, compressibility and expansivity. These are considered the secondary dependant variables and are calculated after the temperature and pressure have been solved for, using the equations of state for water and rock. The equations of state may be written: 
For the fluid,

$$
\begin{gathered}
\rho_{p}=\left.\frac{1}{\rho_{p}} \frac{\delta \rho_{p}}{\delta P}\right|_{T} \\
\cdots \\
\gamma_{p}=\left.\frac{1}{\rho_{p}} \frac{\delta p_{p}}{\delta T}\right|_{P}
\end{gathered}
$$

For the rock,

$$
\begin{gathered}
\beta_{\mathrm{r}}=\left.\frac{1}{\phi} \frac{\delta \phi}{\delta \mathrm{P}}\right|_{\mathrm{T}} \\
\gamma=\left.\frac{1}{\phi} \frac{\delta \phi}{\delta \mathrm{T}}\right|_{\mathrm{P}}
\end{gathered}
$$

where $\beta=$ compreasibility, and $\gamma=$ expanaivity.

The density of the luid is dependant on temperature and pressure and is calcu: lated by (Buscheck, 1980; Bodvarsoon, 1982):

$$
p_{p}=A(T)+B(T) \cdot C(P)
$$

The functions $A(T), B(T)$, and $C(P)$ are given in Appendix $A$.

Viscosity is considered only a function of temperature, and the pressure effects are neglected. The equation for the viscosity of the fluid is written (Bodvarsson, 1982):

$$
\mu=a_{1} 10.0^{\left[\frac{a}{T+a_{0}}\right]}
$$

where $a_{1}=2.414 \times 10^{-5}, a_{2}=247.8$, and $a_{3}=133.15$.

The specific heats for the fluid and the rock are considered constant, as is the effective thermal conductivity. For the three-dimensional code PT, Bodvarsoon (1982) transformed the integral form of the governing equations for fluid and beat into numerical notation and used the integrated finite difference method (Edwards, 1972; Sorey, 1975; Narasimban and Witherspoon, 1976), for their solution.

In Dumerical notation the mass equation becomes

$$
\left(V_{\phi \rho_{\mathrm{f}}}\right)_{\mathrm{a}}\left[\beta_{\mathrm{t}} \frac{\Delta \mathrm{P}_{\mathrm{a}}}{\Delta \mathrm{t}}-\gamma_{\mathrm{t}} \frac{\Delta \mathrm{T}_{\mathrm{a}}}{\Delta \mathrm{t}}\right]
$$




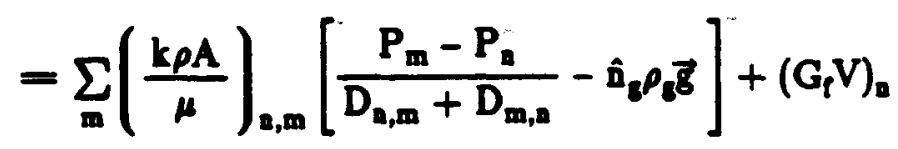

and the energy equation becomes

$$
\begin{aligned}
& {\left[(\rho c)_{m} V\right]_{n} \frac{\Delta T_{\mathrm{g}}}{\Delta t}=\sum_{m}\left[\frac{\left(K_{\mathrm{t}} \Lambda\right)_{\mathrm{a}, \mathrm{m}}}{D_{\mathrm{n}, \mathrm{m}}+\mathrm{D}_{\mathrm{m}, \mathrm{m}}}\left(T_{\mathrm{m}}-T_{\mathrm{g}}\right)\right.} \\
& \left.+\left(\frac{\rho c_{p} A k}{\mu}\right)_{\mathrm{n}, \mathrm{m}}\left(T_{m, \mathrm{a}}-T_{\mathrm{a}}\right)\left[\frac{P_{\mathrm{m}}-P_{\mathrm{a}}}{D_{\mathrm{n}, \mathrm{m}}+D_{\mathrm{m}, \mathrm{e}}}-\hat{\mathbf{n}}_{\mathrm{a}} \rho_{\mathrm{g}} \overrightarrow{\mathrm{g}}\right]\right]+\left(\mathrm{G}_{\mathrm{h}} \mathrm{V}\right)
\end{aligned}
$$

$\beta_{t}$ and $\gamma_{t}$ are the total compressibility and total thermal expansivity, respectively, and are written as

$$
\begin{aligned}
& \beta_{t}=\beta_{r}+\beta_{t} \\
& \gamma_{t}=\gamma_{p}+\gamma_{t}
\end{aligned}
$$

The equations are solved for a node, $n$, connected to an arbitrary number of nodes, $\mathbf{m}$. $D_{\mathrm{a}, \mathrm{m}}$ and $D_{\mathrm{m}, \mathrm{a}}$ represent the diatance from nodes $\mathrm{n}$ and $\mathrm{m}$ to the interface between the two nodes (Figure 6).

The code utilizes an upatream weighting technique for the interface temperatures. The implicit formulation used incorporates an option to use a fully implicit, fully explicit or intermediary scheme by specifying the weighting factor, ap, as a value between 0 and 1:

$$
\begin{array}{ll}
a_{p}=0 & \text { fully explicit } \\
2_{p}=1 & \text { fully implicit } \\
2_{p}=0.5 & \text { Crank-Nicholson }
\end{array}
$$

The spacial gradients are estimated by a linear approximation. The permeability and thermal conductivity of the matrix are calculated using a harmonic mean to ensure continuity of flux at the interface. For a more detailed description of the code see Bodvarsson (1982). 
$-33$

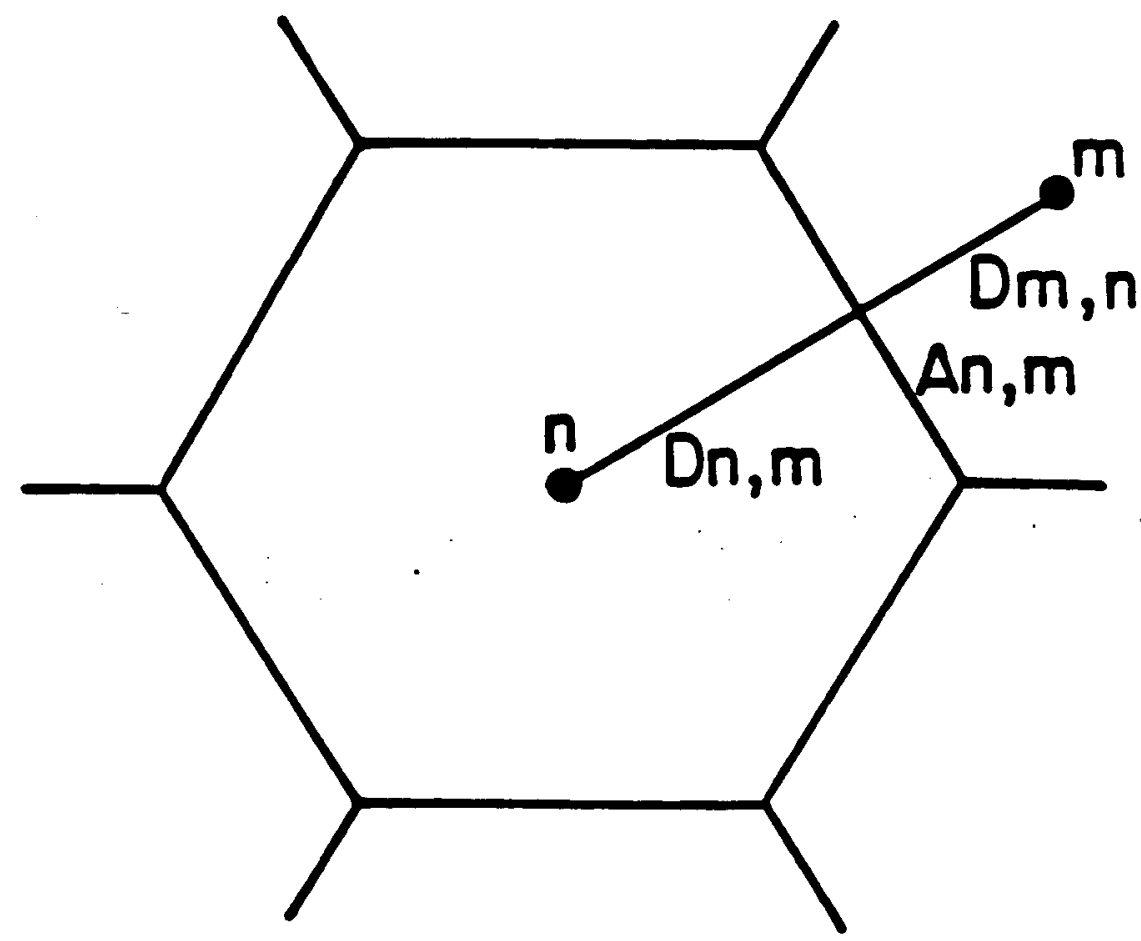

Figure 6.

Sketch of mesh structure with node $\mathrm{n}$ connected to $\mathrm{m}$ surrounding nodes separated by a distances of $D_{n, m}$ and $D_{m, n}$, respectively, and interface area of $A$ (Bodvarsson, 1982). 
To solve the mass and heat equations ( 31 and 32 , respectively), they are combined and solved simultaneously in a single matrix equation of the form

$$
[A]\{x\}=b
$$

The vector $\{x\}$ contains the unknowns $\nabla P$ and $\nabla T$; the vector $\{b\}$ contains the known explicit quantities. The matrix $[\mathbf{A}]$ contains the coefincients, which in general are functions of temperature and pressure, hence making the equations non-linear. The sets of equations are solved using an efficieat direct solver (Duff, 1977) and an iterative scheme for the non-linear coeficients.

In modifying PT and adding silica transport to the code, Lai (1985) utilized an operator aplitting technique to ensble the governing equations for chemical and heat transport to be solved in two fractional atepo. As ween by (29) and (27) the equations for heat and chemical transport are of identical form and can be solved by the same method. Before these equations are solved, the equations for Darey velocity (Eq. 16) and continuity (Eq. 19) are combined to calculate the pressure field, using the integrated faite difference method of the original code PT.

Then, the energy and chemical transport convection-diffusion type equations are solved in two steps. The first step neglects the diffusion and source terms, and leaves for the energy and chemical species equations, respectively:

$$
\int_{V} \frac{\nabla T}{\nabla t} d V+\int_{A} \nabla_{T} T \cdot \hat{n} d A-\int_{V} T \nabla \cdot \nabla_{T} d V=0
$$

and

$$
\int_{V} \sigma_{c} \frac{\delta C S}{\delta t} d V+\int_{A} \nabla_{c} C S \cdot \hat{n} d A-\int_{V} C S \nabla \cdot \nabla_{c} d V=0
$$

where

$$
\begin{aligned}
& \sigma_{\mathrm{T}}=\phi \rho_{\rho_{\mathrm{f}}}+(1-\phi)_{\rho_{\rho_{\mathrm{T}}}} \\
& \sigma_{\mathrm{e}}=\phi \rho_{\mathrm{f}} \\
& \nabla_{\mathrm{T}}=\vec{\nabla}_{\mathrm{d} \rho_{\mathrm{P}}}
\end{aligned}
$$




$$
\nabla_{\mathrm{e}}=\nabla_{\mathrm{d}} \rho_{\mathrm{f}}
$$

These equations are solved by the explicit, monotonized, upwind/central differencing method developed by Van Leer (1977) and expanded by Colella (1984). [See Lai (1985) for a description of this method.]

The second step solves the diffusion and source terms, neglecting the convection term. For the energy and chemical species, the diffusion/source equations to be solved are

$$
\int_{v} \sigma_{T} \frac{\delta T}{\delta t} d V=\int_{V} \nabla \cdot K_{t} \nabla T d V+\int_{V} q_{m} c_{r}\left(T_{t}-T\right) d V
$$

and

$$
\int \sigma_{c} \frac{\delta C S}{\delta t} d V=\int_{v}\left(\nabla \cdot \rho_{p} D_{i j} \nabla C S\right) d V+\int_{v} q_{m}\left(C S_{v}-C S\right) d V
$$

These equations are solved by the integrated finite difference method. When the pressure, temperature and chemistry have been calculated, the water and rock properties are updated. This procedure is repeated until the solution converges. The convergence criteria is set by

$$
\left[\frac{\lambda_{\text {oew }}-\lambda_{\text {old }}}{\lambda_{\text {old }}}\right]_{\max } \leq \tau_{\lambda}
$$

where $\lambda$ refers to $P, T$, or $C ; \tau_{\lambda}$ is the specified residue constant, and "max" refers to the maximum value over the entire mesh.

\subsection{CODE MODIFICATION}

In the present study, the code PTC was expanded to include transport of "nonreactive" chemical components and the stable isotope oxygen-18. Difiusion transport is assumed negligible, and the kinetic reactions for the non-reactive species are not significant within the temperature range of interest in this study. Therefore, the governing equation describing this behavior can be written 


$$
\int \frac{\delta\left(\phi_{\rho} C S\right)}{\delta t} d V=-\int_{A} \rho_{f} \vec{\nabla}_{d} C S \cdot \hat{n} d V+\int_{V} G_{P} C S_{d} d V
$$

The convection term (first term on right-hand side), is solved by the explicit, monotonized, upwind/central differencing method as developed by Lai (1885). The source term is solved by implicit central differencing.

Included in the source term for the oxygen-18 transport is the exchange due to the kinetic reactions between the rock and water for oxygen-18. After the pressure, temperature and oxygen-18 transport due to convection are calculated, and the equation of state parameters are updated, a subroutine is called to calculate the change in oxygen-18 in the water due to kinetic reactions, over one time step. The oxygen-18 value is then updated, and the solutions for all the primary dependant variables are checked for convergence before initiating the next time step.

The subroutine incorporates the option to evaluate oxygen-18 transport for several rock/water systems. These include basalt/seawater; basalt/water, granite/seawater, granite/water, clay/water and quartz sandstone/water. The equations for oxygen-18 transport described in the section on the chemistry of lowtemperature Gelds must be transformed into aumerical form for evaluation in the subroutine as follows:

$$
\begin{aligned}
\delta_{f}^{a+1} & =\delta_{p}^{a}-\left(\frac{W}{S}\right) \cdot \Delta \delta_{f}^{a} \\
\delta_{f}^{e q+1} & =\frac{\left(\delta_{R}^{p+1}-\nabla R W+\left(\frac{W}{S}\right) \delta_{f}^{a}\right)}{\left(1+\frac{W}{S}\right)} \\
\Delta \delta_{f}^{a+1} & =\left(\frac{W+S}{W S}\right) A r_{1}\left(\delta_{f}^{e q+1}-\delta_{f}^{a}\right) \cdot \Delta t \\
\delta_{f}^{a+1} & =\Delta \delta_{f}^{a+1}+\delta_{f}^{a}
\end{aligned}
$$

where $\delta$ is an abreviated form used for $\delta^{18} \mathrm{O}$. At the beginning of each call, $W, S, A, r_{1}$ , and $\nabla_{R}$ are updated using the most recent temperature, porosity and density data. 
A listing of the subroutine is given in Appendix B, along with a description of the input parameters and variables.

\subsection{PERFORMANCE OF THE CODE}

To evaluate the performance of the code, simple transport problems are simulated, and the results compared with known analytical solutions. Performance tests for silica transport have already been completed by Lai (1985). To test the nonreactive species transport, a three-node, one-dimensional problem is selected (Figure 7). The volumes of the two outer nodes are very large, holding the pressure, temperature and chemical concentrations of these nodes constant. A pressure gradient is induced between the nodea by asigning a prewure of 40 bars to node 1 and 20 bars to node 3 . The concentration in the second node is initially zero; the concentration in the first node is $C_{1}=1.0$. The analytical solution describing the concentration within node 2 ( $\mathrm{C}_{2}$ ) as a function of time is written:

$$
C_{2}=D_{1}\left[1-e^{-\left(\frac{V_{A} A}{V_{2} D_{t} t}\right) t}\right]
$$

where subscripts 1 and 2 refer to oodes one and two. Table 4 contains the solutions for a specific time for both the analytical and numerical methods; the results show an excelleat match. 


\begin{tabular}{|c|c|c|}
\hline $\begin{array}{l}v_{1}=10^{20} \mathrm{~m}^{3} \\
P_{1}=40 \text { bars }\end{array}$ & $\begin{array}{r}V_{2}=10^{6} \\
2\end{array}$ & $\begin{array}{c}V_{3}=10^{20} \\
\dot{3} \\
P_{2}=20 \text { bars }\end{array}$ \\
\hline
\end{tabular}

Figure 7. Three node mesh used in testing transport of the non-reactive chemical components. 
TABLE 4. Performance test of conservative species transport using the code PTCC.

\begin{tabular}{lll}
\hline Time (year) & Analytical Solution & Numerical Solution \\
\hline 0.1893 & 0.7648 & 0.7650 \\
0.3431 & 0.9279 & 0.9280 \\
0.5184 & 0.9811 & 0.9813 \\
1.4371 & 0.9999 & 0.9999 \\
\hline
\end{tabular}

To test the performance of the code for the kinetic reactions of oxy gen-18, a single element model is selected, eliminating convection. Temperature and pressure are assumed constant. The rate and equilibrium constants are both functions of temperature and will remain constant for a constant temperature. The total moles of oxygen18 in the fluid, W, the total moles of oxygen-18 in the solid, S, for the systems, and the total surface area of the grains, $A$, are all dependent on the densities of water and rock, porosity, and the volume of the system. These parameters do not vary throughout the problem, therefore $W, S, A$ will also remain constant. The analytical solution is linear and solved in one step:

$$
\delta(t)_{t}=\delta_{f}^{e q}-\left(\delta_{p}^{e q}-\delta_{f}^{i}\right) e^{-\left(Y A_{1}\right) k}
$$

where $Y=(W+S) / W S$.

In Eq. 41, the initial $\delta_{R}^{18}$ and $\delta_{f}^{18}$ remain constant. In the numerical method, the initial $\delta_{R}^{18}$ and $\delta_{f}^{18}$ are updated after each time step. Although this method is more consistent with the kinetic reactions of oxygen-18 in an actual system, it is not consistent with the analytical solution. To achieve a match with the analytical solution, the initial $\delta_{R}^{18}$ and $\delta_{f}^{18}$ must be held constant in the numerical method. The results of this procedure, presented in Table 5, show an excellant match with the results of the analytical method. 
TABLE 5. Performance test on the kinetic reaction of oxygen-18 using the code PTCC.

\begin{tabular}{rcc}
\hline $\begin{array}{c}\text { Time } \\
\text { (years) }\end{array}$ & $\begin{array}{c}\text { Analytical } \\
\text { Solution }\end{array}$ & $\begin{array}{c}\text { Linearized Numerical } \\
\text { Solution }\end{array}$ \\
\hline \hline 6.3 & -6.754 & -6.755 \\
25.4 & -4.024 & -4.022 \\
31.9 & -3.376 & -3.374 \\
178.0 & 0.001 & 0.003 \\
3171.0 & 0.070 & 0.070 \\
\hline
\end{tabular}

It is also interesting to examine how much of a difference updating the initial $\delta_{R}^{18}$ and $\delta_{f}^{18}$ can make on the system. Figure 8 shows a comparison between the results of the analytical solution and the numerical solution (updating $\delta_{R}^{18}$ and $\delta_{f}{ }^{18}$ ). Measurements taken on geothermal system of the oxygen-18 in the fluid are recorded with one decimal place accuracy or better, so the difference shown in the figure could introduce a substantial amount of error in to a numerical modeling scheme.

As a second test on the performance of the numerical code in modeling the kinetic oxygen-18 transport, the time for a non-convecting, non-conducting system to reach equilibrium was examined. The numerical results for several temperatures were compared with the results obtained when using the equation given by Cole, (1983):

$$
t(\sec )=\frac{-\ln (1-\alpha)(W / S)\left(\omega \rho X_{f}\right)}{3(1+(W / S)) r_{1}\left(10^{-1}\right)}
$$

to estimate the equilibrium time by hand calculation. (All parameters are as previously defined.) Determining the exact equilibrium time from the numerical results was difficult, as the change in $\delta^{18}$ remains very small for many years before attaining equilibrium. To maintain a systematic approach, $10^{-1}$ was chosen as the limit for the amount of change per time step. When the change per timestep became smaller than 


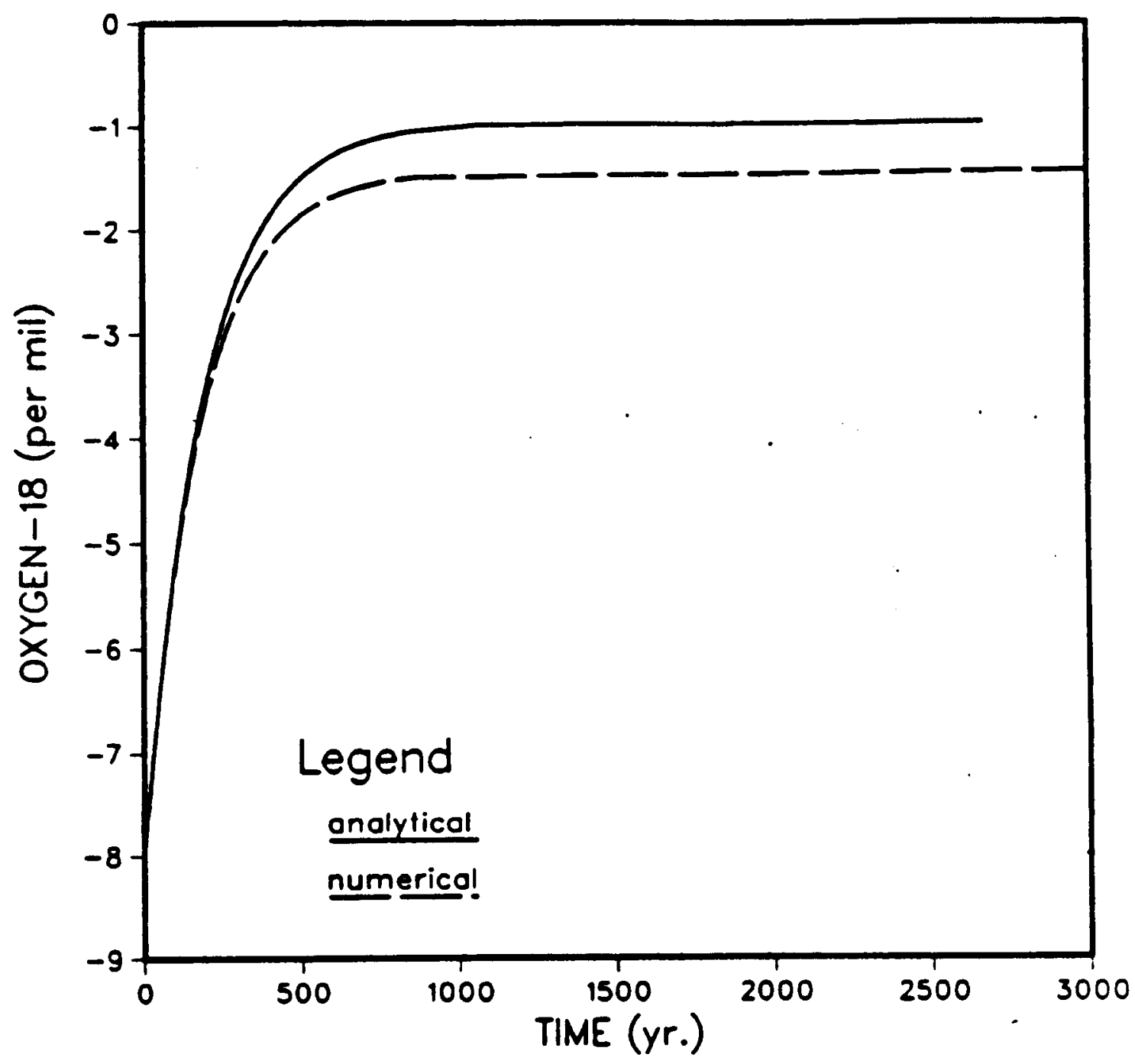

Figure 8.

Analytical and numerical solutions to kinetic transport problem for oxygen-18. 
this value, the system was considered in isotopic equilibrium. Table 6 lists the results of each method; the comparison between the two methods of solution is quite good.

TABLE 6. Comparison of the times to reach chemical equilbrium at various temperatures between the results obtained by the code PTCC and those obtained using the analytical equation developed by Cole (1983), for the time to reach chemical equilbrium at various temperatures:

\begin{tabular}{cccc}
\hline $\begin{array}{c}\text { Temperature } \\
(\cdot \mathrm{C})\end{array}$ & $\begin{array}{c}\text { Rate conntant } \\
\left(\mathrm{mol} / \mathrm{m}^{2} \cdot \mathrm{s}\right)\end{array}$ & $\begin{array}{c}\text { Tima: analytical } \\
(\mathrm{sec})\end{array}$ & $\begin{array}{c}\text { Time: PTCC } \\
(\mathrm{cec})\end{array}$ \\
\hline 50 & $2.501 \times 10^{-13}$ & $1.46 \times 10^{13}$ & $0.43 \times 10^{13}$ \\
100 & $2.780 \times 10^{-12}$ & $1.32 \times 10^{12}$ & $0.5 \times 10^{12}$ \\
150 & $1.750 \times 10^{-11}$ & $2.10 \times 10^{11}$ & $2.0 \times 10^{11}$ \\
200 & $7.453 \times 10^{-11}$ & $4.00 \times 10^{10}$ & $4.7 \times 10^{10}$ \\
\hline
\end{tabular}




\subsection{APPLICATIONS OF THE CODE}

\subsection{SENSITIVITY STUDIES}

Before attempting to model a complex geothermal system, or applying the code to a feld problem, it is very useful to perform a series of sensitivity studies to determine how certain parameters can affect chemical transport. The kinetic reactions of oxygen-18 and silica in a porous media were examined first. The study included the influence of the type of rock/fuid system on oxygen-18 transport and the significance of the the average grain radius (or $A / V$ in the case of silica), the porosity, the temperature and the volume of a geothermal system on the kinetic reactions of both the oxygen-18 and silica. Second, the convective transport of a conservative chemical species was examined. The study used silica as the component, but since the kinetic reactions of silica were not considered in this part of the study, the results apply equally to any conservative component. The study included the significance of the porosity and volume on convective chemical transport. The method used in the sensitivity studies involved systematically varying each of these parameters while holding all other parameters constant and noting the effects on the oxygen-18/silica transport.

\subsubsection{Approsch}

To examine the transport of oxygen-18 and silica by kinetic reactions, a simple, single element model was developed, eliminating convective transport. The values for the field properties of the model, listed in Table 7a, are comparable to actual field properties of many geothermal systems. The value for the average grain is characteristic of a fine-grain porous medium. Each parameter remains constant unless it is the one being studied. A basalt/water system was used in all the studies (excluding the rock/luid study), because the Geld examples reviewed later in the present work involve basalt/water systems. For the same reason, alpha-cristobalite was selected as the type of silica in the model. The initial oxygen-18 and silica in the fluid are not in chemical 
equilibrium at the given temperature of the model (see Table 7a). Thus, at the start of the problem, the components begin to shift towards equilibrium, and the effects of the field parameters on this shift can be examined.

The model developed to study convective transport of a chemical component in a porous media included a warm region (the field area) with cool recharge coming in from the top and side. Fluid is produced out of the warm region at $100 \mathrm{~kg} / \mathrm{s}$; the recharge amounts coming in from the top and side are equal (50 kg/s from each region). Table $7 \mathrm{~b}$ lists the values for the field properties assumed in the study. Once again, each parameter remains constant unless it is being studied. Alpha-cristobalite was used for the form of silica in the system. Figure 8 shows a sketch of the system. Although it is very simple, many low-temperature geothermal oystems have similar patterns of recharge and field property values.

TABLE 7a. Values of the parameters used in the single element model for the sensitivity studies of the kinetic reactions.

\begin{tabular}{lc}
\hline Parameter & Value \\
\hline Volume & $1 \times 10^{9} \mathrm{~m}^{3}$ \\
Porosity & $10 \%$ \\
Permeability & $1 \times 10^{-14} \mathrm{~m}^{2}$ \\
Temperature & $125^{\circ} \mathrm{C}$ \\
$\delta_{\mathrm{f}}^{18}$ (initial) & $-8.0 \mathrm{per} \mathrm{mil}$ \\
Silica (initial) & $25 \mathrm{ppm}$ \\
$\omega$ & $0.0 \times 10^{-4}$ \\
A $/ \mathrm{V}$ & 10.0 \\
\hline
\end{tabular}




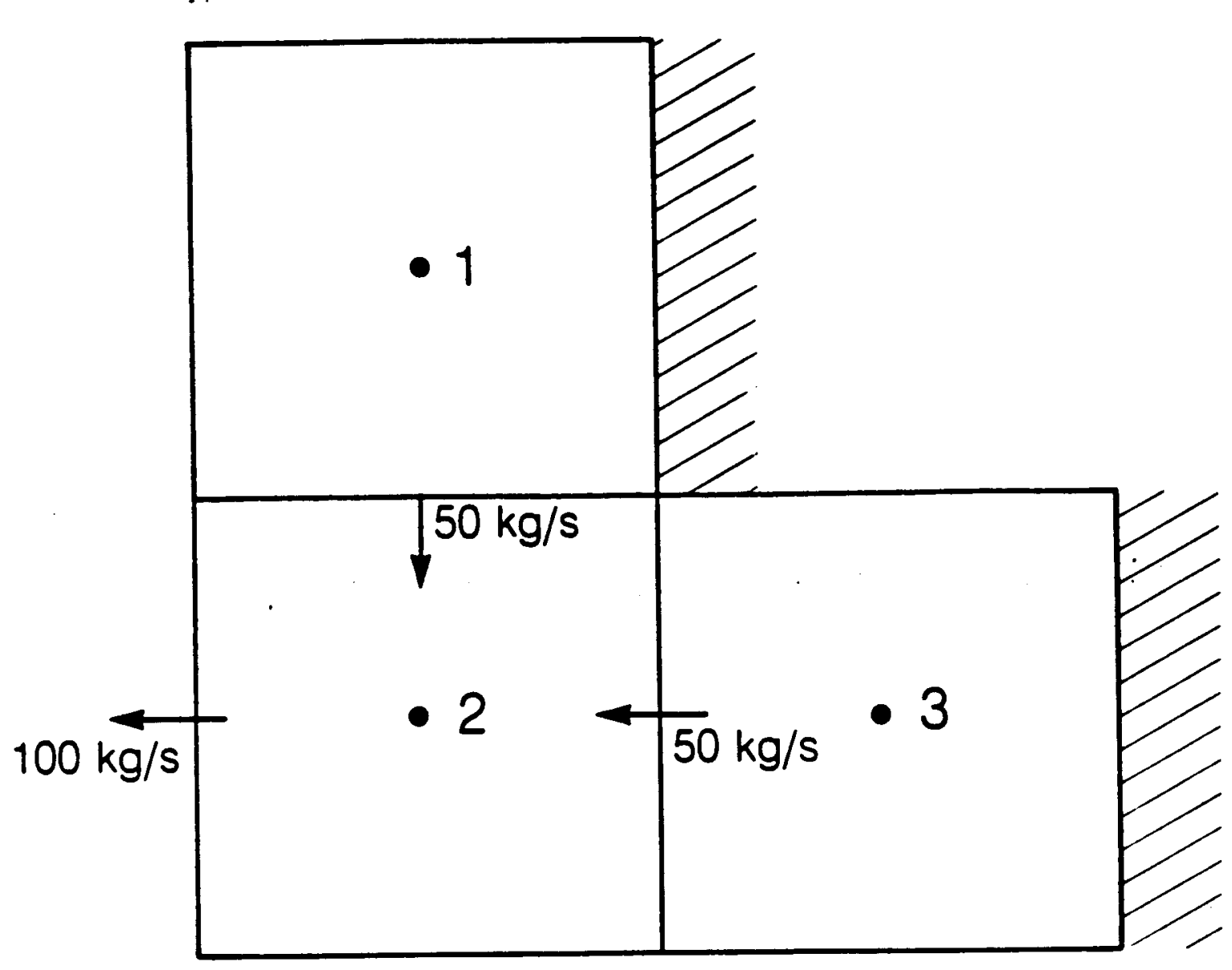

Figure 9. Sketch of three-node mesh used in sensitivity studies. 
TABLE 7b. Values of the parameters used in the model for the convective sensitivity studies.

\begin{tabular}{rc}
\hline Parameter & Value \\
\hline $\begin{array}{r}\text { Volume (field) } \\
\text { Porosity }\end{array}$ & $1 \times 10^{\circ} \mathrm{m}^{3}$ \\
Temperature & $10 \%$ \\
(field) & \\
(top) & $125^{\circ} \mathrm{C}$ \\
(side) & $50^{\circ} \mathrm{C}$ \\
Silica & \\
(field) & $75{ }^{\circ} \mathrm{C}$ \\
(top) & $184 \mathrm{ppm}$ \\
(side) & $50 \mathrm{ppm}$. \\
\hline
\end{tabular}

\subsubsection{Study of kinetic reactions}

\section{Oxygen-18}

The influence of the rock/fluid system on the oxygen-18 transport was studied using the single element model described above. The oxygen-18 content is plotted against time for each rock/fluid system in Figure 10. The same initial oxygen-18 content in the rock (5.6 per mil) was used for all rock/liuid systems to more clearly see the differences in the kinetic transport between each system. A noticeable aspect of Figure 10 is the different shape of the curves between the rock/liuid systems. The shapes of the curves are governed primarily by the kinetic rate constant and slightly by the value of the equilibrium constant. 


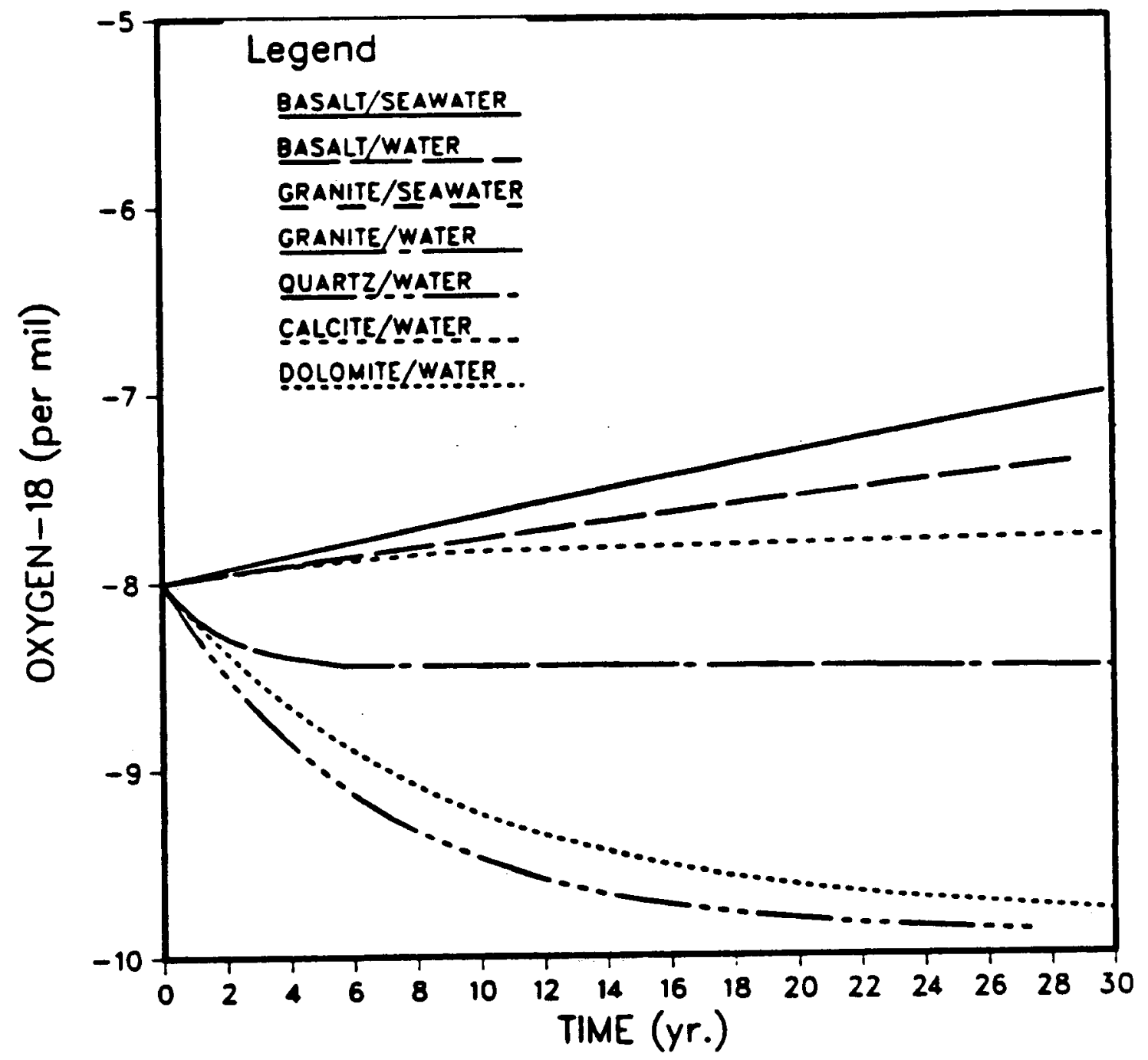

Figure 10. The influence of the rock/fluid system on the kinetic reactions of oxygen-18. 
The curves for the basalt/liuid systems are linear; while the curves for the dolomite/water and quartz/water show a steady curving drop before lattening out towards the end of the thirty year period. This can be most clearly understood by referring to Table 8, which lists the values for the rate constant (as $\log r_{1}$ ) and the $\delta_{f}^{e q}$ at $150^{\circ} \mathrm{C}$, for each rock/fluid system. The rate constants of the dolomite/water and quartz/water systems are much higher at this temperature than the basalt/fluid systems. Thus, the basalt systems move much more slowly towards equilibrium.

TABLE 8. Comparison of the equilibrium and rate constants between rock/fuid systems at $125^{\circ} \mathrm{C}$.

\begin{tabular}{lcr}
\hline Rock/fuid ayatem & $\delta_{\text {pq }}^{c a}$ (per mil) & $\log \mathrm{r}_{1}$ \\
\hline Granite/seawater & -8.53 & -9.15 \\
Granite/water & -8.53 & -10.62 \\
Calcite/water & -7.75 & -8.98 \\
Dolomite/water & -10.05 & -9.00 \\
Basalt/seawater & -0.43 & -11.10 \\
Basalt/water & -3.35 & -11.10 \\
\hline
\end{tabular}

The granite/seawater and calcite/water systems also have relatively high rate constants, but do not show the curvature of the dolomite/ and quartz/water systems. This can be explained by the equilibrium constants of the different systems. The granite systems and calcite/water system are very near their $\delta_{f}^{\text {eq }}$ values at the start of the problem. The high rate constants for the granite/seawater and calcite/water systems allow them to shift quickly towards equilibrium, causing the curves to almost immediately flatten out. In the case of granite/water, the proximity of the initial oxygen-18 content of the system to the $\delta_{f}^{e q}$ at the start of the problem allows the system to shift rapidly to the equilibrium value, even though the value of the rate constant is very low at $125^{\circ} \mathrm{C}$. 
Another interesting aspect of Figure 10 is the affect of seawater versus pure water in the basalt and granite systems. According to the results, seawater in place of pure water has a significant effect on a basalt system but not on a granite system. This is most likely not true. As was discussed in section 2.2 , the temperature function of the kinetic rate constant for a basalt/water system and of the equilibrium rock-water fractionation ( $\Delta_{R}$ eq ) for a granite/seawater system are not available. Therefore, the same rate constant for basalt/seawater was assumed for basalt/water, and the same $\Delta_{R}^{e q}$ function for granite/water was assumed for granite/seawater.

The values of $\delta_{f}^{e q}$ for the two basalt systems are significantly different. This is logical considering the much higher content of oxygen-18 found in seawater than meteoric waters. However, inspecting the rate constants for the granite systems at $125^{\circ} \mathrm{C}$ (see Table 8) also indicates a aigaificant difference between the rate constants for systems of the same rock type but containing differing water types. This suggests that seawater in place of water affects the rate at which a system shifts toward equilibrium as well as the equilibrium value. Therefore, assumptions made in section 2.2 and mentioned above, could introduce errors when calculating the $\delta_{f}^{18}$ transport.

Before concluding the rock/Guid study it is necessary to point out the effect of the choice of $\delta_{R}^{18}$, the initial oxygen-18 content of the rock. As was mentioned above, the $\delta_{R}^{18 !}$ was beld constant between runs. However, actual oxygen-18 contents can differ greatly between rock types (see Table 3 for a list of the range in $\delta_{R}^{18}$ for the rock types used in the present work). The initial value of $\delta_{R}^{18}$ significantly infuences the $\delta_{f}^{\text {eq }}$ of a system (see equation 12). Figure 11 compares the transport of oxygen-18 in a dolomite/water system with a $\delta_{R}^{184}$ of 5.6 per mil to that of the same system with a $\delta_{R}^{181}$ of 15.0. The rate at which the two systems reach equilibrium is approximately the same, being governed by the rate constant, but the oxygen-18 content in the second system is now increasing. The figure helps to clarify that in most real systems, interactions between the rock and water will tend to increase the oxygen-18 content.

Following the rock/luid study, the effects of varying the average grain radius on the kinetic reactions of oxygen-18 were investigated. Figure 12 shows the effects of 


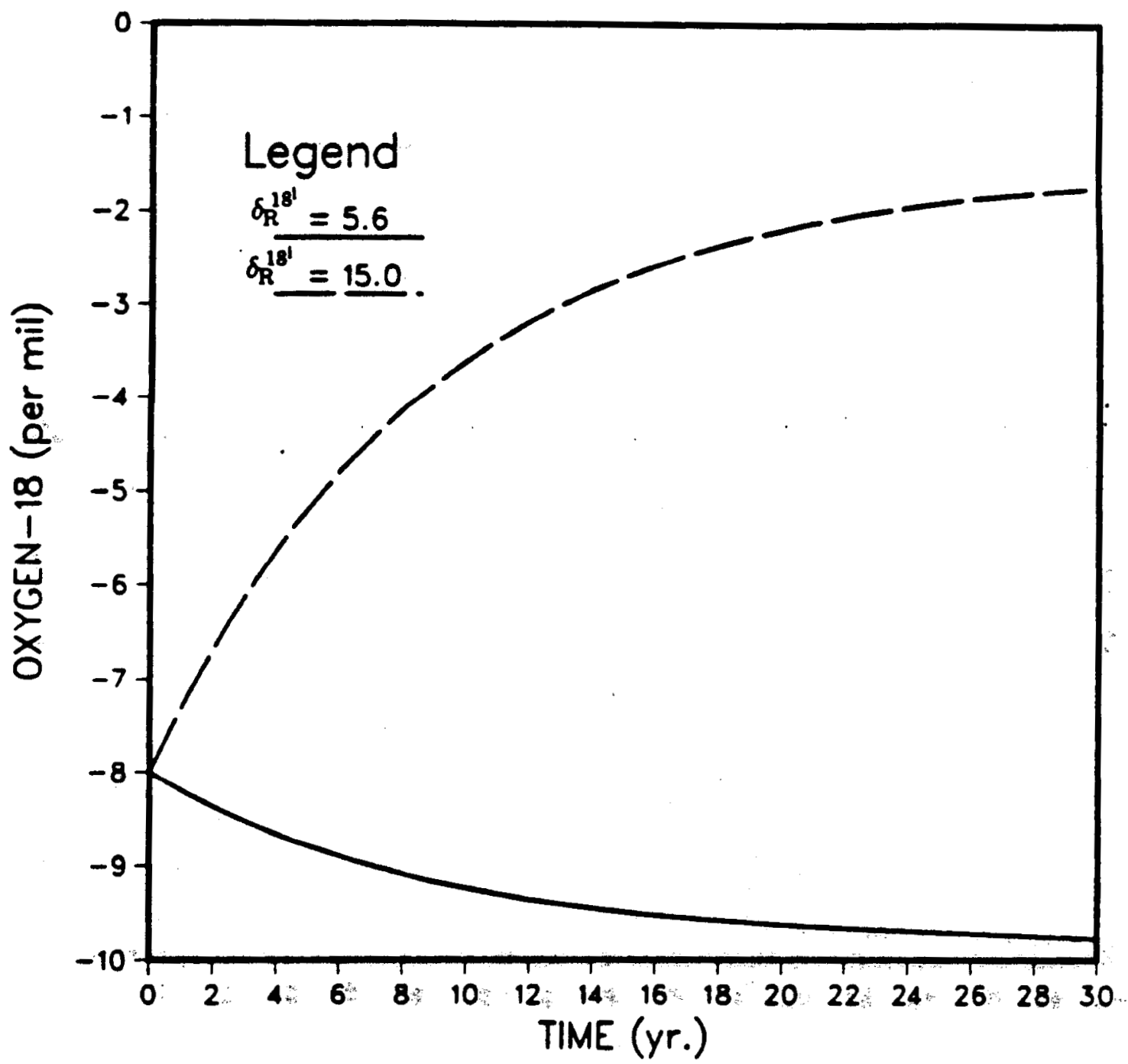

Figure 11. Comparing the effects of $\delta_{R}^{181}$ on the kinetics of oxygen-18 in a dolomite/water system at a temperature of $125^{\circ} \mathrm{C}$. 
varying the average grain size, $\omega$, on the oxygen-18 equilibrium. As the surface area depends on $(1 / \omega)$ (see Eq. 11a), the rate of change of oxygen-18 is inversely proportional to the average grain size. Therefore, as the average grain size is decreased from $10^{-2} \mathrm{~m}$ to $10^{-6} \mathrm{~m}$, the rate of change of oxygen-18 increases rapidly. The ultimate effect of this incresse is for the system to schieve equilibrium much more quickly. Since the model was held at the same temperature for all the runs, the value of $f^{m}$ is also the same. Thus, when $\omega=10^{-6} \mathrm{~m}$, the system reaches chemical equilibrium within 12 years, while for the larger grain sizes, the shift towards equilibrium has barely begun after 12 years.

For this study to be most useful, an understanding of actual grain sizes found in rock systems in essential. In fine-grained, highly consolidated materials, fuid flow will be dominantly through fractures. Thus, the effective $\omega$ could be quite large $(>0.01$ m). While in loosely consolidated, very foe-grained aystems, w would range between $10^{-5} \cdot 10^{-6}$. Moderately consolidated, medium grained systems would have an $\omega$ between the above extremes. This auggests that, while in loosely consolidated granular systems the kinetic reactions of oxygen-18 occur rapidly, the kinetic reactions of oxygen-18 in highly compacted, fractured systems could be negligible over short time spans (i.e. the approximate thirty years of productivity of a geothermal system under exploitation).

Next, the significance of the porosity of a geothermal system on the kinetic reactions of oxygen-18 transport were examined. From the results of the porosity study (plotted in Figure 13) it is clear that the kinetic reactions occur most quickly for systems with low porosities: This is due to the $(1-\phi) / \phi$ dependence in the equation solving for the change in oxygen-18 with time. The two constants, surface area, $A$, and the term $(S+W) / S W$, when multiplied together become:

$$
\frac{A(S+W)}{S W}=(3 / \omega)\left[\frac{1}{\rho_{P} X_{f}}\left(\frac{1-\phi}{\phi}\right)+\frac{1}{P_{R} X_{R}}\right]
$$

where the symbols are as previously described. When $\phi=1 \%$, the term $(1-\phi) / \phi$ is 99.0 and $A(S+W) / S W$ is about give times larger than when $\phi=5 \%$ and $(1-\phi) / \phi=19$. 


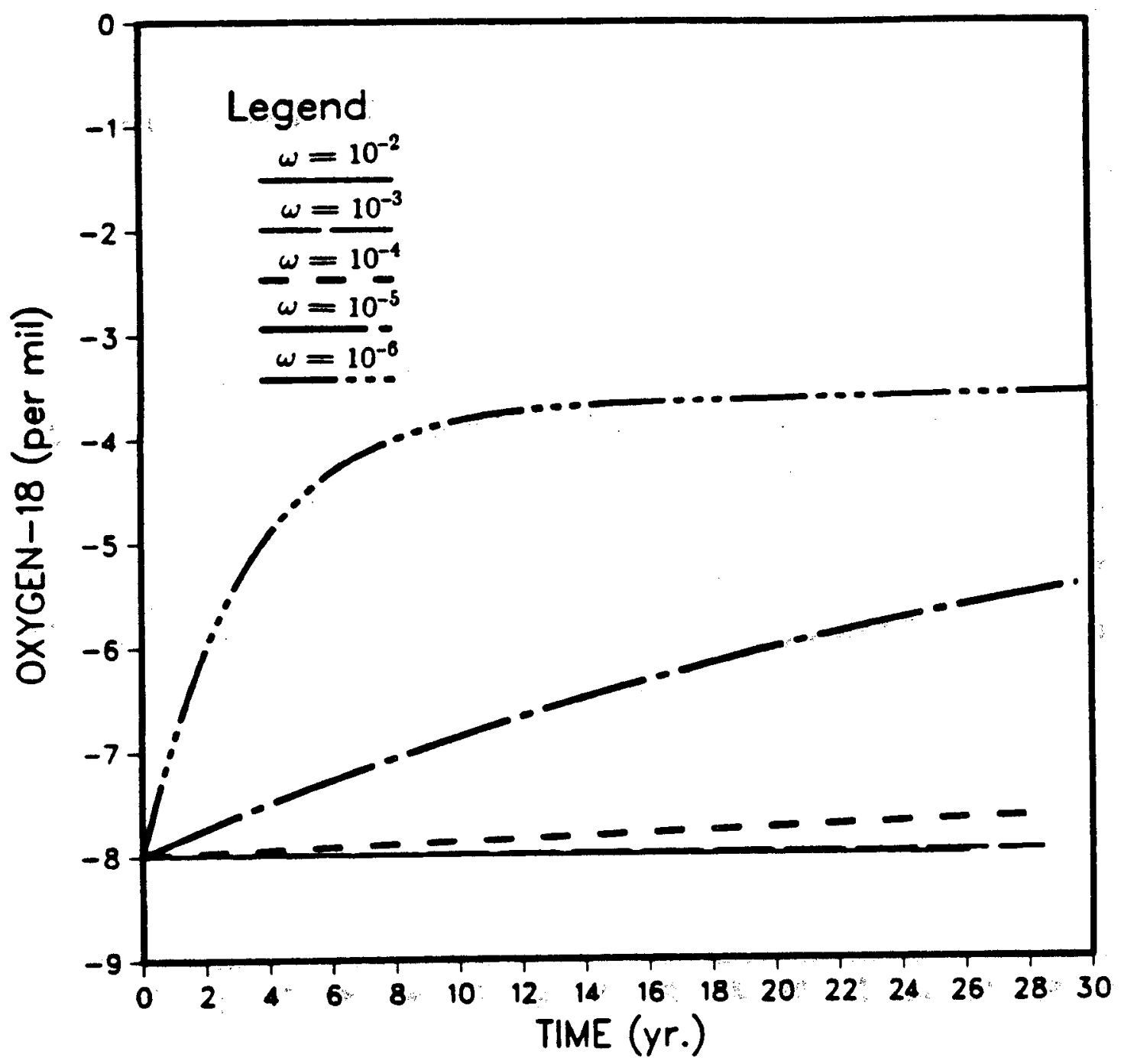

Figure 12. Significance of the average grain radius on the kinetic reactions of oxygen-18. 


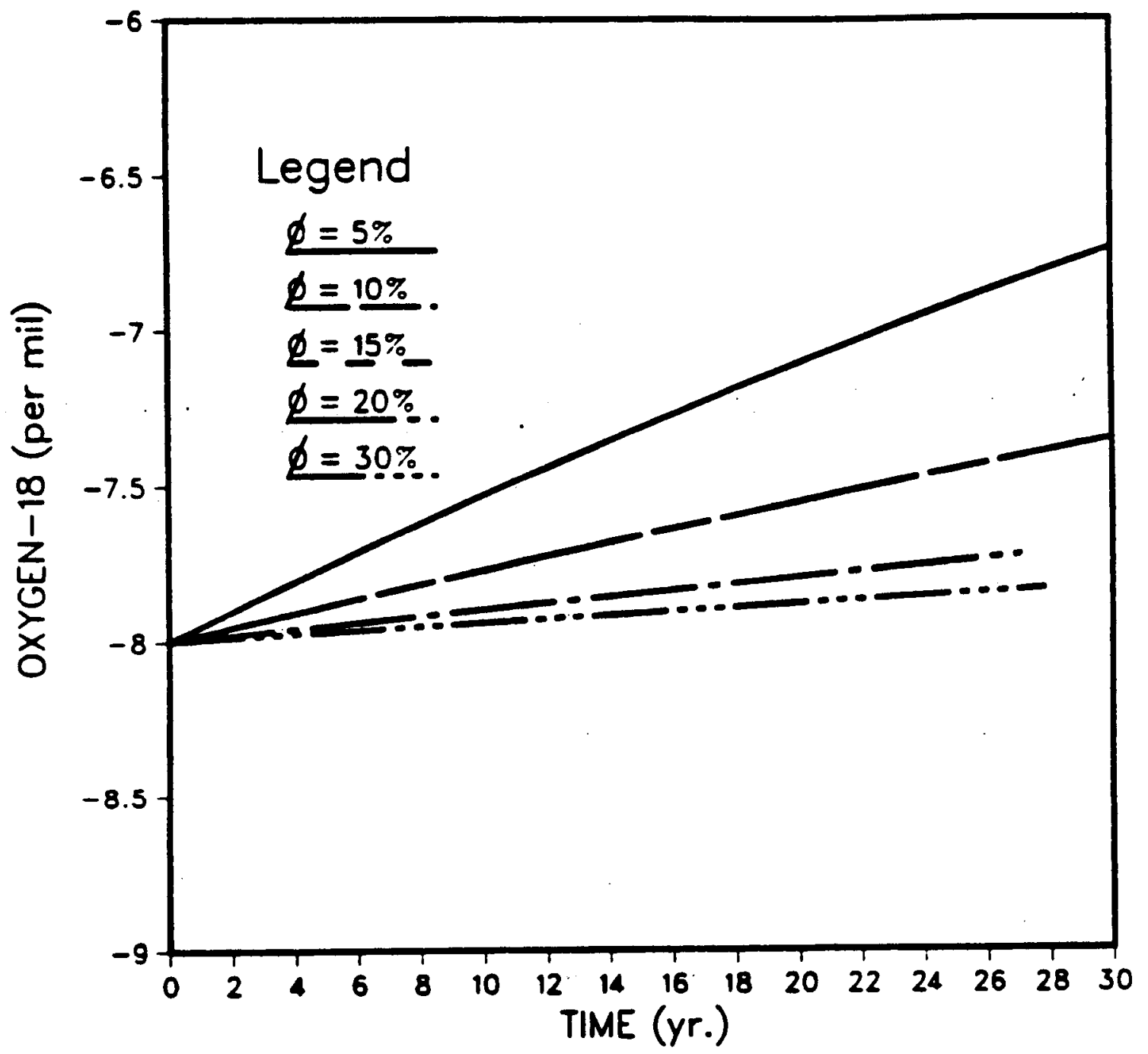

Figure 13. Significance of porosity on kinetic reactions of oxygen-18. 
The equation for the change in oxygen-18 per time step (see-Eq. 9), is directly proportional to $A(S+W) / S W$, which explains the large difference in the behavior of the oxygen-18 transport between $\phi=1 \%$ and $\phi=5 \%$. As $\phi$ increases, the change in (1$\phi) / \phi$ (and therefore $A(S+W) / S W$ ) becomes much smaller, and the oxygen-18 curves will lie more closely together.

Also noticeable in Figure 13, is the increase in linearity with increasing porosity. Once again this is due to a dependence on $(1-\phi) / \phi$ in the term $W / S$, found in the equation for the equilibrium oxygen-18 content (see Eq 12) for a bacalt/water system where:

$$
W / S=\left(\frac{\phi}{1-\phi}\right)\left(\frac{\rho_{P} X_{f}}{\rho_{R} X_{R}}\right)
$$

The net effect with increasing porosity is a more negative equilibrium value, making the system closer to being in isotopic equilibrium at the initiation of the problem. Thus, as was seen in the study on the different rock/fluid systems, the curves become more linear when they are closer to equilibrium at the offset.

The effects of temperature on the kinetics of oxy gen-18 in a basalt/water system were studied next. At the lower temperatures, $\Delta_{R}{ }^{\text {WW }}$ is larger, making $\delta_{p}^{e q}$ more negative and closer in absolute value to the initial oxygen-18 content of the fluid. Also at lower temperatures, the kinetic rate constant is much smaller. Both of these effects tend to make the curve more linear at lower temperatures and the small kinetic rate constant increases the amount of time necessary to reach equilibrium. These effects show up clearly on Figure 14 a plot of the oxygen-18 content versus time for various temperatures.

For completeness, the effects of volume on the kinetic reactions of oxygen-18 were examined. A review of the rate equation (see Eq. 9) indicates that the reservoir volume will not effect the kinetics of oxygen-18. Although surprising at first, when the term $A(S+W) / S W$ in the rate of change equation for $\delta^{18}$ is examined more closely it 
$-55$

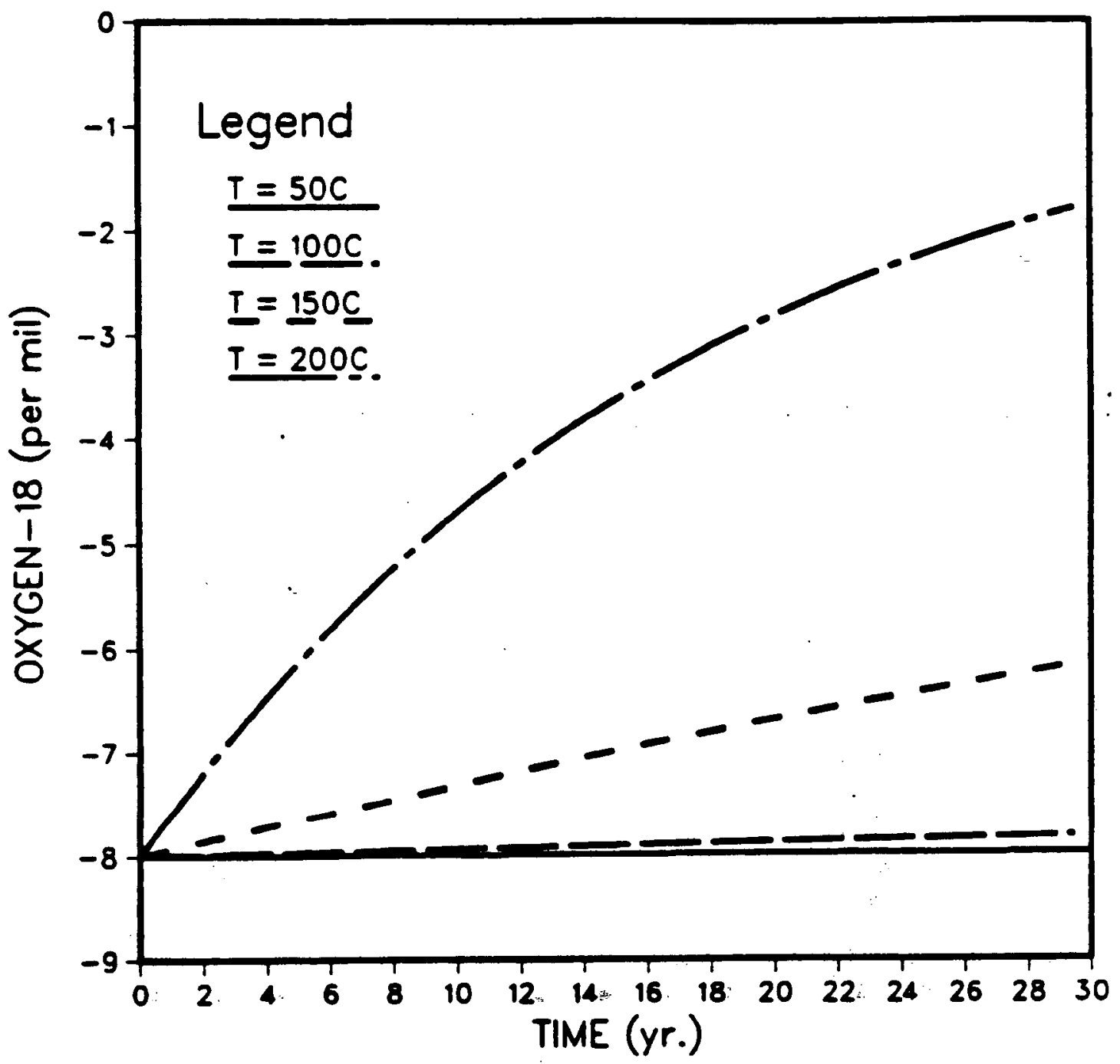

Figure 14. Significance of temperature on the kinetic reactions of oxygen-18. 
becomes:

$$
\begin{aligned}
& \Lambda \frac{(S+W)}{S W}=\frac{3 V(1-\phi)}{\omega}\left[\left(\frac{1}{V \phi \rho_{f} X_{r}}\right)+\left(\frac{1}{V(1-\phi) \rho_{R} X_{R}}\right)\right] \\
& =3 \frac{(1-\phi)}{\omega}\left[\frac{1}{\phi \rho_{f} X_{P}}+\frac{1}{(1-\phi) \rho_{R} X_{R}}\right]
\end{aligned}
$$

and it can be seen that the volume term drops out. Neither the kinetic rate equation nor the equilibrium fractionation value are dependent on the volume; thus the kinetic rate of change of oxygen-18 is completely independent of the volume size of the field if conrection is neglected.

Silice

The effects of temperature, porosity and surface area per volume (A/V), on the kinetic reactions of silica in a porous medium were also studied using the single element model with the parameter values as listed in Table 6a. For the first study, temperature was varied from $50^{\circ} \mathrm{C}$ to $200^{\circ} \mathrm{C}$, while holding all other parameters constant. The results, plotted in Figure 15, show a large jump in the effects of the kinetic reactions between $100^{\circ} \mathrm{C}$ and $200^{\circ} \mathrm{C}$. However, this indicates only that the silica concentration in the $100^{\circ} \mathrm{C}$ system is closer to the equilibrium concentration at the start of the problem, than is the silica concentration in the $200^{\circ} \mathrm{C}$ system. To more clearly see the effects of temperature on the kinetic reactions of silica, a second case was run; again varying the temperature from $500^{\circ} \mathrm{C}$ to $200^{\circ} \mathrm{C}$, but choosing an initial silica concentration of $500 \mathrm{ppm}$ in the fluid. Thus, the system at $200^{\circ} \mathrm{C}$ was initially the closest to its equilibrium concentration of silica ( $477 \mathrm{ppm}$.), while the system at $50^{\circ} \mathrm{C}$ was the furtbest from its equilibrium concentration of $51 \mathrm{ppm}$. Comparison of the results of the second case (Figure 16) to the results of the first, gives a better indication of the importance of temperature on the kinetic reactions. The shape of the curve will indicate how rapidly the system is moving towards equilibrium. In the first case, the 


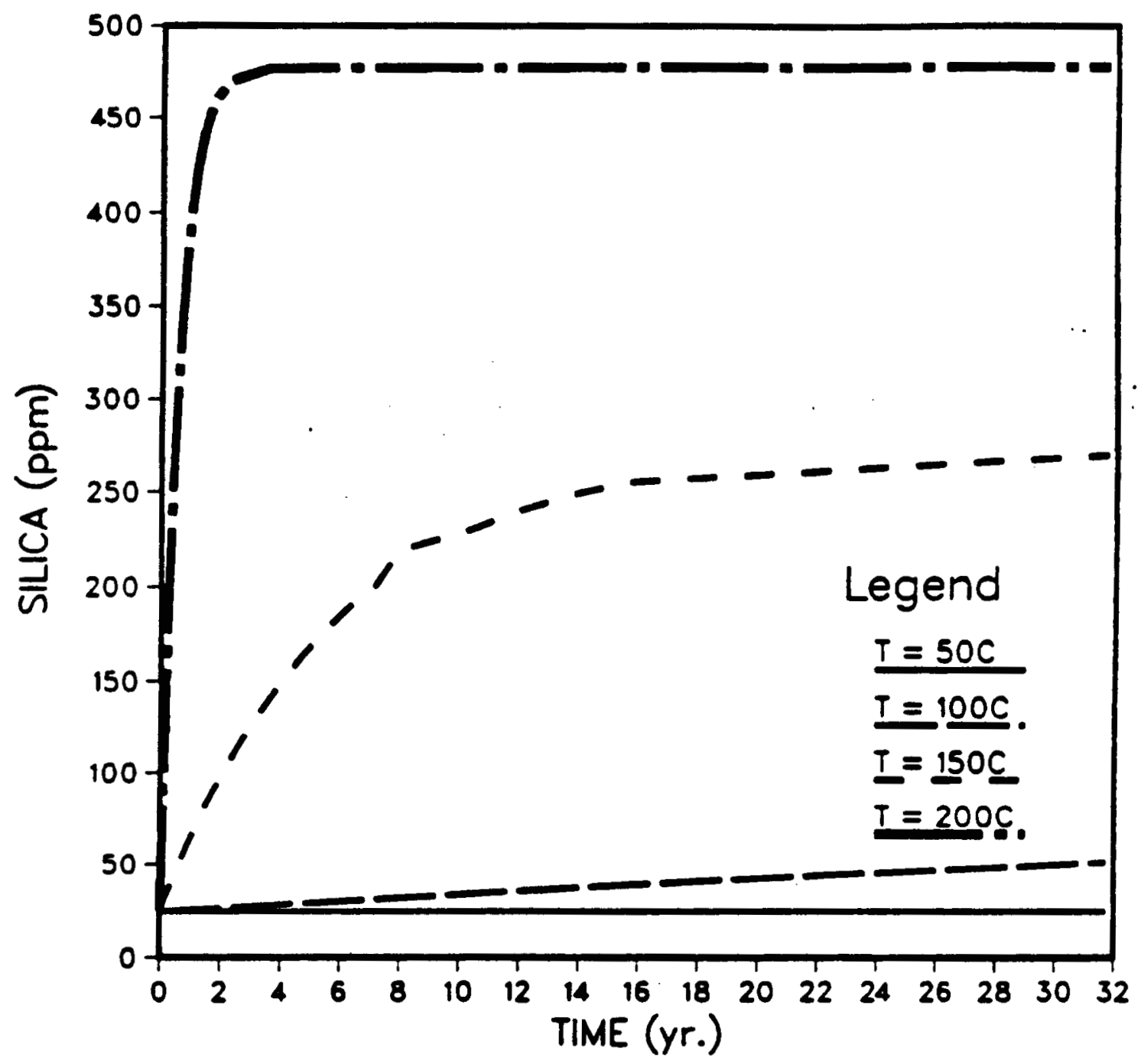

Figure 15. Significance of temperature on the kinetic reactions of silica. Initial silica is $\mathbf{2 5} \mathrm{ppm}$. 


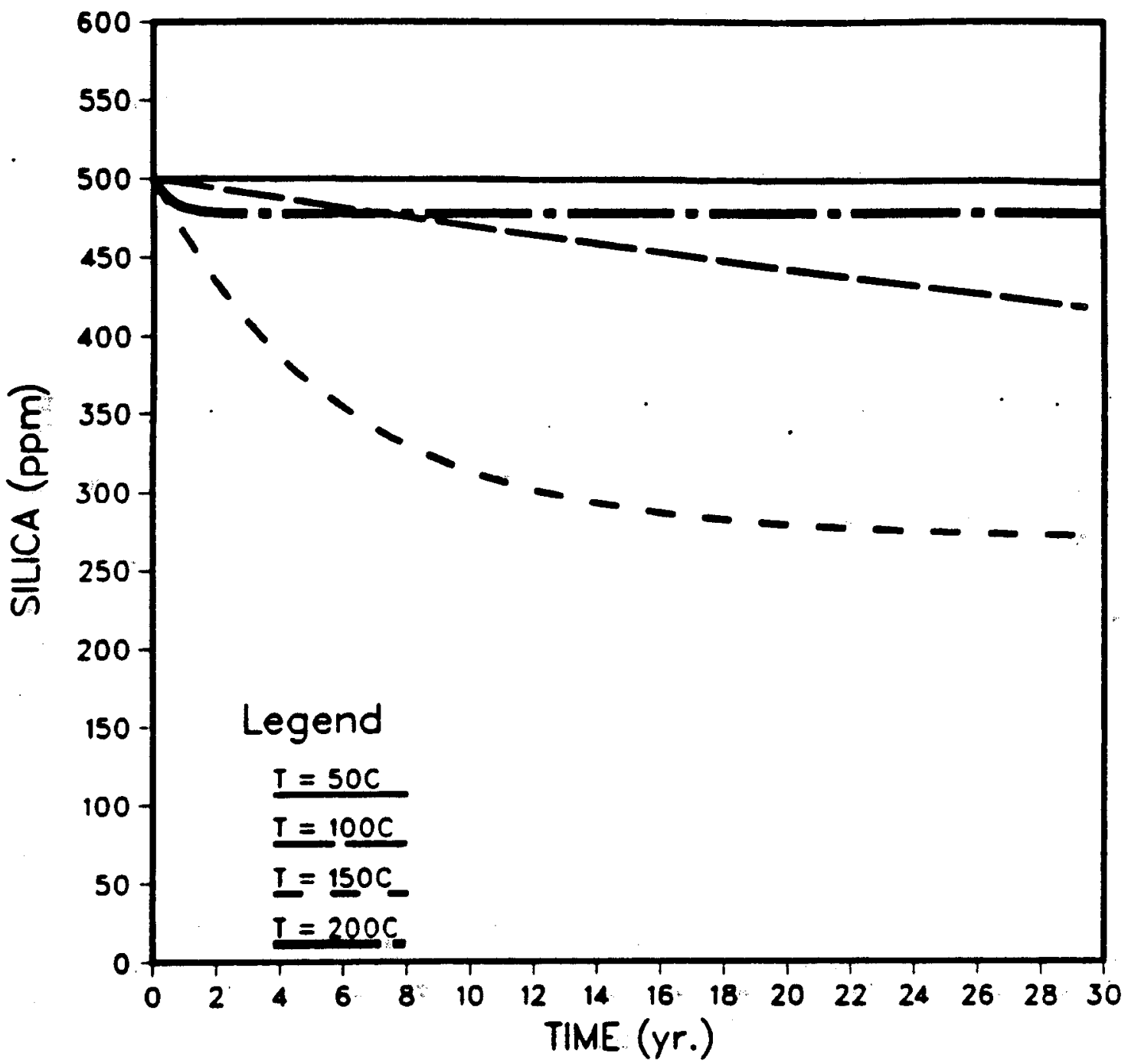

Figure 16. Significance of temperature on the kinetic reactions of silica. Initial silica is $500 \mathrm{ppm}$. 
system at $200^{\circ} \mathrm{C}$ moves very rapidly toward equilibrium, as demonstrated by the step-like curve. The system at $50^{\circ} \mathrm{C}$, in the second case moves much more slowly towards equilibrium as demonstrated by the nearly horizontal, linear curve. Comparison of the two plots auggest that below $150^{\circ} \mathrm{C}$ the kinetic effects on silica transport decrease significantly in importance.

Next, the significance of porosity on kinetic reactions of silica were examined. Reviewing the kinetic rate of change of silica (see Eq. 1), indicates that neither the volume nor the porosity of a system will affect the kinetic reactions. The $A / V$ term is essentially empirical and is not calculated using the actual field volume. Therefore, the kinetic reactions of silica are independent of volume size and porosity.

Finally, the affect of the surface area open to reaction per volume of the system was atudied. $A / V$ was varied from 1. to 1000 , the temperature was held at $125^{\circ} \mathrm{C}$, and the initial silica concentration was $500 \mathrm{ppm}$. The results, plotted in Figure 17, demonstrate the importance of the $A / V$ value on how rapidly a system moves towards equilibrium. The higher the $A / V$ term, the more rapidly the silica concentration in a system will equilibrate, and the shape of the curve becomes increasingly more step-like. This may be understood more clearly by referring to the equation describing kinetic transport (see Eq. 1), which shows the rate of change of silica to be proportional to $A / V$. Thus, if $A / V$ is varied, the rate of change of the silica concentration will vary accordingly.

\subsubsection{Studies on convective chemical transport}

Studies on the significance of porosity and field volume size on convective chemical transport were performed using the model with recharge in from the top and side described in the approach, and having the parameters of Table $7 \mathrm{~b}$. The results of the porosity study, plotted in Figure 18, indicate that systems with lower porosities will transport conservative components more quickly than those with higher porosities. This is due to the inverse proportionality in the transport equation between the rate of change in concentration and the mass of fuid in the system ( $V \phi \rho_{f}$ ). 


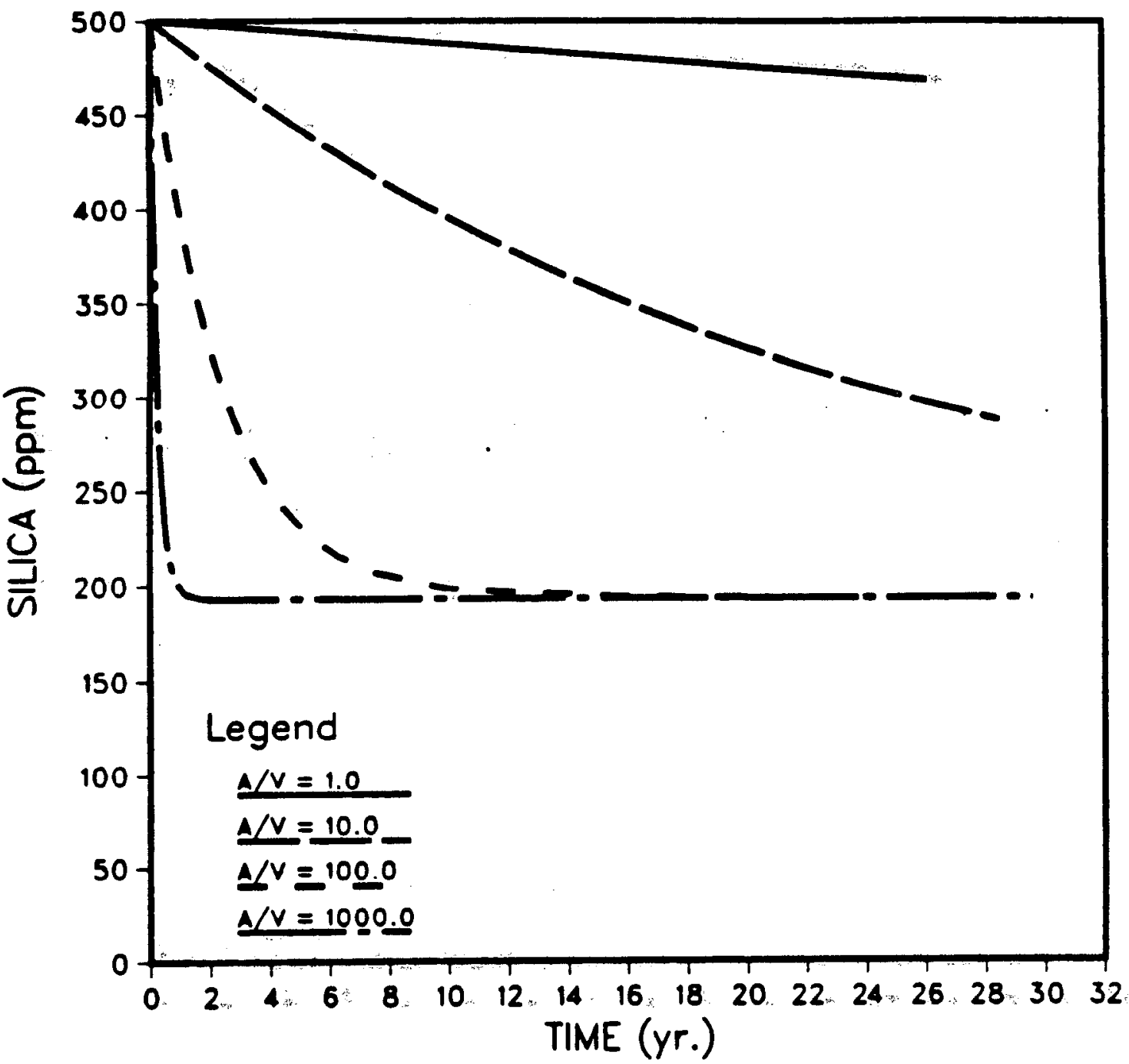

Figure 17. Significance of $\mathrm{A} / \mathrm{V}$ on the kinetic reactions of silica. 
The case above involved silica, but without the kinetic effects (ie: silica was assumed conservative). It is also of interest to examine how the kinetics might influence the transport of silica in a convective system. A moderate value of $A / V$ was chosen $\left(A / \ddot{V}=10.0 \mathrm{~m}^{-1}\right)$, and a case run using the same system as above with $10 \%$ porosity and including kinetic reactions. It is apparent that the two effects, convection and kinetic reactions, are opposing each other in this system (Figure 19). This is because the difference in temperatures between the separate recharge areas are not as large as the differences in the silica concentrations, thus the change in temperature in the warm region is not as rapid as that of the silica concentration. As the concentration of the silica is being lowered due to the convective transport, the kinetic reactions are causing the silica concentration to increase towards an equilibrium set by the temperature.

The results of the study on the volume, plotted in Figure 20, indicates a strong dependence between the volume and amount of chemical transport. This is due to the inverse proportionality between the volume and the rate of change of the chemical concentration. Therefore, if the volume is decreased by an order of magnitude, the rate of chemical changes will increase proportionally.

In summary, the sensitivity studies on the kinetic reactions of oxygen-18 and silica and the convective transport of chemical components are found to be helpful in determining which parameters have the most (or least) significant effects. Temperature and $A / V$ determine the importance of the kinetic reactions of silica in a geothermal system. Due to the proportionality between the rate of change of silica and $A / V$, varying $A / V$ appears to have the greatest effects on the shape of the silica versus time curve. Porosity and volume have no affect on the kinetic reactions of silica. Likewise, for oxygen-18 transport, the temperature and average grain radius played the most significant role in determining the importance of the kinetic reactions and the shape of the curve. However, unlike the kinetics of silica, the kinetic reactions of oxygen-18 are also significantly affected by the porosity, with the transport becoming much more rapid as the porosities decrease. In the study on convective transport, the volume significantly affected the transport of a chemical component, due to the inverse 


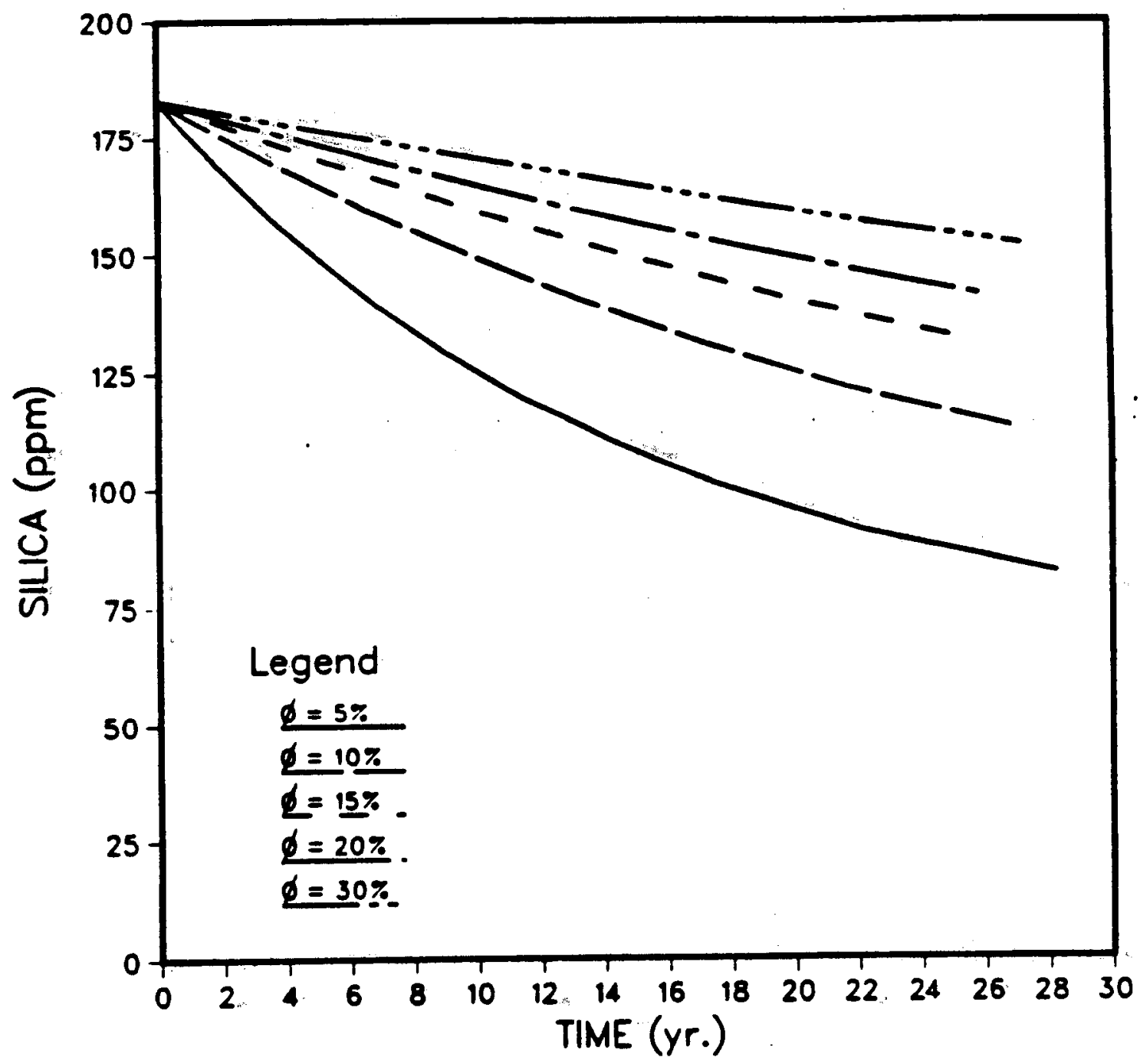

Figure 18. Significance of porosity on silica transport by convection only. 


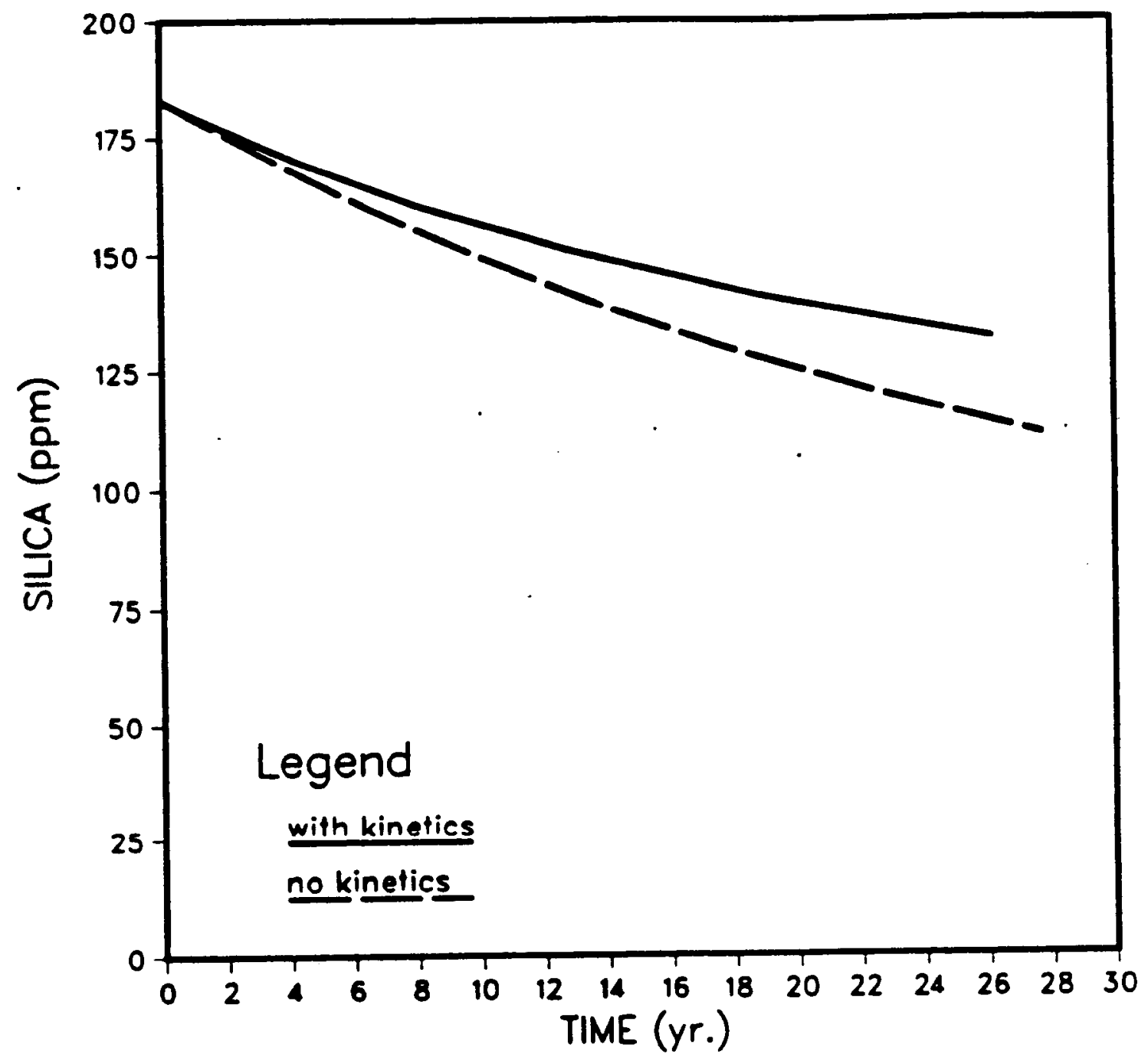

Figure 19. Comparison between the convective transport of silica with and without kinetic reactions. 
$-64$

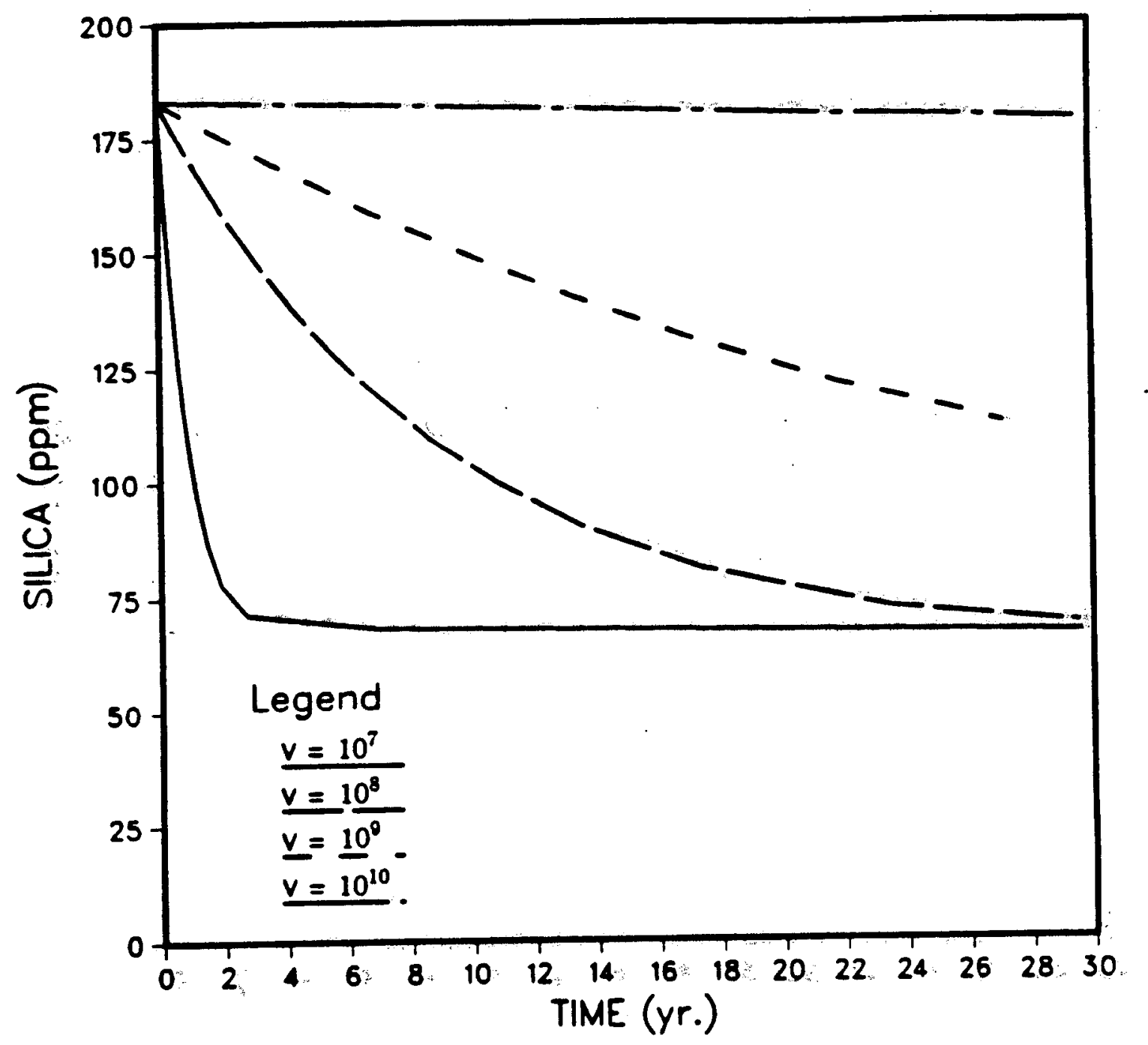

Figure 20. Significance of volume on silica transport by convection only. 
proportionality with the rate of change of the concentration of the component. The porcosity is also inversely proportional to the change in the concentration in the rate equation, but its effects are less pronounced because it was varied over a much smaller range. 


\subsection{NON-DMMENSIONAL STUDY}

After atudying the effects and significance of various parameters on silica and oxygen-18 transport, it is useful to perform a dimensional analysis on the governing equation for chemical transport. The goal in this exercise is to characterize the governing equation by dimensionless groups of parameters. If successful, the number of dimensionless parameters will be many less than the total number of parameters describing the system. Further sensitivity studies may then be performed by holding some of the dimensionless groups constant, while varying the values of those remaining. The reaults may be plotted in the form of type curves. Field data can then be matched with the type curves to get estimates of field parameters.

To non-dimensionalize the chemical transport equation, ceveral simplifying ascumptions must be made. First, the field in asaumed to have only two zones of recharge, one from the top (noted by subscript in this study), and one from the side (noted by subscript b). The amount of fluids coming in from the top and side is equal to the amount of fluid being produced (ie: mass is conserved; $q=q_{a}+q_{b}$ ); and both the flux from top or side is proportional to $q_{(}\left(q_{b}-\bar{\alpha} q_{i} q_{b}=\bar{\beta} q\right)$. Second, transport due to dispersion/diffusion is neglected. Third, temperature is assumed to be linear function of time such that,

$$
T=\bar{a} t+\bar{b}
$$

where

$$
\begin{aligned}
& \bar{a}=\frac{q}{x}\left(\alpha T_{2}+\tilde{\beta} T_{b}-T_{0}\right)\left(\frac{c_{i} \rho_{t}}{c_{R} \rho_{R}}\right) \phi \\
& \bar{b}=T_{0}
\end{aligned}
$$

and

$$
x=V \phi \rho_{r}
$$

This assumption will always be approximately valid if the flow rates from the two recharge zones does not change significantly with time This verified by Figure 21 ; 
plot of temperature versus time for various field volumes at production rates of 250 $\mathrm{kg} / \mathrm{s}$ and $25 \mathrm{~kg} / \mathrm{s}$.

Fourth, the kinetic rate constant and equilibrium constant are both assumed to be linear functions of temperature. Over short temperature ranges (between $75^{\circ} \mathrm{C}$ $150^{\circ} \mathrm{C}$ ), this sosumption is approximately valid for both silics and oxygen-18, as is shown in Figures 22, 23 and 24; for oxygen-18, the equilibrium constant actually is a linear function of temperature (see Eq. 12). From the Ggures, the temperature dependent functions are found to be:

For silica ( $\alpha$-cristobalite),

$$
\begin{aligned}
& C^{\circ 9}=a^{\prime} T+b^{\prime} \\
& k_{1}=A^{\prime} T+B^{\prime}
\end{aligned}
$$

where

$$
\begin{aligned}
& \mathrm{a}^{\prime}=5.001 \\
& b^{\prime}=-123.64 \\
& A^{\prime}=2.0 \times 10^{-0} \\
& B^{\prime}=-178.9 \times 10^{-0}
\end{aligned}
$$

For oxygen-18 in a basalt/seawater system,

$$
\begin{aligned}
& \delta^{\circ}=a^{\prime} T+b^{\prime} \\
& r_{1}=A^{\prime} T+B^{\prime}
\end{aligned}
$$

where

$$
\begin{aligned}
& \mathrm{a}^{\prime}=\left[\frac{0.01463}{1+\left(\frac{\phi}{1-\phi}\right)\left(\frac{\rho_{\mathrm{P}} \mathrm{X}_{\mathrm{r}}}{\rho_{\mathrm{R}} \mathrm{X}_{\mathrm{R}}}\right)}\right] \\
& b^{\prime}=\frac{\delta_{R}^{i}-7.85+\left(\frac{\phi}{1-\phi}\right)\left(\frac{\rho_{f} X_{f}}{\rho_{R} X_{R}}\right) C_{0}}{1+\left(\frac{\phi}{1-\phi}\right)\left(\frac{\rho_{f} X_{f}}{\rho_{R} X_{R}}\right)}
\end{aligned}
$$




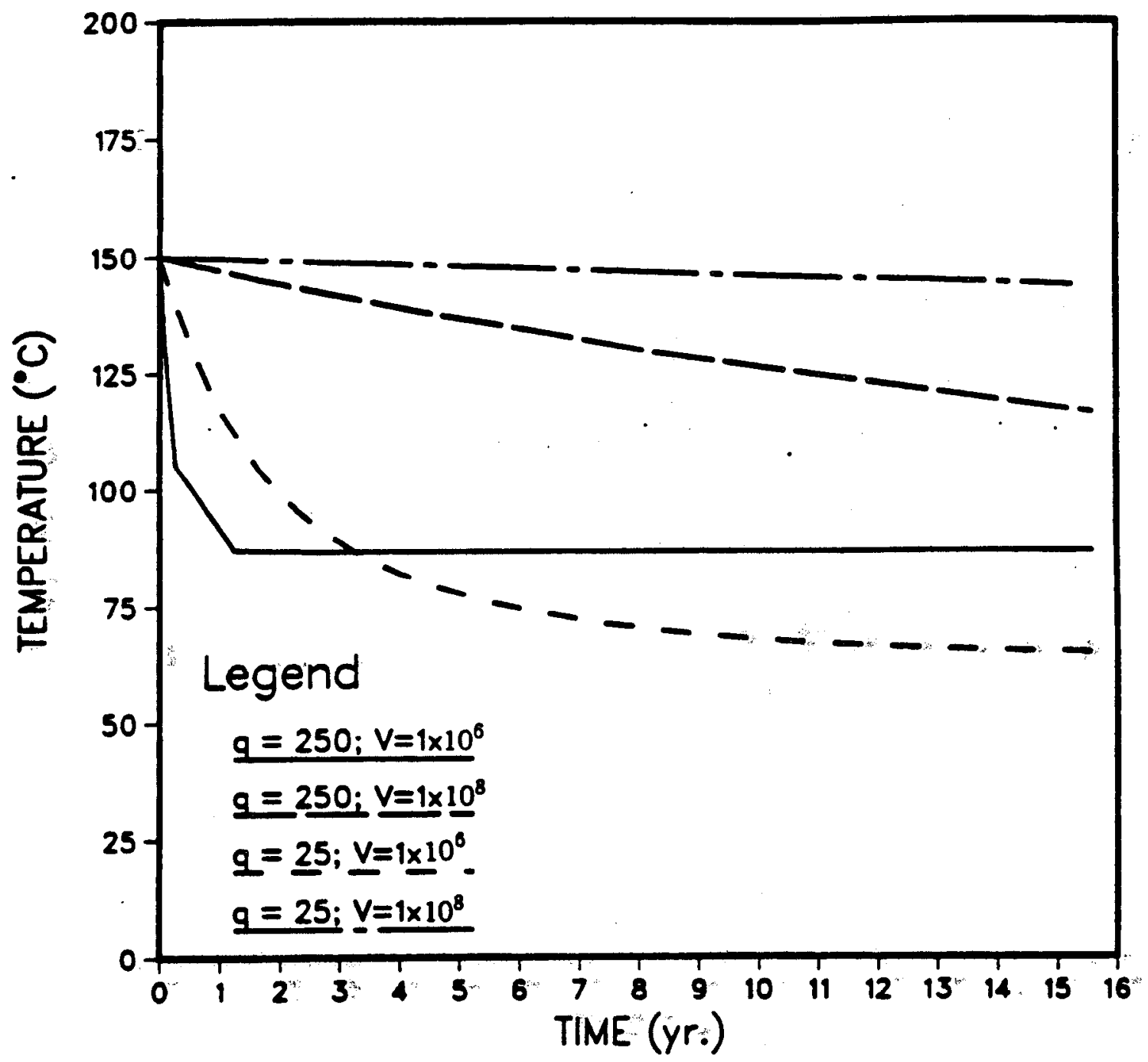

Figure 21. Temperature versus time for various field volumes and flow rates. 


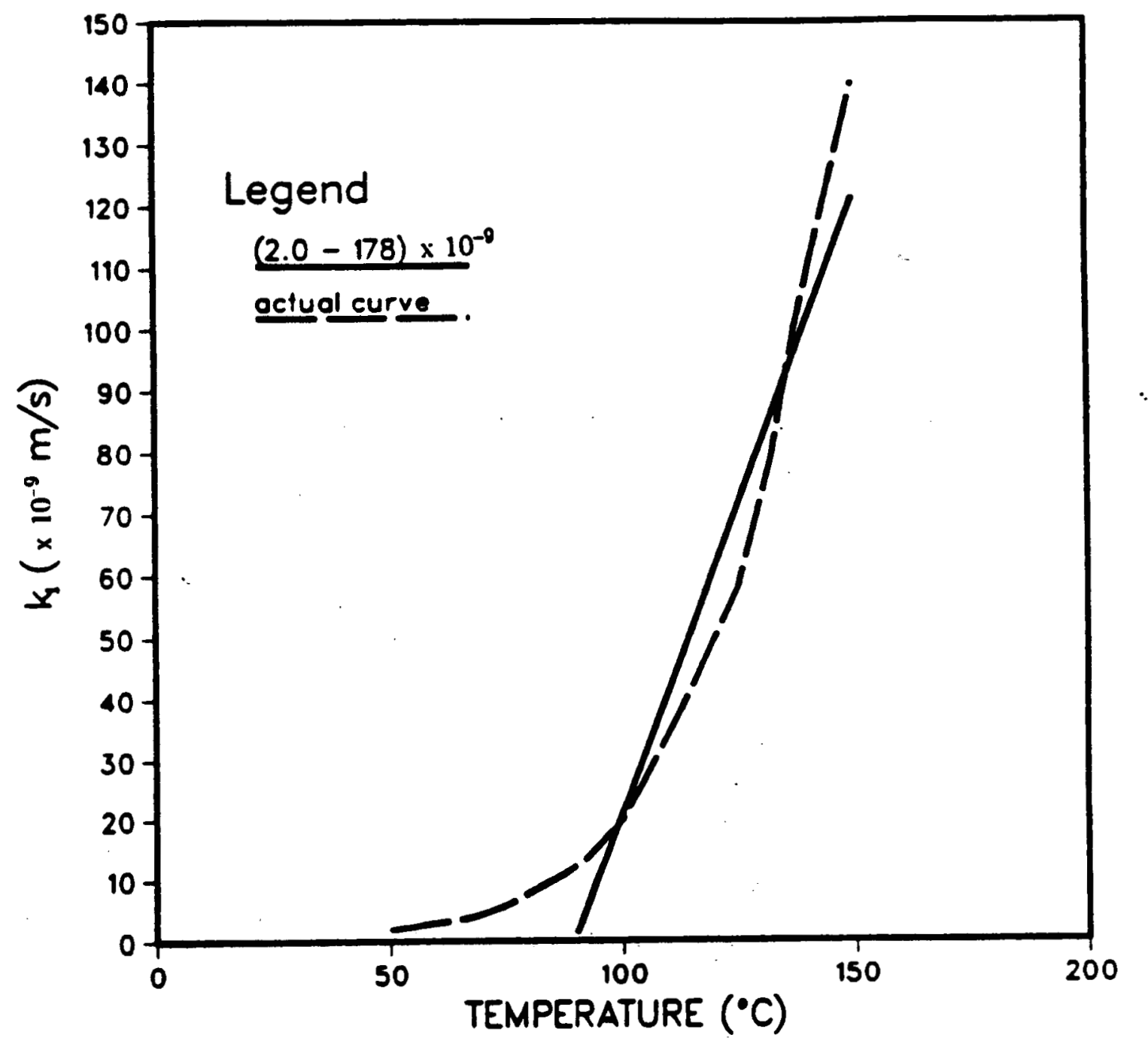

Figure 22.

Fitting a linear temperature function to the kinetic rate constant for silica. 
$-70$

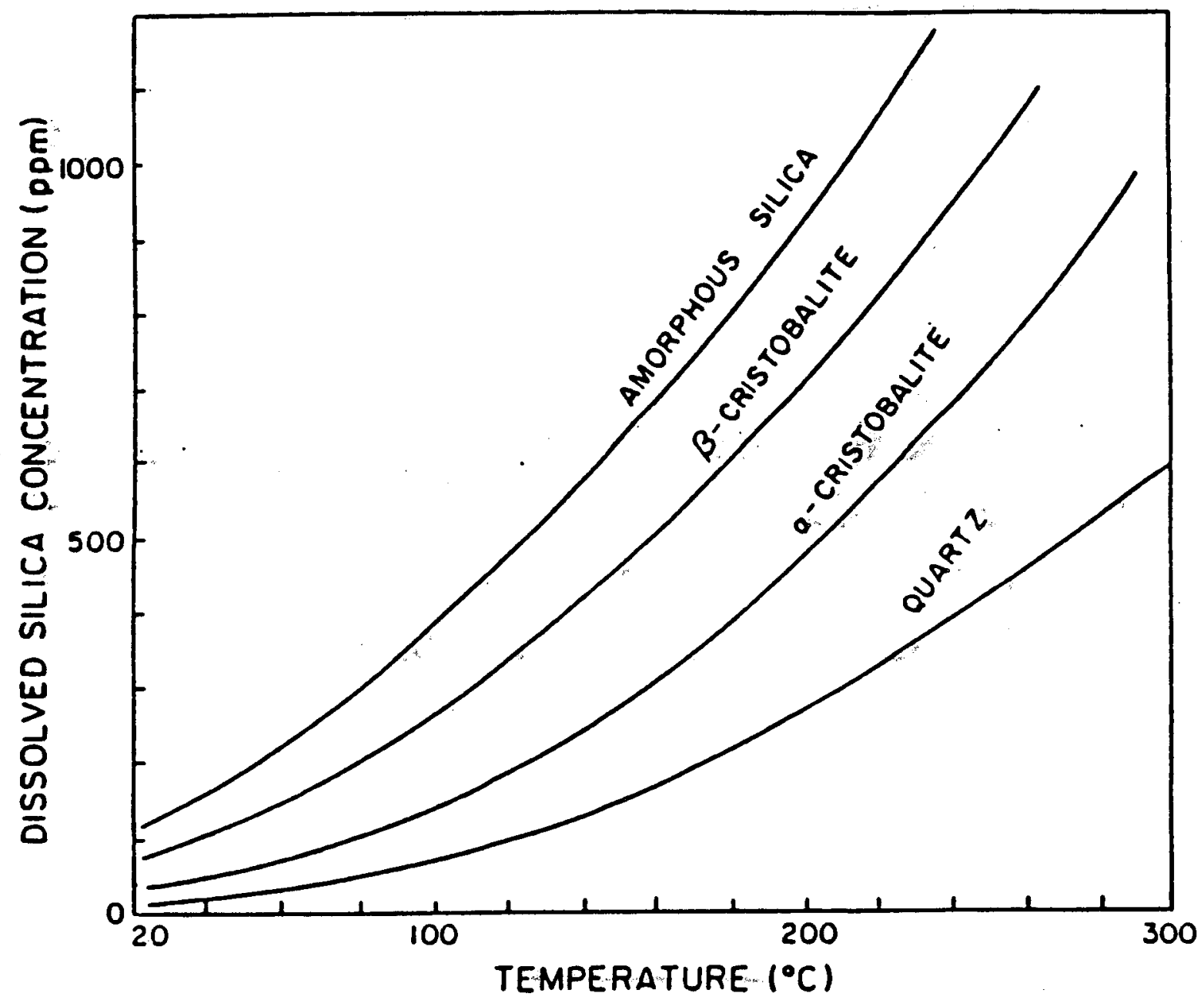

Figure 23. Equilibrium solubilities for silica (from Robinson, 1982). A linear function of temperature is assumed over the temperature range $80^{\circ} \mathrm{C}$ to $150^{\circ} \mathrm{C}$, for $\alpha$-cristobolite. 
-71 .

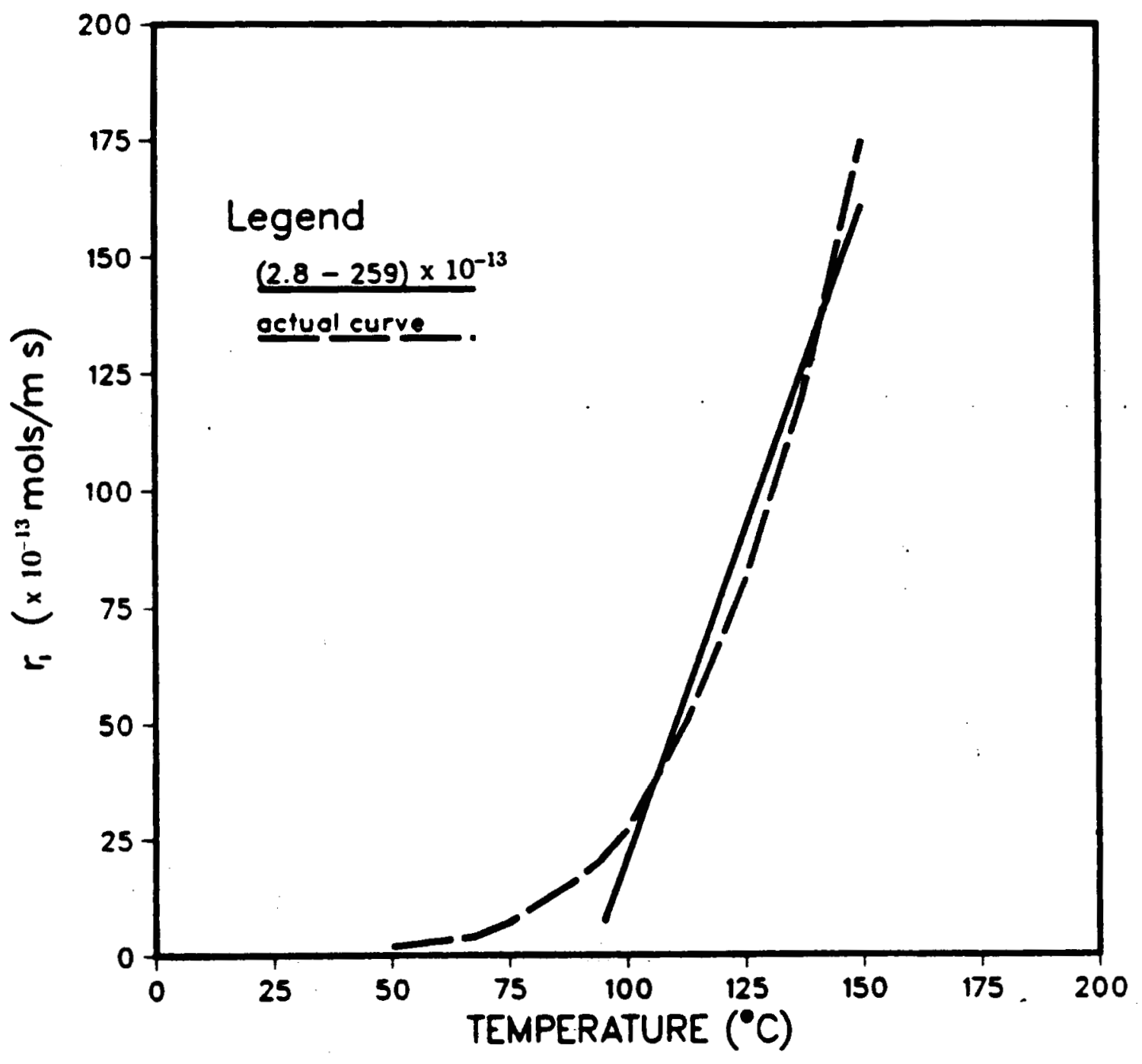

Figure 24. Fitting a linear temperature function to the kinetic rate constant for oxygen-18. 


$$
\begin{aligned}
& A^{\prime}=2.8 \times 10^{-13} \\
& B^{\prime}=-259.0 \times 10^{-13}
\end{aligned}
$$

To non-dimensionalize the governing equation, a step-by-step inspectional analysis technique, described by Tillotson and Nielson (1983) was used. The technique consists of the following steps;

(1) List the physical law and boundary conditions.

$$
\frac{d C}{d t}=\left(\frac{Q}{x}+Y c_{2} \bar{B}\right)-\left[\frac{q}{x}+c_{2} Y\right] c-\left(Y c_{1}\right) t C+\left(Y c_{1} \bar{A}\right) t^{2}+\left(Y\left(c_{1} \bar{B}+c_{2} \bar{A}\right)\right) t
$$

and at $t=0 ., C=C_{0}$. The constants $T, B, c_{1}$ and $c_{2}$ are defined:

$$
\begin{aligned}
& \bar{A}=a^{\prime} \dot{a} \\
& \bar{B}=a^{\prime} \tilde{b}+b^{\prime} \\
& c_{1}=A^{\prime} \tilde{a} \\
& c_{2}=A^{\prime} \tilde{b}+B^{\prime}
\end{aligned}
$$

The constant $Y$ is defined differently for silica and oxy gen-18. For silica:

$$
\mathbf{Y}=\mathbf{A} / \mathbf{N}
$$

and for oxy gen-18:

$$
Y=A\left(\frac{W+S}{S W}\right)
$$

(2) Put rariables in dimensionless form.

$$
\begin{aligned}
& C^{*}=\frac{C}{C_{0}} \\
& \tau=\left(\frac{q}{x}\right) t
\end{aligned}
$$

(3) Substitute back into physical law.

$$
\frac{C_{0} q}{x} \cdot \frac{d C^{*}}{d \tau}
$$




$$
\begin{aligned}
& =\left(\frac{Q}{x}+Y c_{2} B\right)-\left[\frac{q}{x}+c_{2} Y\right] C_{0} C^{*}-\left(Y c_{1}\right) \frac{x}{q} C_{0} \tau C^{*} \\
& \cdots+\left(Y c_{1} \bar{A}\right)\left(\frac{x}{q}\right)^{2} \tau^{2}+Y\left(c_{1} B+c_{2} \bar{A}\right) \frac{w}{q} \tau
\end{aligned}
$$

(4) Divide equations by the leading coeficient of one term.

$$
\begin{aligned}
\frac{d C^{*}}{d \tau} & =\left(\frac{Q}{x}+Y c_{2} B\right) \frac{x}{q C_{0}}-\left[\frac{q}{x}+c_{2} Y\right] \frac{x}{q} C^{*}-\left(Y c_{1}\right) \frac{x^{2}}{q^{2}} r C^{*} \\
& +\left(Y c_{1} \bar{A}\right)\left(\frac{x}{q}\right)^{3} \frac{\tau^{2}}{C_{0}}+\frac{Y}{C_{0}}\left(c_{1} B+c_{2} \bar{A}\right)\left(\frac{x}{q}\right)^{2} \tau
\end{aligned}
$$

(5) Determine the dimensionless groups by inspection.

$$
\begin{array}{cc}
D_{1}=\frac{Y c_{1} x^{2}}{q^{2}} & D_{3}=\frac{Q}{\bar{A} x} \\
D_{2}=\frac{Y c_{2} x}{q} & D_{4}=\frac{B}{\bar{A}} \frac{q}{x} \\
D_{s}=\frac{q}{x} \frac{C_{0}}{\bar{A}}
\end{array}
$$

The equation can now be written in dimensionless form as:

$$
\begin{aligned}
\frac{d C^{*}}{d \tau}= & \left(\frac{D_{3}+D_{2} D_{1}}{D_{5}}\right)-\left(1+D_{2}\right) C^{*}-D_{1} \digamma C^{*} \\
& +\left(\frac{D_{1}}{D_{5}}\right) \tau^{2}+\left(\frac{D_{2}+D_{2} D_{4}}{D_{5}}\right) \tau
\end{aligned}
$$

Equation 47 is nonlinear and cannot be readily solved analytically. Instead, the numerical code (PTCC) was used and the results are presented in terms of the dimensionless parameters. To test the uniqueness of the dimensionless parameters, the the overall group values are held constant, while parameters within the group are varied. For example, $D_{1}$ is held constant, but $Y, c_{1}, x$, and $q$ are varied such that when they are multiplied as $\left(Y_{c_{1}} x\right) / q^{2}$, the value remains constant. In order to do this for all fre of the dimensionless parameters, the groups must be written in terms of the 
fundamental parameters and set equal to the values of the first run. To find the values of the second run, one parameter is changed (such as porosity) and the equations are solved simultaneously for the new values of the remaining parameters. If the dimensionless groups are unique, the results of the two runs will match identically. The test runs used the following values for the dimensionless parameters, for silica;

$$
\begin{aligned}
& D_{1}=-18.8, \\
& D_{2}=86.7 \\
& D_{3}=-1.5, \\
& D_{4}=-0.6, \\
& D_{6}=-0.5
\end{aligned}
$$

and for oxygen-18;

$$
\begin{aligned}
& D_{1}=2.1, \\
& D_{2}=22.4, \\
& D_{3}=3.5, \\
& D_{4}=44.8, \\
& D_{5}=-18.8 .
\end{aligned}
$$

The results are plotted in Figures $25 \mathrm{a}, \mathrm{b}$ as dimensionless concentration versus dimensionless time for silica and oxygen-18, respectively. As is demonstrated in the figures, the runs match identically for both silica and oxygen-18.

After validating the dimensionless groups, it must be decided which of these groups will be most useful to study. Since the dimensionless parameters for silica and oxygen-18 are nearly identical, the studies could be performed equally on one or the other. To avoid repetition, studies on the dimensionless parameters were performed using silica transport only. As a first attempt, to study the effects of $q / x, D_{1}$ and $D_{2}$ were varied, (by varying $q / x$ ) and holding the other dimensionless groups constant. For the study, $q / x$ was varied over several orders of magnitude and the results plotted as 

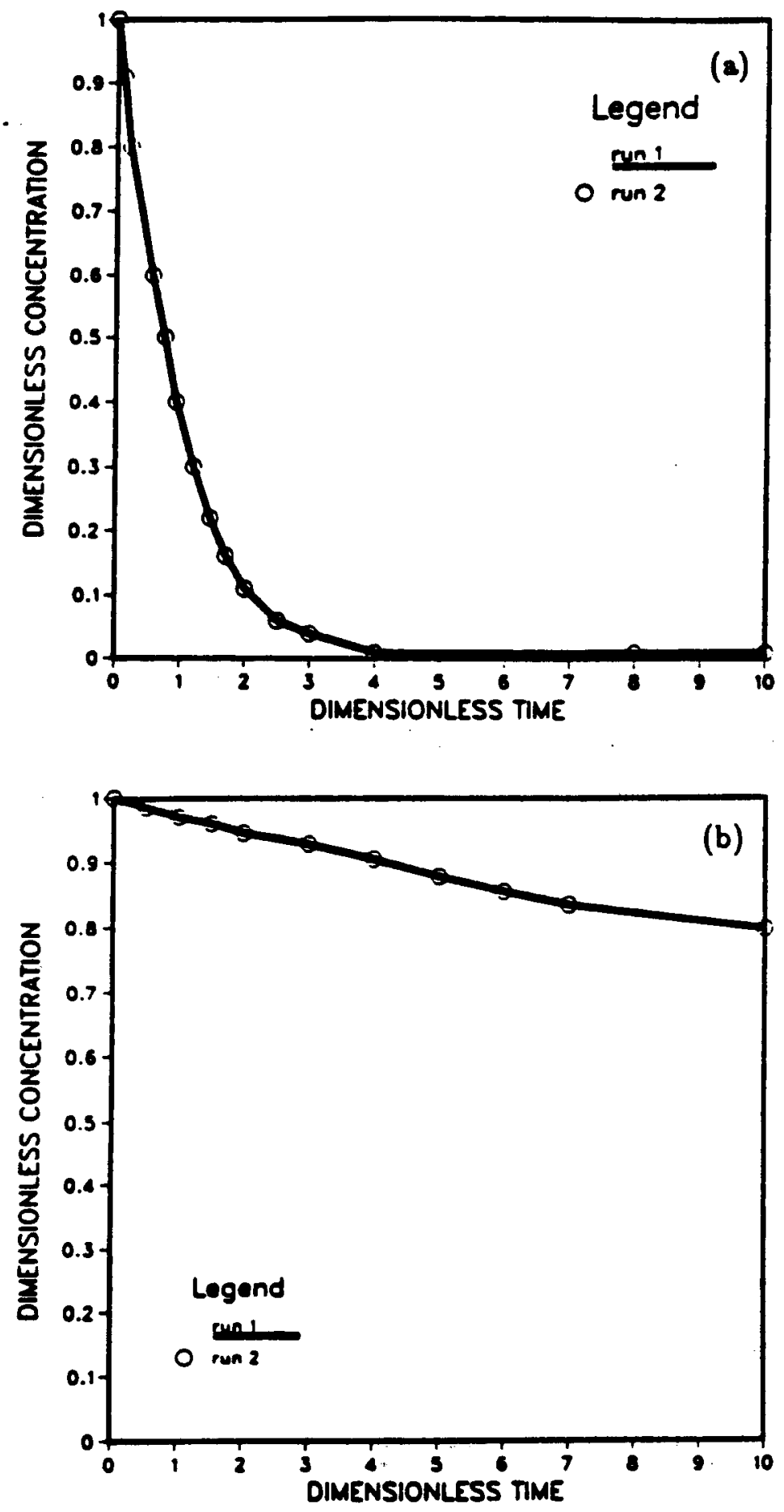

Figure 25. Testing the uniqueness of the nondimensional parameters for, (a) silica and (b) oxygen-18. 
type curves in Figure 26. In the figure, $C^{*}$ is shown plotted against $r D_{2}$. It is necessary to multiply $\tau$ by $D_{2}$ before plotting. Because $\tau$ varies proportionally with $q / x$, when $q / x$ changes by an order of magnitude, the dimensionless time will as well. The range in values between type curves becomes very large and are cumbersome to plot. If $r$ is multiplied by $D_{2}, q / x$ will cancel out. $A$ indicated in the figure, when the volume increases, and/or the production rate decreases, the change in chemical concentration become smaller and the curves flatten out. The larger the reservoir volume (or, equivalently, the larger the flow rate), the shorter the time for the inflow of lower con-: centration waters to have an effect.

As a second attempt, $D_{3}$ was varied by changing the amount of flow in from the top and sides (varying $\tilde{\alpha}$ and $\bar{\beta}$ ). It is not atrictly corroct that the other dimensionless parameters remained constant, but $D_{3}$ is much more affected by a change in $\bar{\alpha}$ and $\bar{\beta}$; the amount of error assumed by regarding the other parameters as constant between runs is less than $10 \%$.

To demonstrate the usefulness of type curves made from varying $D_{3}$, field data from the Ellidaar feld in Iceland was analyzed. The Ellidaar field is a low-temperature Geld located near the sea; in the southweatera part of the country, in predominantly fractured basalts. Figure 27 gives a simple conceptual model of the system. The field was modeled previously by Lai et al. (1985), using a similar model and they estimated the field parameters as:

$$
\begin{aligned}
& V=2.5 \times 10^{8} \mathrm{~m}^{3}, \\
& \phi=5 \%, \\
& A / V=5.5 \mathrm{~m}^{-1}, \\
& \bar{\alpha}:=0.9 ; \quad \bar{\beta}=0.1 .
\end{aligned}
$$

The high value of $\alpha$ indicates large recharge from above.

The silica concentration data from the field was plotted non-dimensionally against time (Figure 28). $A$ set of type curves were made (Figure 29), varying $D_{3}$ and using a simple three-element model; similar to the one shown in Figure 9 , with the feld 
$-77-$

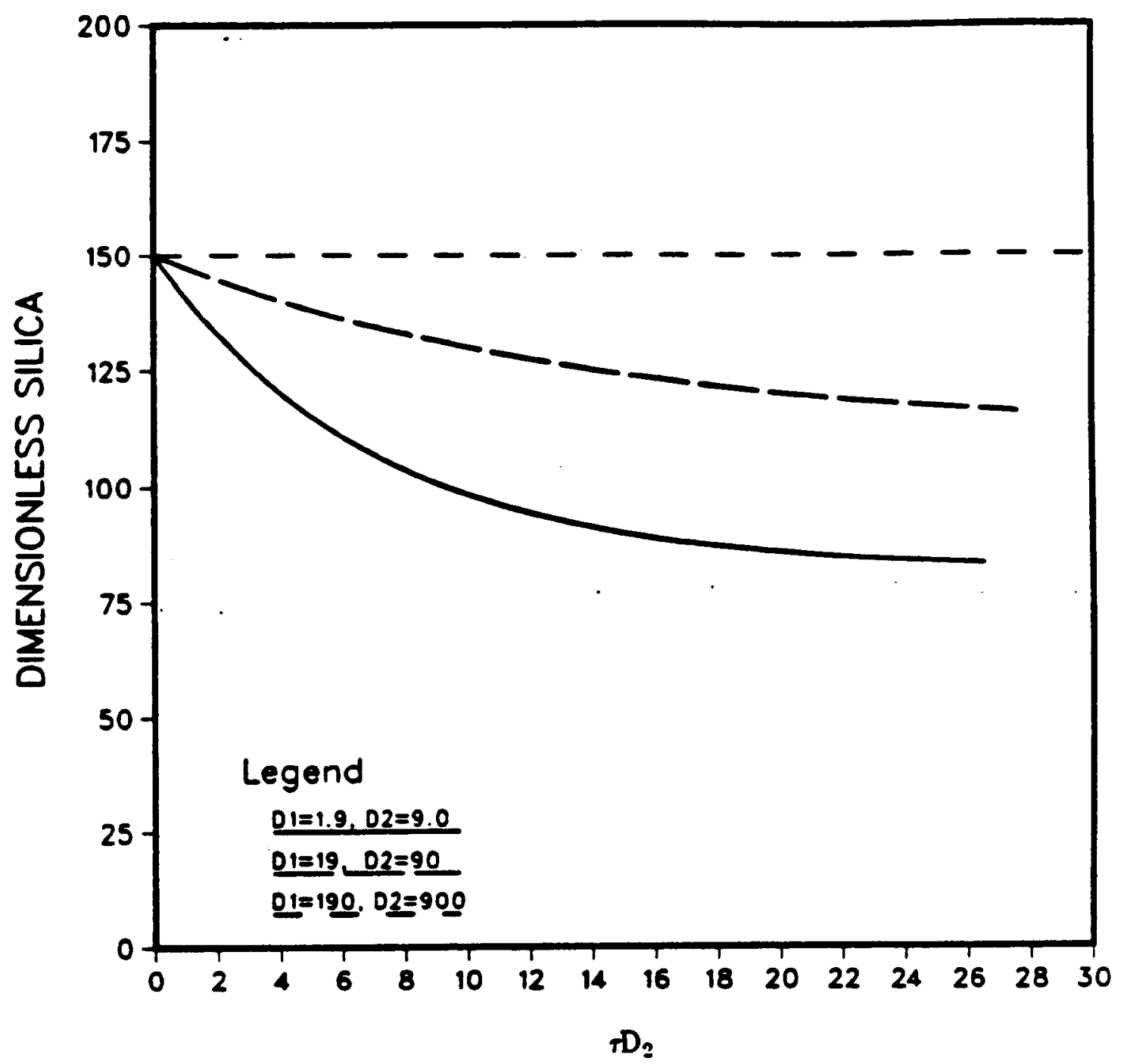

Figure 26. Type curves for different values of the dimensionless parameters, $D_{1}$ and $D_{2}$, by varying $q / x$. 
G.S.

8

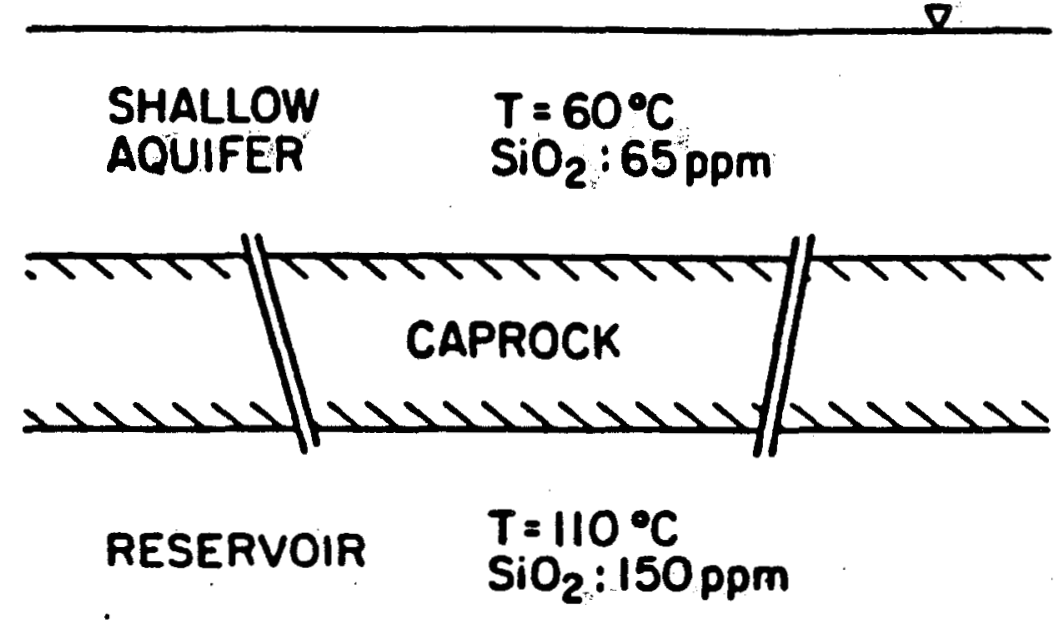

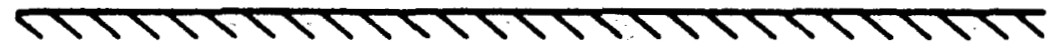

recest-eoro

Figure 27. Simple cross-sectional sketch of the Ellidaar geothermal system (Lai, 1985). 


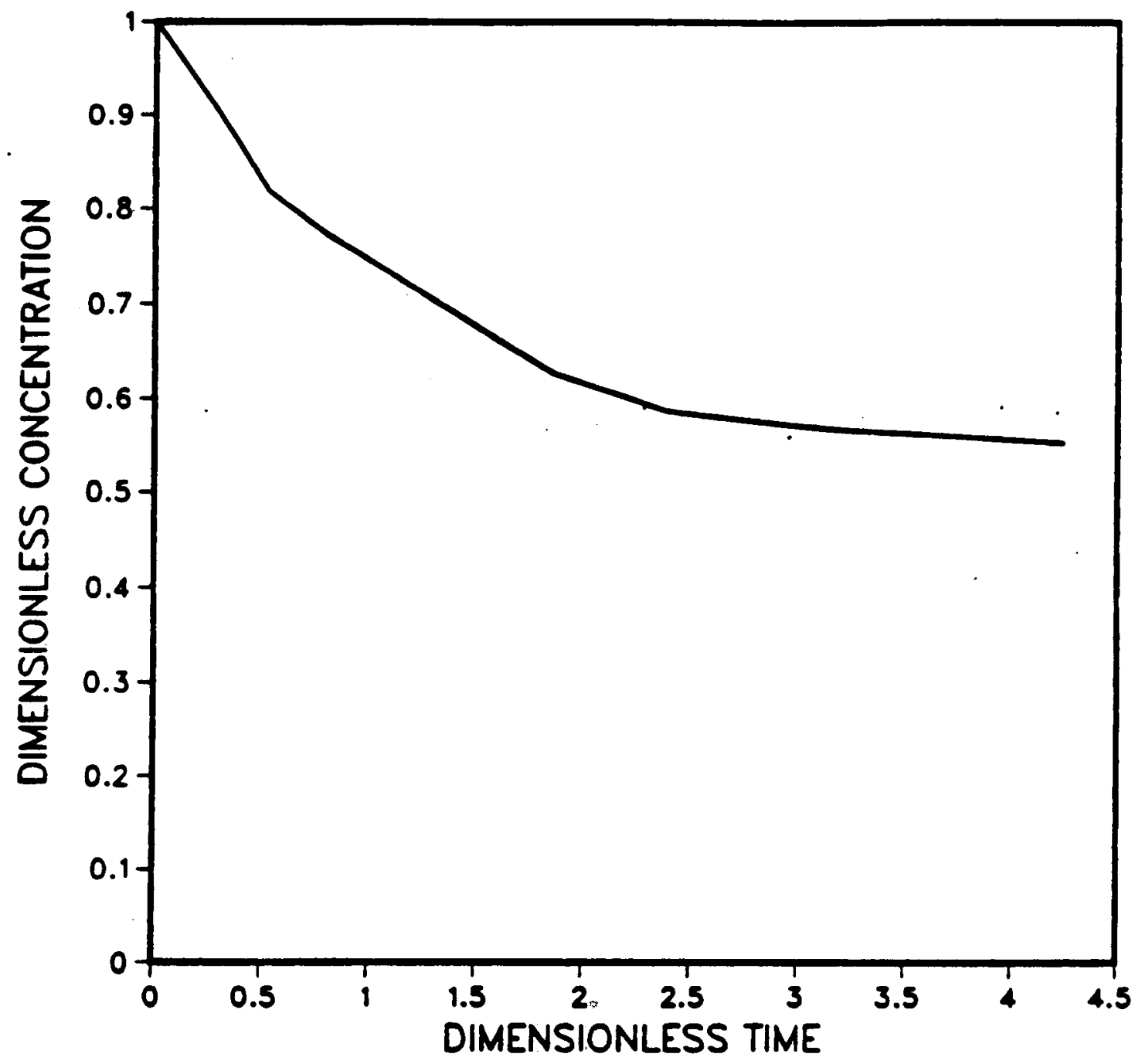

Figure 28. Field data from the Ellidaar geothermal field (Hettling, 1984) for silica plotted non-dimensionally against dimensionless time. 


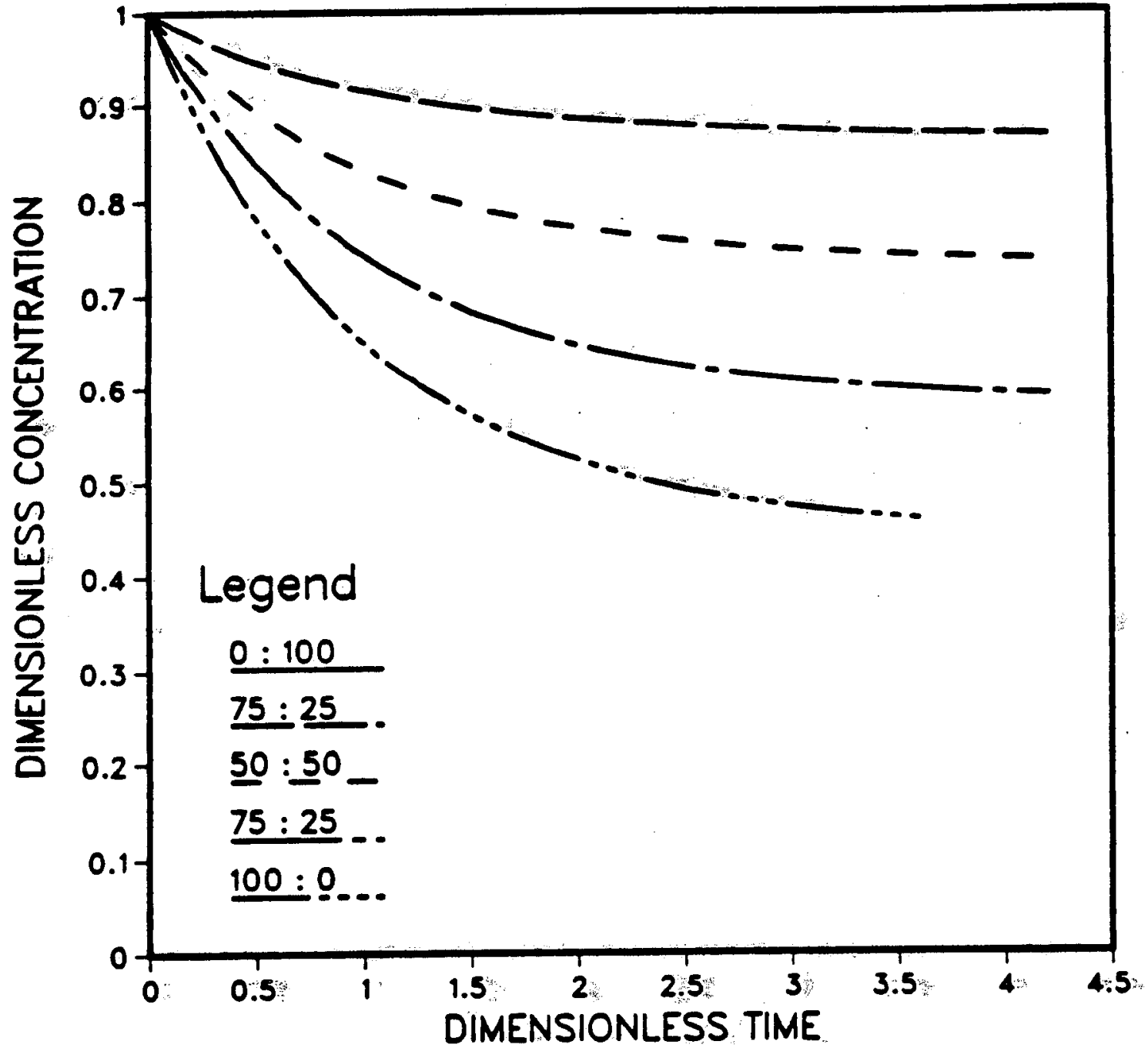

Figure 29. Type curves of range in dimensionless parameter $D_{3}$, showing effect of relative recharge in from the top and side. The curves are identified in the legend by the variations made in the ratio of $\alpha$ to $\beta$ multiplied by 100 (where $100 x-\alpha=\%$ flux from the top; $100 \times \dot{\beta}=\%$ flux from the side). 
parameters of the Ellidaar field. In Figure 29, it was found to be more helpful to identify the curves by the ratio of $\bar{\alpha}$ to $\bar{\beta}$ multiplied by 100 (where $100 \times \bar{\alpha}=\%$ fiux from top; $100 \times \bar{\beta}=\%$ lux from side), to indicate the changes in the amounts of recharge from the top and side associated with varying $D_{3}$. The field data was then matched with the type curve. The curve fell between the 75:25 and 100:0 curves, which agrees with the estimates by Lai.

Several more sets of type curves were then generated by varying the field properties. Table 9 lists the values of the dimensionless parameters $D_{1}, D_{2}, D_{4}$ and $D_{5}$, along with the number of the figure which shows a plot of the resulting type curves obtained by holding these values constant and varying $D_{3}$. The first set of type curves was obtained by increasing the poronity to $10 \%$ (Figure 30 ); the second, by increasing $q / x$ by en order of magnitude (Figure 31); the third, by decreasing $q / x$ by an order of magnitude from the original value (Figure 32); and the fourth, by increasing A $V$ from 5.5 to 25.0 (Figure 33). Again, the field data was tested for a match. No match was found between the Geld data and the type curves of different porooity and $q / x$ values, indicating the choice of porosity $=5 \%$ and $V=2.5 \times 10^{8}$ are the inost accurate estimates of the parameters. A match with the fourth type curve, with a larger $A / V$, was poasible. However, in the second match, the Geld data curve also fell between the 75:25 and 100:0 curves, in agreement with the estimate by Lai.

TABLE 9. Values of the dimensionless parameters held constant in Figures 29 through 33.

\begin{tabular}{llllr}
\hline Figure & $D_{1}$ & $D_{2}$ & $D_{4}$ & $D_{5}$ \\
\hline 29 & 18.8 & 86.7 & 9.60 & -0.50 \\
30 & 18.8 & 43.4 & 4.80 & -0.25 \\
31 & 1.88 & 8.67 & 9.60 & -0.50 \\
32 & 188. & 867. & 9.60 & -0.50 \\
33 & 94.0 & 434. & 9.60 & -0.50 \\
\hline
\end{tabular}




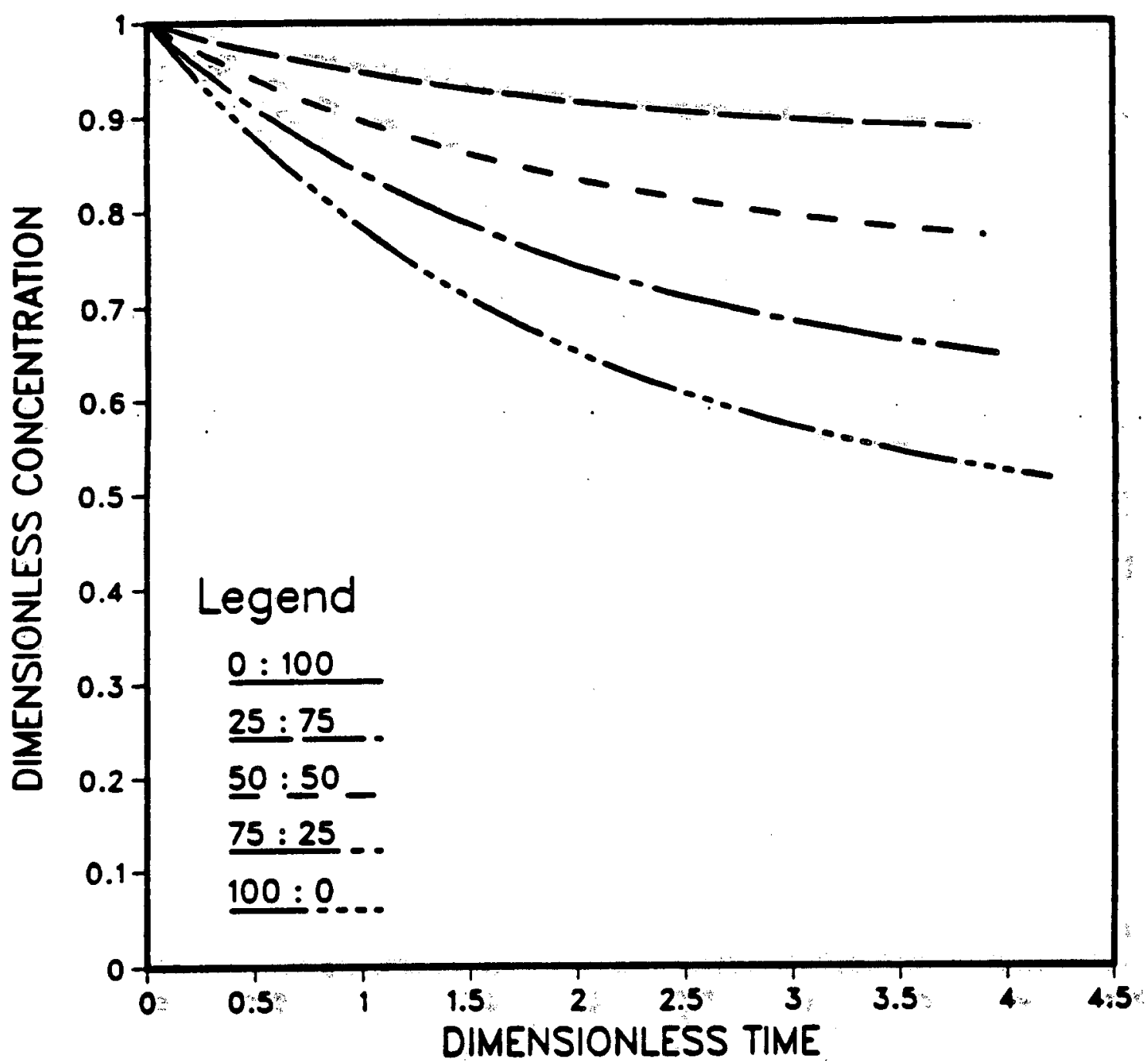

Figure 30. Type curves of range in dimensionless parameter $D_{3}$. Porosity has been raised from $5 \%$ to $10 \%$. The curves are identified in the legend by the variations made in the ratio of $\alpha$ to $\beta$ multiplied by 100 (where $100 \times \alpha=\%$ flux from the top; $100 \times \beta=\%$ flux from the side). 


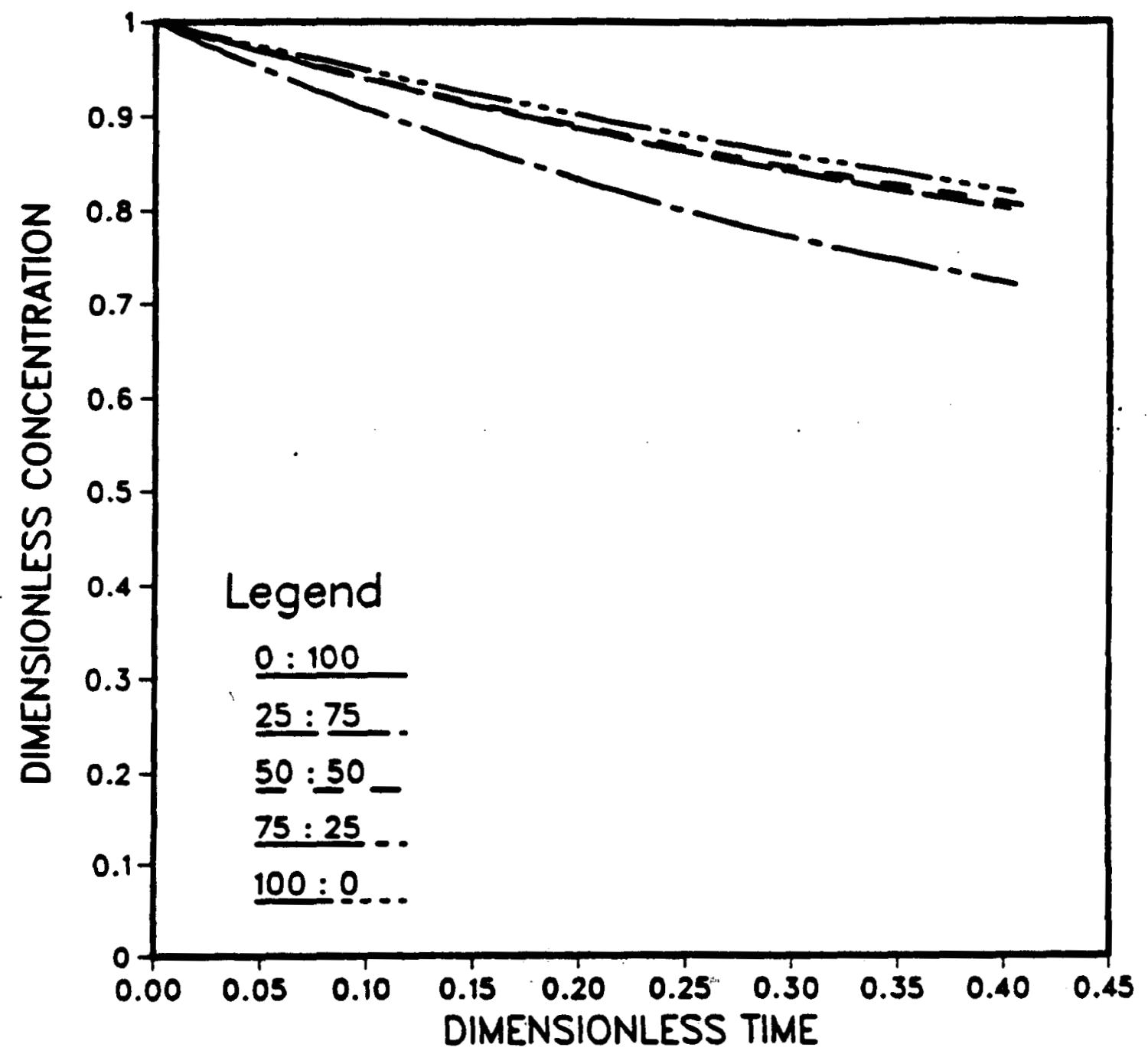

Figure 31. Type curves of range in dimensionless parameter $D_{3}$. The $q / x$ has been decreased by an order of magnitude. The curves are identified in the legend by the variations made in the ratio of $\bar{\alpha}$ to $\beta$ multiplied by 100 (where $100 \times \bar{\alpha}=\%$ flux from the top; $100 \times \bar{\beta}$ $=\%$ fux from the side). 


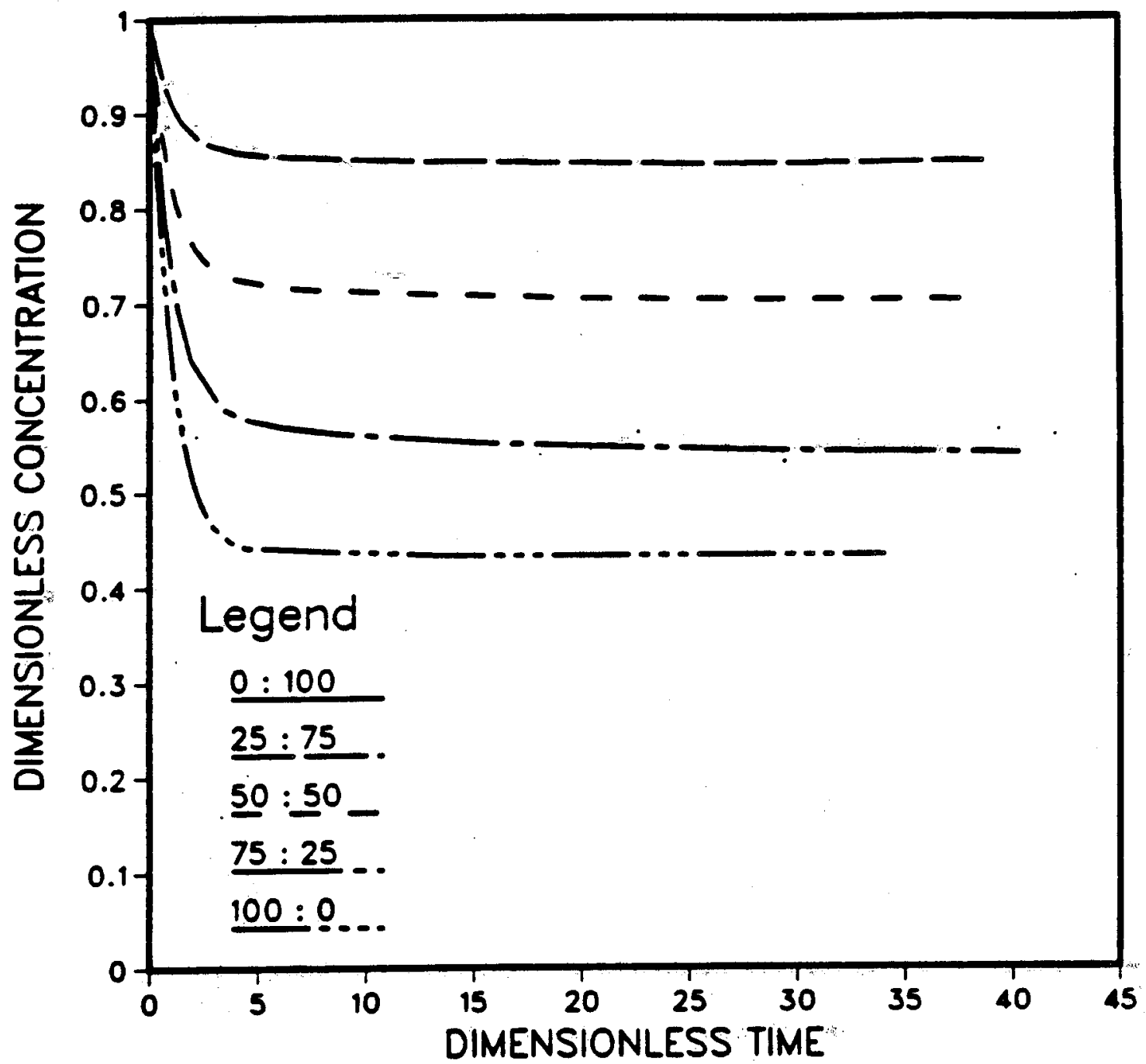

Figure 32. Type curves of range in dimensionless parameter $D_{3}$. The $q / x$ has been increased by an order of magnitude. The curves are identified in the legend by the variations made in the ratio of $\alpha$ to $\bar{\beta}$ multiplied by 100 (where $100 x \bar{\alpha}=\%$ flux from the top; $100 \times \bar{\beta}$ $=\%$ flux from the side). 


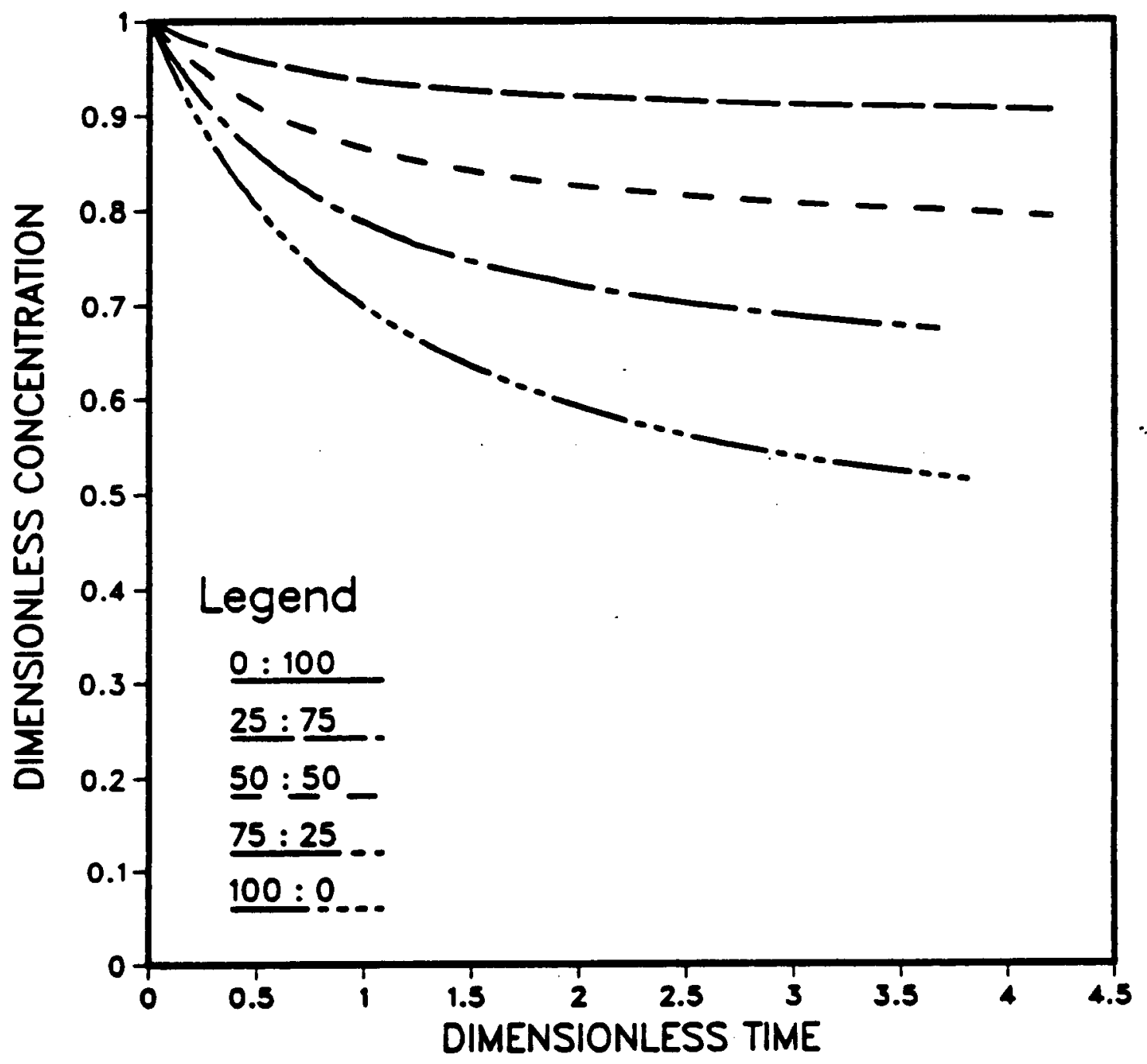

Figure 33. Type curves of range in dimensionless parameter $D_{3}$. The value of $A / V$ has been increased from 5.5 to 25.0. The curves are identified in the legend by the variations made in the ratio of $\alpha$ to $\bar{\beta}$ multiplied by 100 (where $100 \times \bar{\alpha}=\%$ flux from the top; $100 \times \bar{\beta}$ $=\%$ flux from the side). 
As seen from this field example, the type curves can be useful in giving approximate values for the amount of flux coming from the top and sides, the volume (from $q / x)$, and the porooity, without lengthy trial and error matching of temperature, pressure and ohemical concentration data. A simple mesh with "ballpark" estimates for the field parameters must be designed, and several sets of type curves developed as in the above example. Then, the best match of the field data with the type curves can be determined, and the field parameters estimated. However, is was also seen that an accurate estimate of the $A / V$ value appears not to be possible from the type curve matches. 


\subsection{FIELD EXAMPLES}

If a more accurate solution to the field parameters are necessary, a numerical model should be used to match the field data (pressure, temperature, and concentrations change with time). This technique was applied to the field data from two lowtemperature fields. The first field example was the Ellidaar geothermal field, Iceland, described in the previous section. The second was the Seltjarnarnes field, also in Iceland.

\section{Ellidan feld}

The main purpose in modeling the Ellidas field wa to check the values of the parametere found in this atudy againat those found by Lai. Also, to see if the additional chemical data utilized in this study actually helps define more unique parameters. As a Grst approximation, a very simple two layer system was designed, with recharge from the top at $60^{\circ} \mathrm{C}$ and from the sides at the same temperature as the hot reservoir $\left(110^{\circ} \mathrm{C}\right)$. It should be noted that the actual field recharge patterns are probably much more complex, with perhaps considerable recharge from a deeper, cooler source. The model included Guoride, sodium, silica, and oxygen-18 transport. Concentrations from the upper recharge zones were estimated based on data from shallow wells in the region; the concentrations of the components coming from the side were assumed identical to the initial concentrations in the hot reservoir (refer to Figure 27 for sketch of system). By matching the temperature decline data and the change in fluoride and sodium data with time; the amount of luid coming in from the top and sides could be estimated. Although the rate of change in concentration for two conservative species will be the same, both fluoride and sodium were modeled to get more reliable results. This study found that $\mathbf{8 5 \%}$ of the recharge of the fluid came from the top, while $15 \%$ came from the side. Figures 34,35 and 36 show bow the field data for temperature, fluoride and sodium concentrations versus time, with the match of the numerical model. These values for the recharge are felt to be more unique and reliable than the results reported by Lai. In this study, three individual sets of data 
$-88$

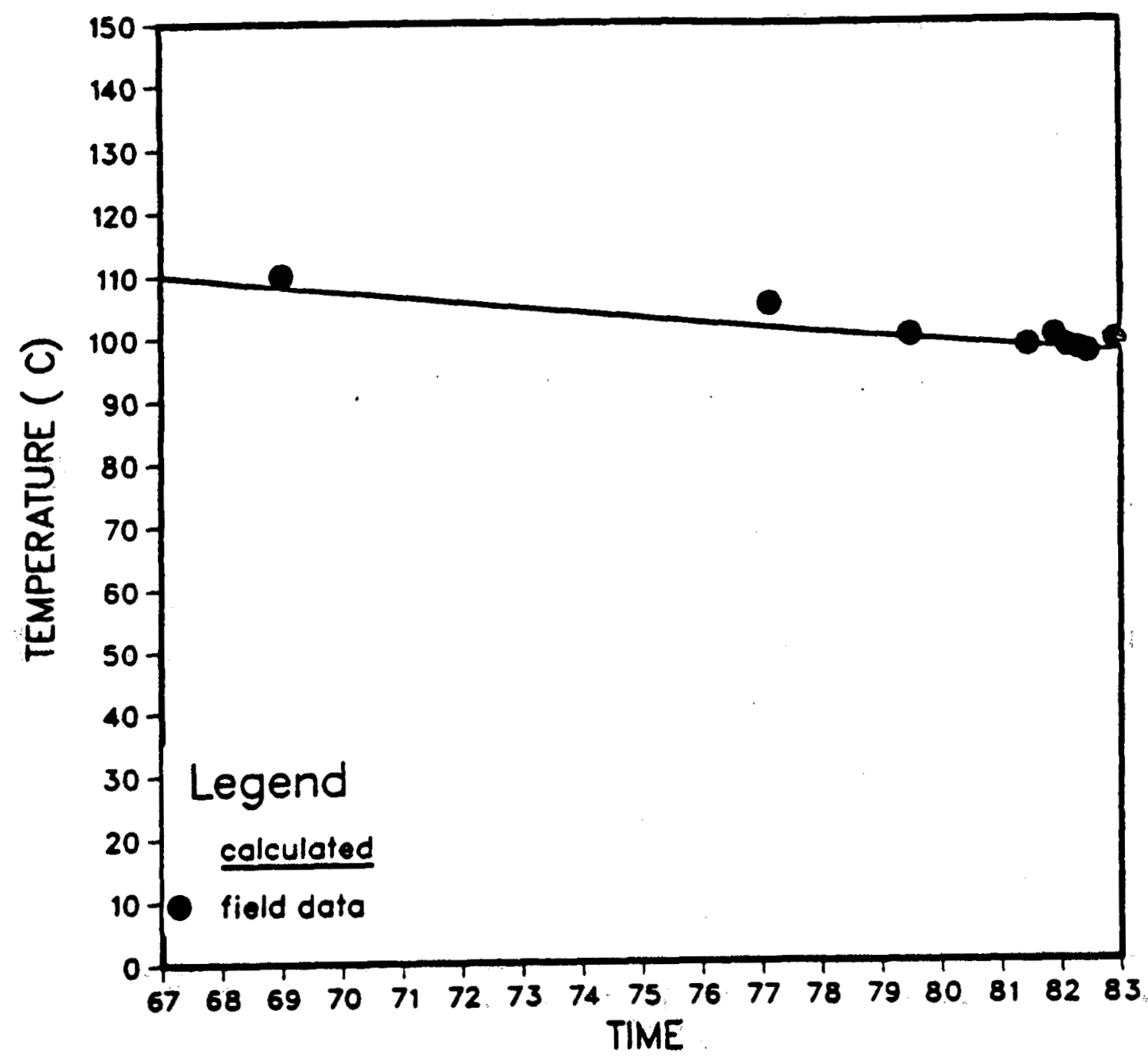

Figure 34. Plot of temperature versus time showing match between numerical model and field data from the Ellidaar field. 


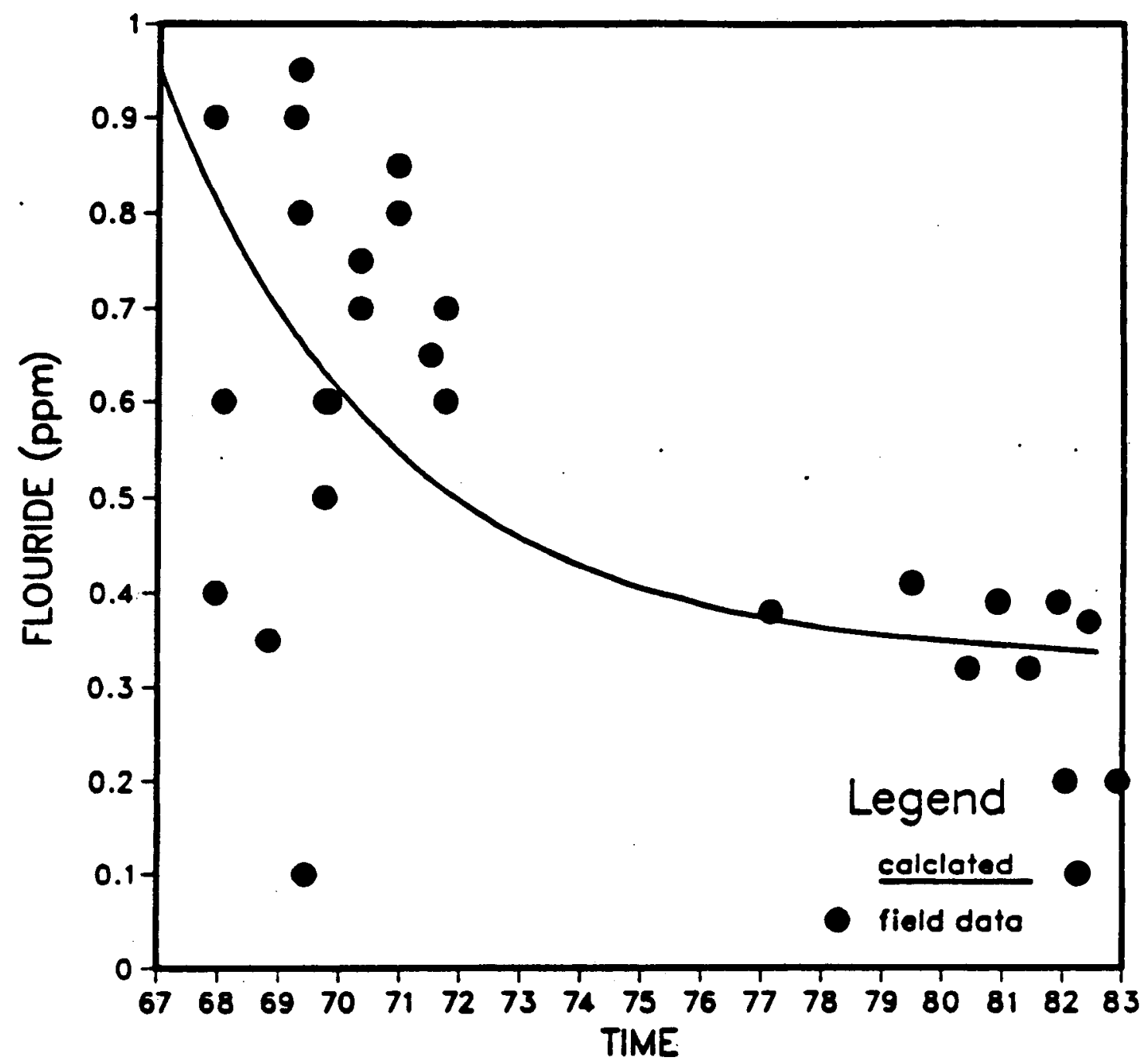

Figure 35. Plot of fuoride versus time showing the match between the numerical model and feld data from the Ellidaar Geld. 


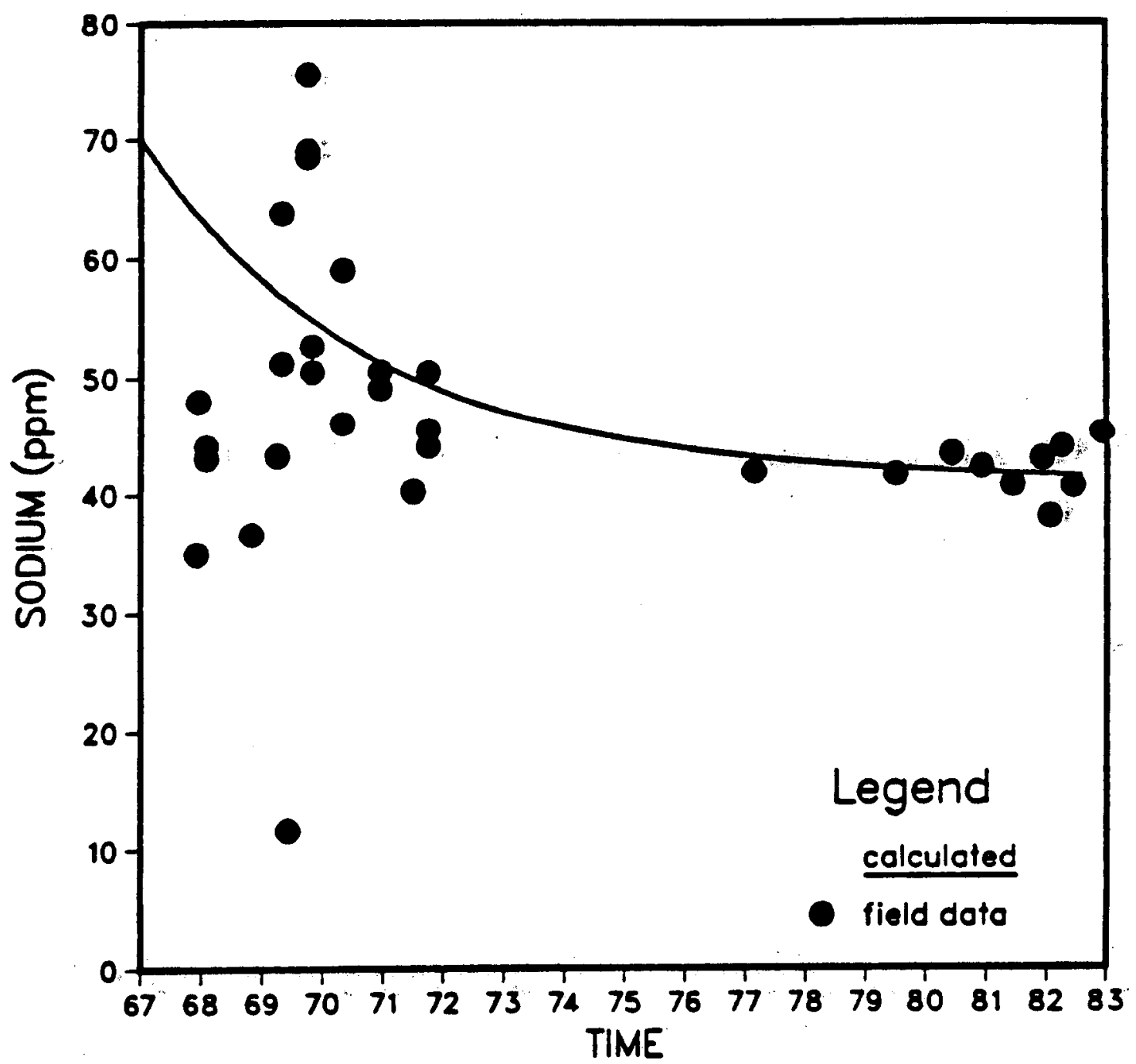

Figure 36. Plot of sodium versus time showing the match between the numerical model and feld data from the Ellidaar field. 
(temperature, fluoride, and sodium) had to be matched before the amount of recharge could be defined, while previously the recharge amounts were defined only by the temperature data.

Matching the silica and oxygen-18 data to define the porosity and volume of the field revealed some serious drawbacks in the trial and error technique. When matching the silica data, ignoring the oxygen-18 data, it was found that the data could be matched over a range in porosity from $2 \%$ to $15 \%$, simply by varying the A/V term of the kinetic transport. Also, the oxygen-18 transport could be matched using a wide range in the average grain radius and the porosity. Thus, some method was required to determine the correct $A / V$ or $\omega$, before an accurate porosity could be defined. The empirical equation used to compute the $A / V$ term by Rimstidt (1979) is written:

$$
A / V=8.55\left(\frac{1}{r}\right)
$$

where $r$ is the average grain radius (not necessarily equal to $\omega$ ).

If an average grain radius could be defined from field data, the $A / V$ value can then be calculated, and the porosity uniquely determined. This was tested on the Ellidast data, choosing an average grain radius of $0.1 \mathrm{~mm}=10^{-4} \mathrm{~m}$ (reasonable for basalts), so A/V was equal to $8.55 \times 10^{4}$. Unfortunately, when this value was used in the numerical model, the silica concentration curve was not even close to being a match to actual field data.

As a secoad attempt at defining $A / V$, it was noted that if a connection between $\omega$ and $A / V$ could be found, then one of the two sets of chemical data could be used to define $\omega$ and $A / V$, while the other set could be: used to define the porosity. As was seen in Section 2.2, the equation defined by Cole, et al., (1983) for the surface area of reaction is written:

$$
S A=\frac{3 V(1-\phi)}{\omega}
$$

For silica transport, the ' $A$ ' in $A / V$ is the surface area of quartz open for reaction. Therefore, it could be written in terms of SA by: 


$$
A=\tilde{x}(S A)=\tilde{x}\left[\frac{3 V(1-\phi)}{\omega}\right]
$$

where $\tilde{x}$ is the fraction of quartz present in the rock. For example, if the rock was made up of $30 \%$ quartz, then $x=0.3$ and $A=0.3(S A)$.

$A / V$ could then be found by:

$$
A / V=\frac{3 \times(1-\phi)}{\omega}
$$

If this theory is correct, a trial and error technique can be applied by varying $\omega$. (and therefore $A / V$ ) and the porosity until a match between the numerical model and field data is achieved by both silica and oxygen-18. This technique was applied succesofully to the field data from Ellidas, and a match was achieved for both oxygen-18 and ailica using a porosity of $5 \%$ and average grain radius of $0.11 \mathrm{~m}(A / V=10)$. Figures 37 and 38 plot the field data for silica and oxygen-18 versus time, overlain with the best results achieved by the numerical model. The results indicate a connection between the average grain radius and $A / V$, but the values are not similar to those generally found for porous medium reservoirs: It is probable that the fractured nature of the Ellidar system causes the large values in grain radius In other $w$ is not the actual grain radius, but the effective radius of the average block size surrounded by fluid flow paths. suggesting that the two parameters are empirical.

It should be noted that the match with the oxygen-18 data is based upon very sketchy data. Oxy gen-18 readings for the feld have only been taken since 1980 . Much of the information gained in concentration curves comes from the shape of the curve near the beginning of the production of the field, and to define a curve at all, an initial: reservoir oxygen-18 value is necessary. Since this data was not available, deuterium data was used to calculate the oxygen-18 content of the surface waters using the relation (Henley, Truesdell, Barton; 1984):

$$
D=8 \delta_{f}^{18}+10
$$

The $\delta^{18}$ content of the surface waters was then used to calculate the equilibrium value of oxygen-18 in the reservoir assuming a temperature of $110^{\circ} \mathrm{C}$ by: 
$-93-$

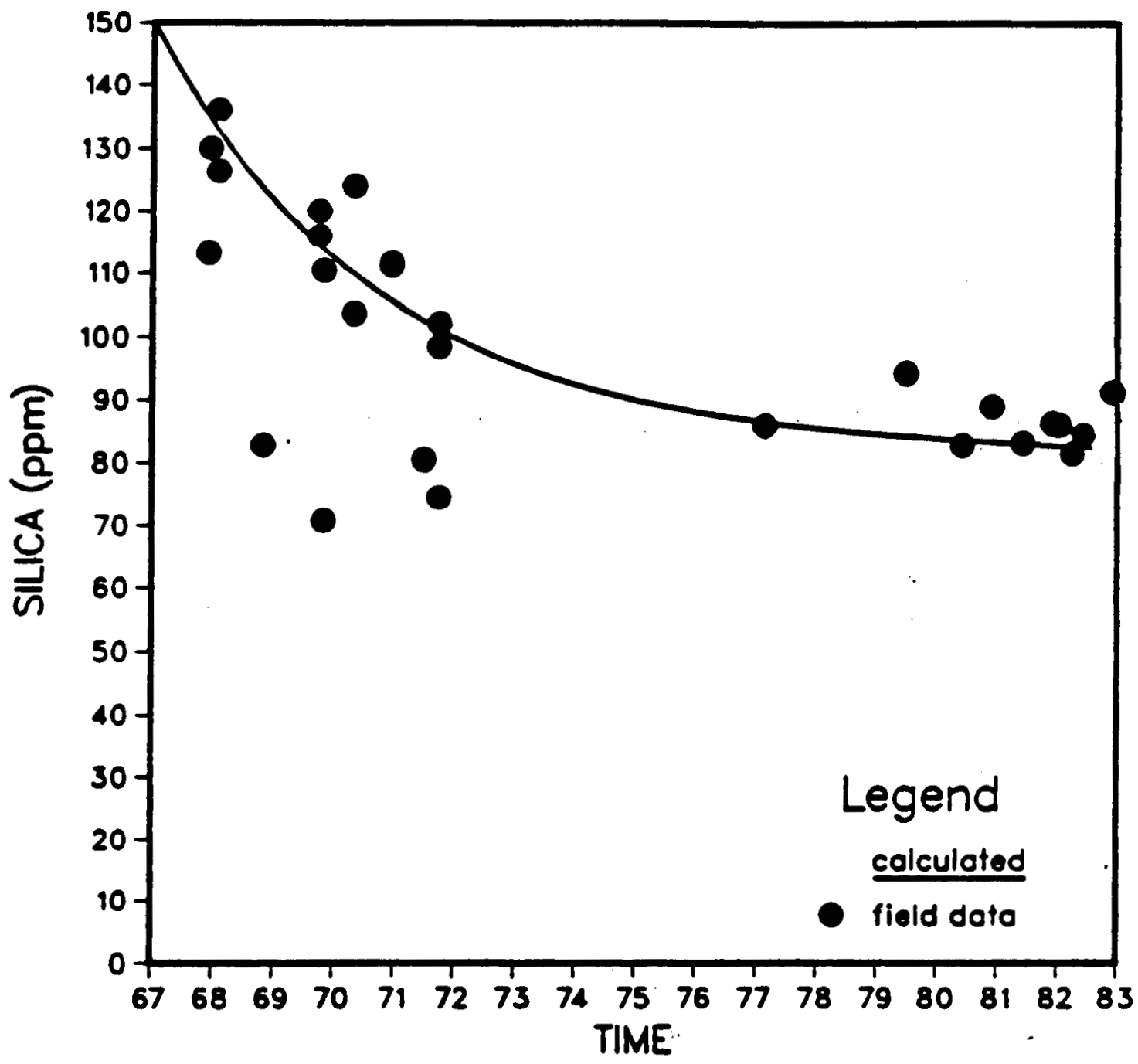

Figure 37. Plot of silica versus time showing the match between the numerical model and field data from the Ellidaar field. 


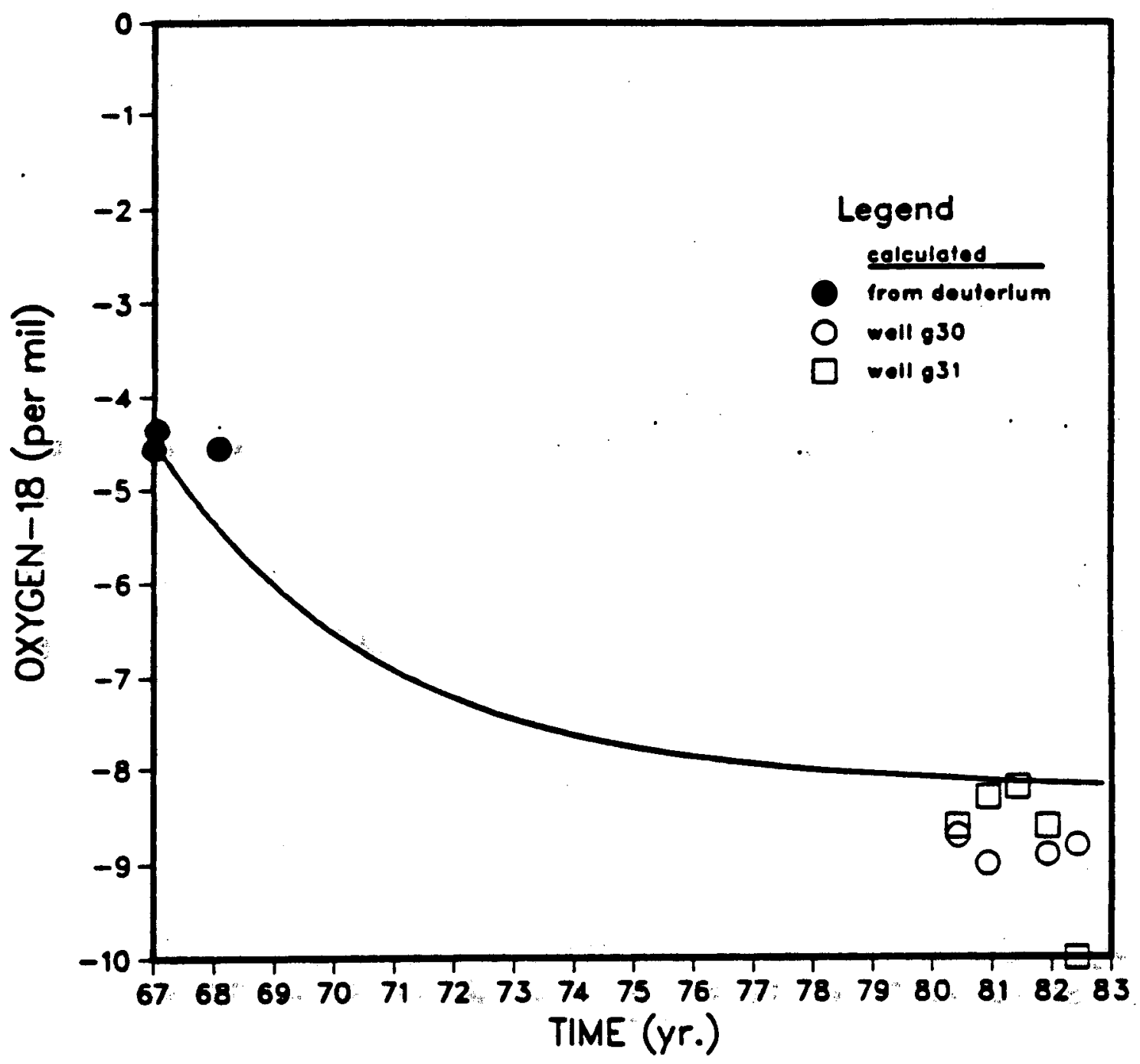

Figure 38. Plot of oxygen-18 versus time showing the match between the numerical model and field data from the Ellidaar field. 


$$
\delta_{q}^{18 m}=\frac{\delta_{R}^{i}-\Delta_{R}^{* q}+(W / S) \delta_{f}^{i}}{1+(W / S)}
$$

where all parameters are as defined previously. A value of -4.5 was obtained and used as the initial oxygen-18 value in the hot reservoir.

\section{Seltjarnarnea field}

The second field chosen for study was the Seltjarnarnes geothermal field in southwestern Iceland. It is located on the outskirts of the capital, Reykjavik. Six wells have been drilled in the area: four production wells and two observation wells. The geological setting is similar to Ellidasr, except Seltjarnarnes is much closer to the sea (cee Figure 39 for a map of the area). The rewervoir rocks are predominantly basalt laves and hysoclantites. The water in of meteoric origin, but the produced Guids have become increasingly more asline in recent years. Production of the hot reservoir began in the mid-1960s at rate of $3 \mathrm{l} / \mathrm{s}$. In 1971 , production was increased to $33 \mathrm{l} / \mathrm{s}$ and again increased in 1981 to $50 \mathrm{l} / \mathrm{s}$. Although the salinity of the field has been increasing indicating an influx of seawater, the oxygen-18 content has decreased slightly. These two phenomena appear to contradict one another, as the very high oxygen-18 content of seawater relative to the local meteoric water should cause an increase in the oxygen-18 content of the hot reservoir. This suggests that the majority of the recharge comes from deeper, non-saline water.

Based upon the available data, a simple model of the field was developed. In the beginning, a simple two layer mesh was employed. The regions directly above and adjacent to the hot field were asoumed to have fuid of nearly the same composition as that initially present in the geothermal reservoir (chloride $=500 \mathrm{ppm}$, sodium $=300$ Ppm). The silica concentrations in the top and side were the equilibrium values of each zone for the assumed temperatures and the oxygen-18 content was slightly more negative in the lower recharge zone. Figure 40 shows a sketch of the mesh and the initial concentrations and temperatures. The temperatures of the different zones were derived from well data. 


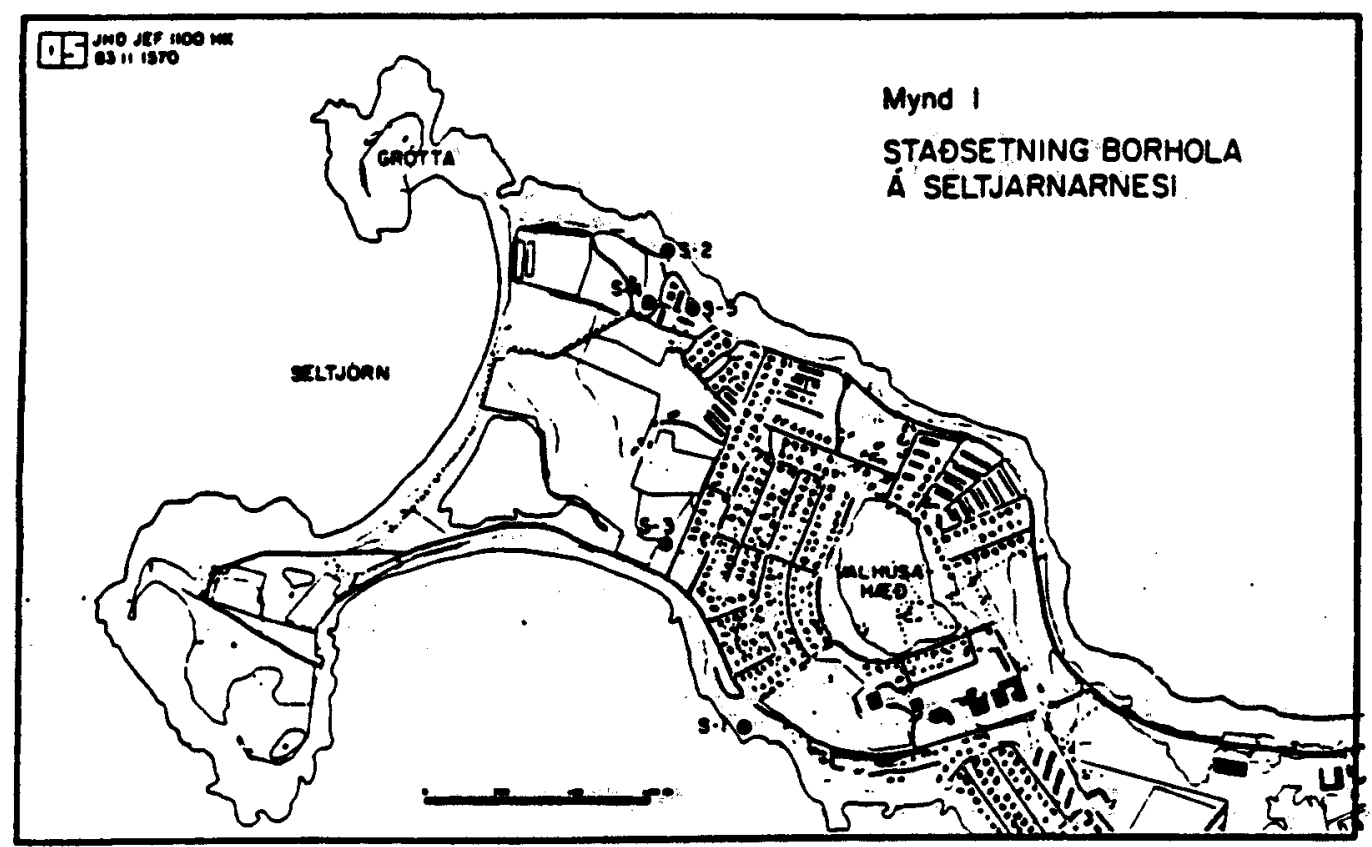

Figure 39. Map of Seltjarnarnes geothermal field, Iceland showing layout of wells and main production area (Kristmannsdottir, 1986). 


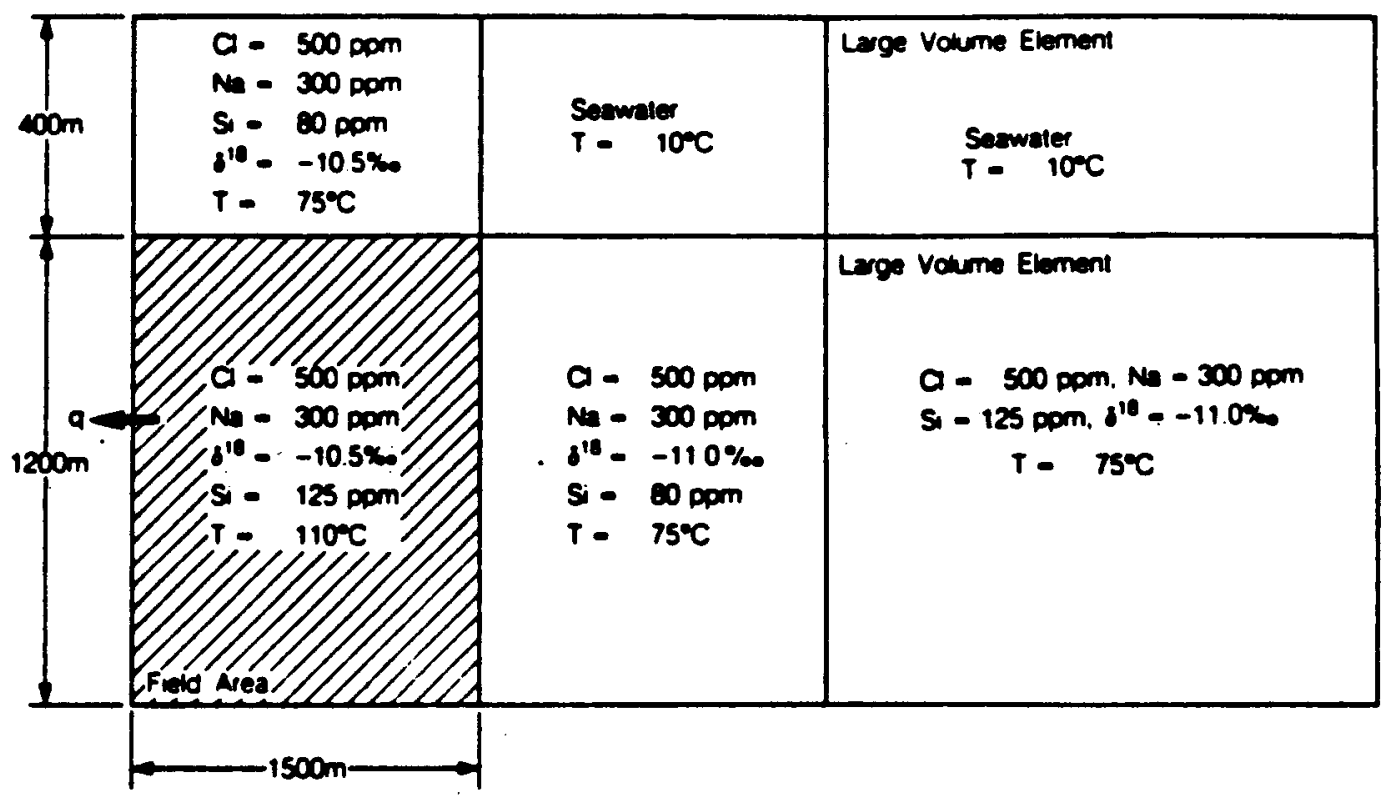

xQ2 012 12ans

Figure 40. Two-layer mesh used to model the Seltjarnarnes geothermal area Iceland, including the initial conditions and values of field parameters. 
Using a trial and error procedure a match for the data obtained. Figures 41 - 45 show the field data plotted against time for silica, chloride, sodium, oxygen-18 and temperature, along with the computed results obtained from the numerical model. Due to the wide scatter of the field data, it was difficult to determine accurately the field parameters inferred from the match. The results obtained suggest a reservoir volume between $7.5 \times 10^{8} \mathrm{~m}^{3}$ and $1.0 \times 10^{9} \mathrm{~m}^{3}$ and a porosity between $2 \%$ and $5 \%$ was necessary to match the field data. The matches shown in the figures were obtained with a model having a reservoir volume of $7.5 \times 10^{8} \mathrm{~m}^{3}$, a porosity of $2 \%$, and $82 \%$ of the recharge into the field coming from the less saline side region. This model was chosen as the best match as it was the only model, within the ranges of volume and porosities given above, to show a decrease in the oxygen-18 over time, as was documented in the feld data. The lower porosity and smaller volume size required less recharge from the more saline top and more recharge from the side. The values for $A / V$ and $\omega$ were found to be 1.0 and 0.35 , respectively, in all the matches made with models having reservoir volumes and porouities within the ranges given. The low value for $A / V$ (and therefore high value for $\omega$ ) indicates that the kinetic reactions of silica and oxygen-18 play a relatively small role in this system. To illustrate this point, a plot (Figure 46) was made with oilica concentration versus time for two cases: with kinetic reactions and without (convection only), using the "best match" model. It must be emphasized that due to the use of such a coarse mesh, these are only rough estimates of the field parameters and flow patterns. To determine the field parameters more uniquely, aner mesh must be designed. This was the next step applied in modeling the Seltjarnarnes field.

Tulinius et al (1987) designed a two-dimensional, areal grid to model the pressure and temperature conditions of the Seltjarnarnes geothermal field. The central part of the grid is shown in Figure 47. The mesh contains 316 elements; small 50 meter square nodes surround the wells, with the nodes becoming progressively larger away from the well field region. To achieve a match with the pressure data, six zones with different permeabilities and porosities were necessary. The main geothermal field area was located in a high permeability zone $\left(k=8.0 \times 10^{-14} \mathrm{~m}^{2}\right)$, incorporating wells SN-02 - 
$-99-$

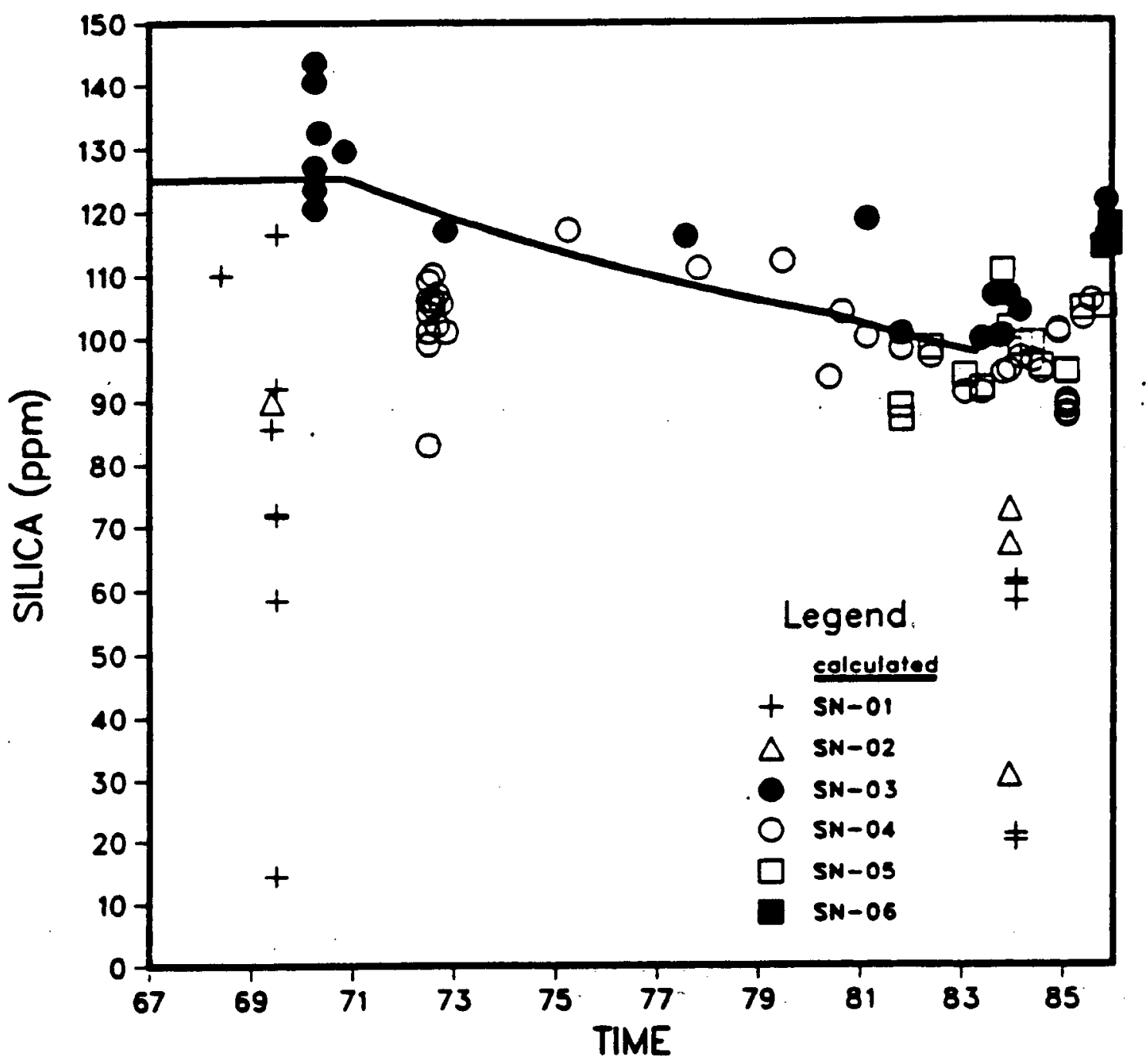

Figure 41. Plot of silica versus time showing the match between the numerical model and field data from the Seltjarnarnes geothermal area, Iceland. 


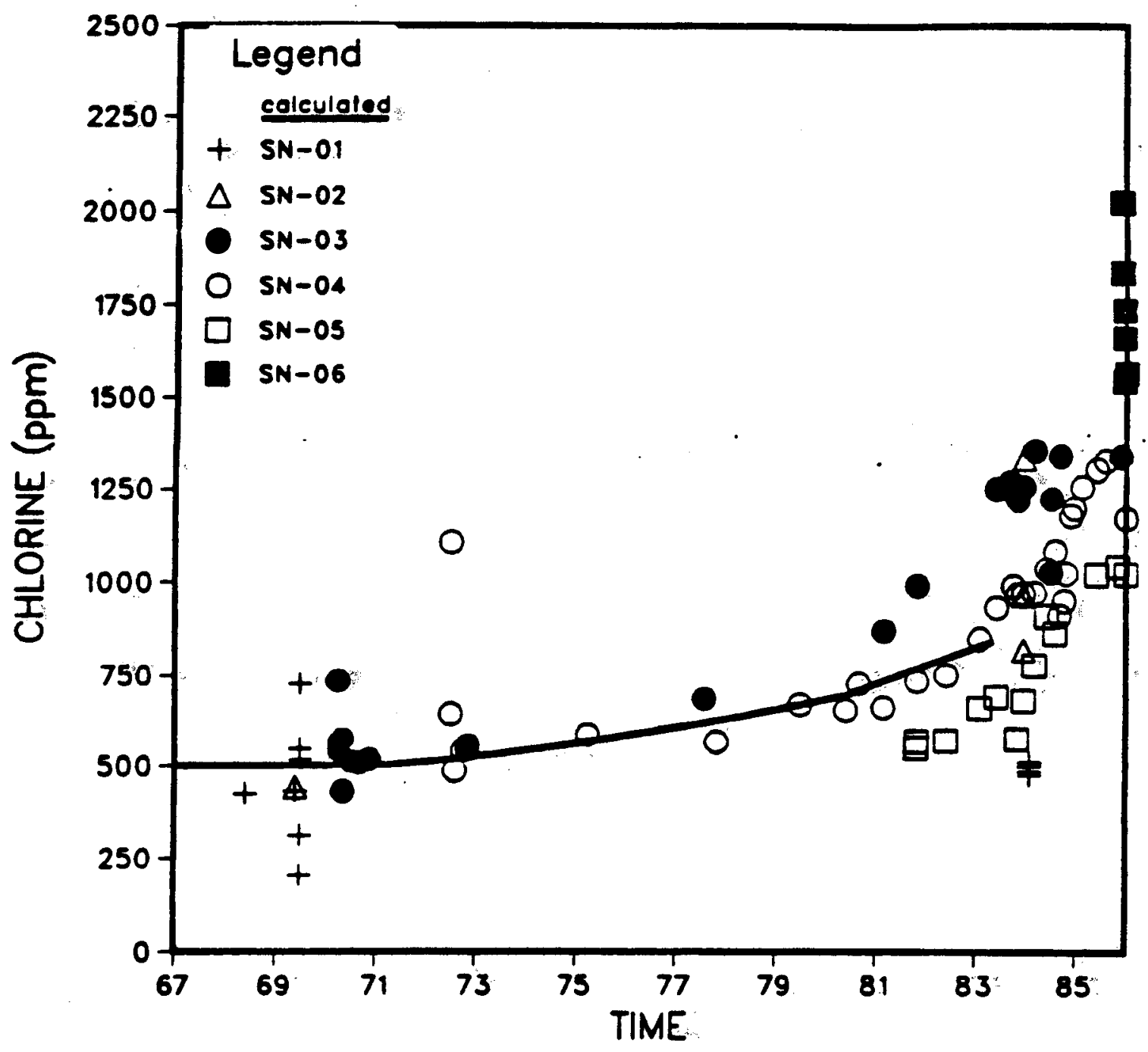

Figure 42. Plot of chloride versus time showing the match between the numerical model and field data from the Seltjarnarnes geothermal area, Iceland. 


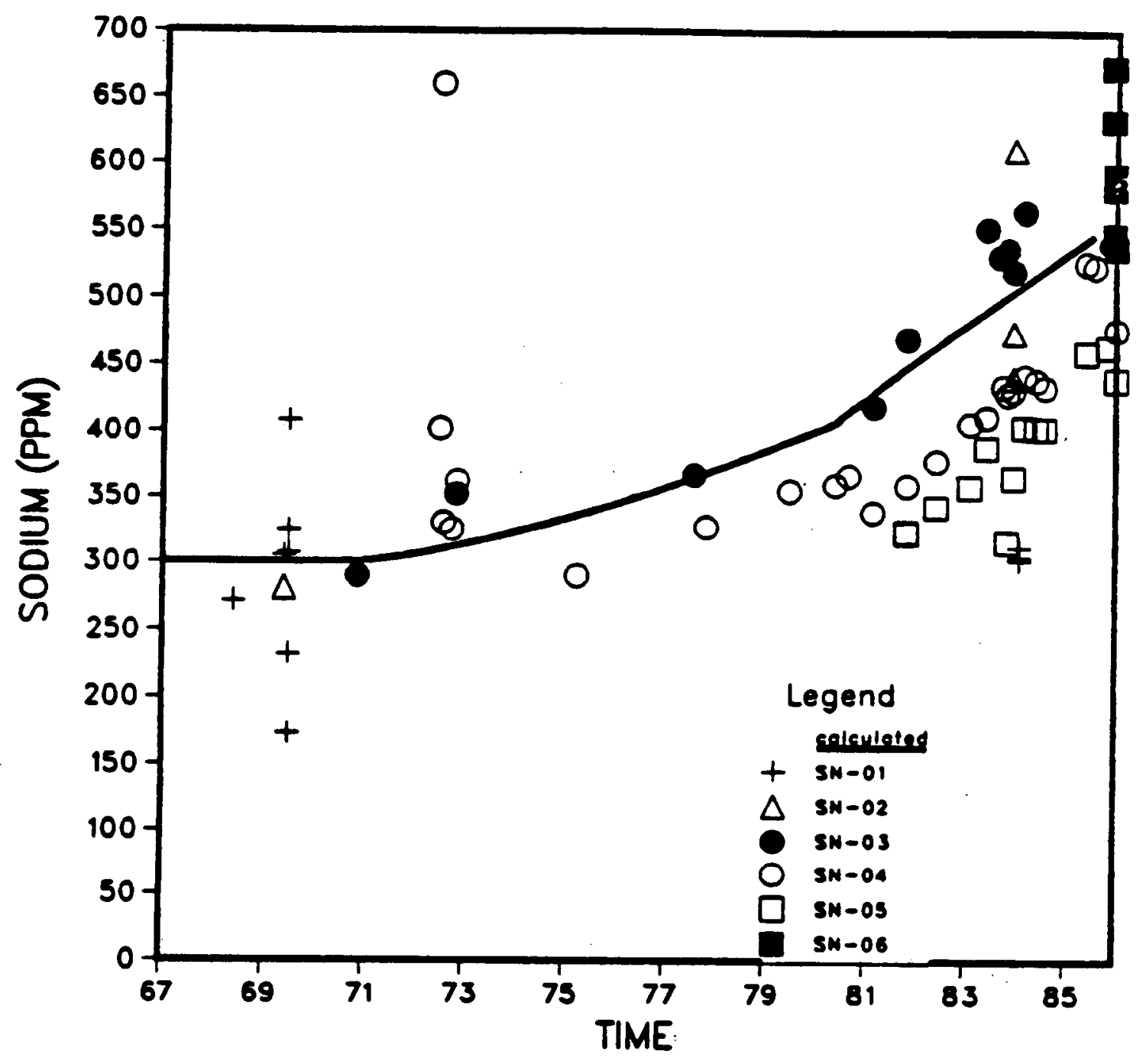

Figure 43. Plot of sodium versus time showing the match between the numerical model and field data from the Seltjarnarnes geothermal area, Iceland. 


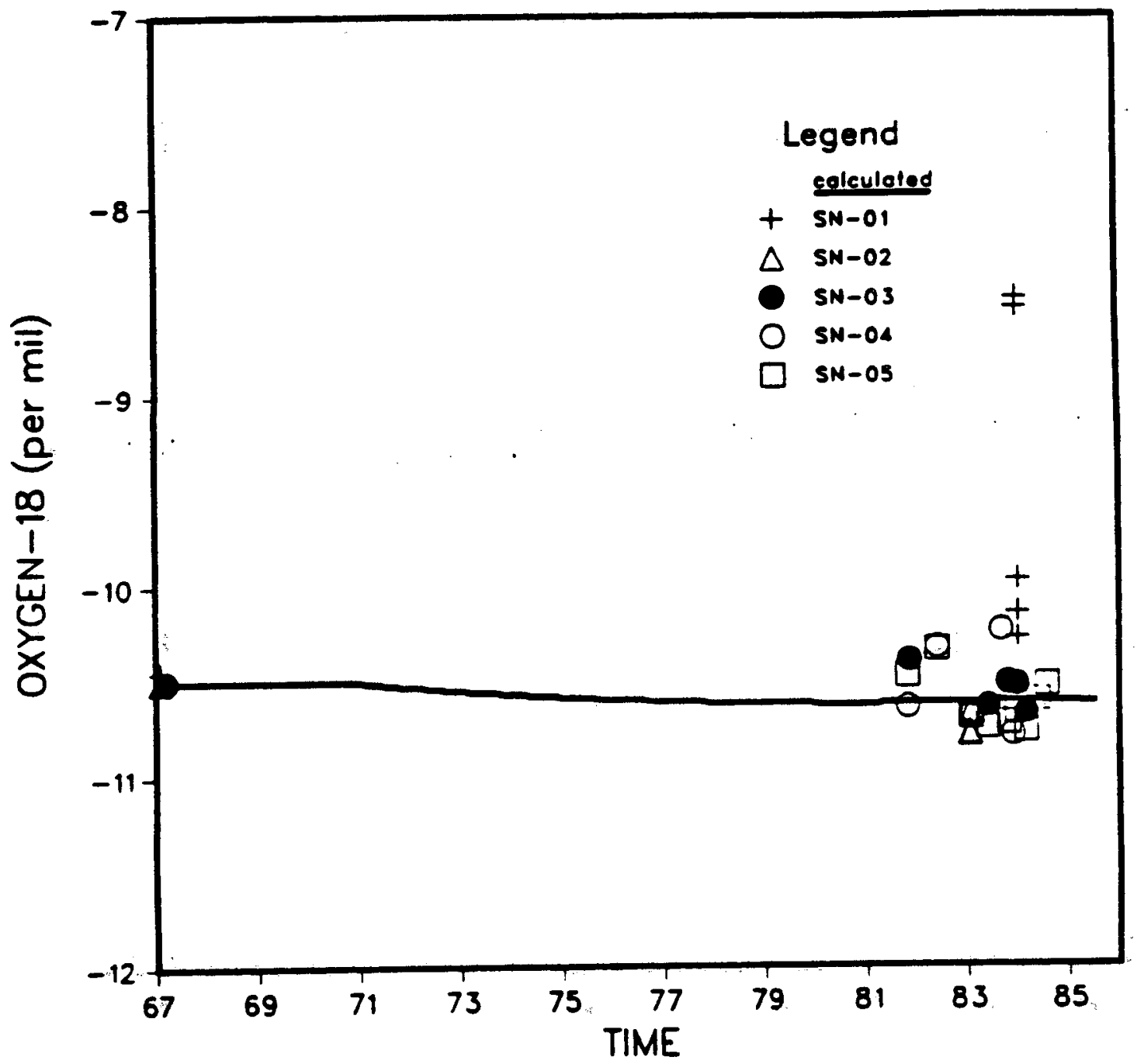

Figure 44. Plot of oxygen-18 versus time showing the match between the numerical model and field data from the Seltjarnarnes geothermal area, Iceland. 


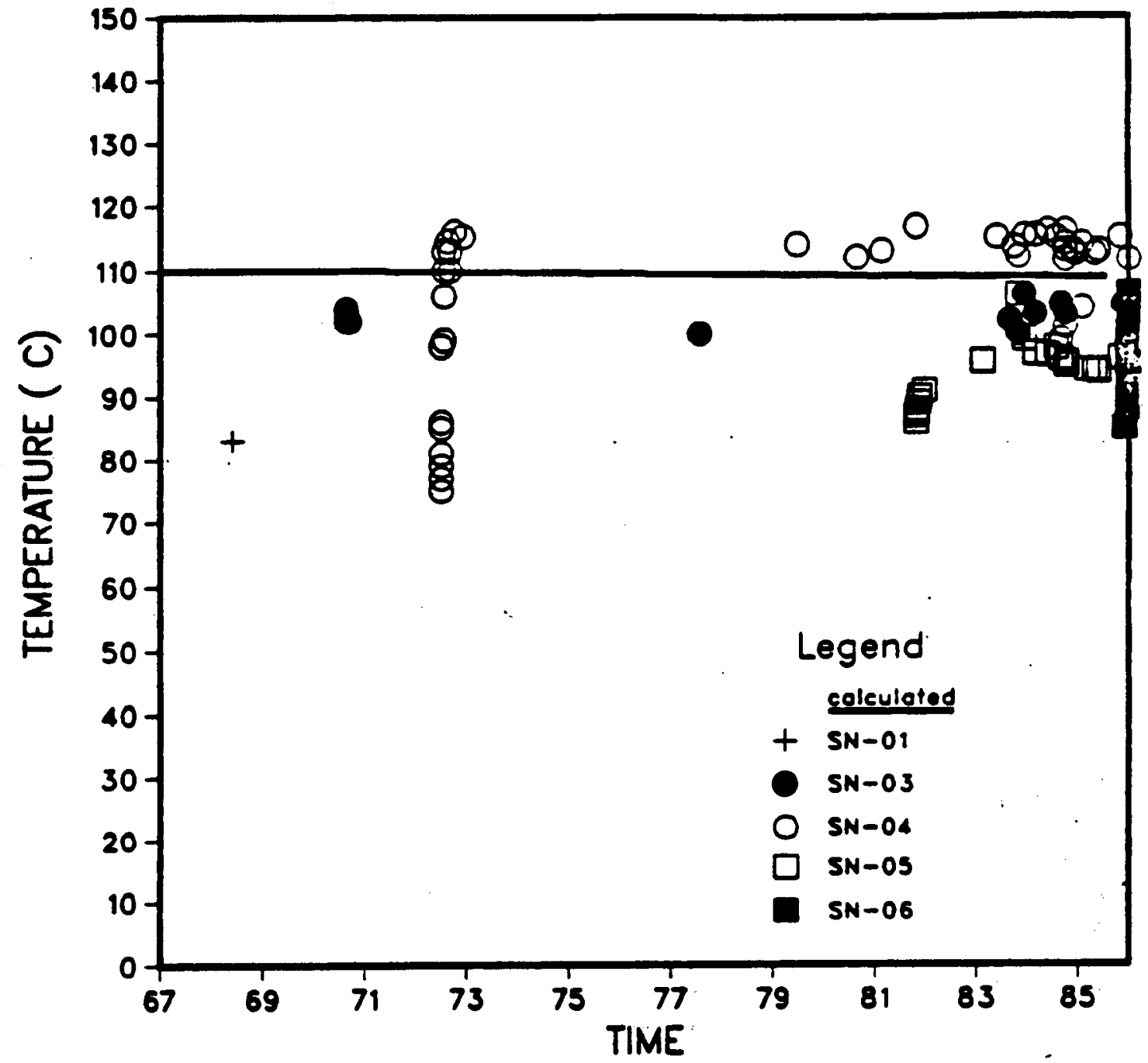

Figure 45. Plot of temperature versus time showing the ratch between the numerical model and feld data from the Seltjarnarnes geothermal field, Iceland. 
$-104$

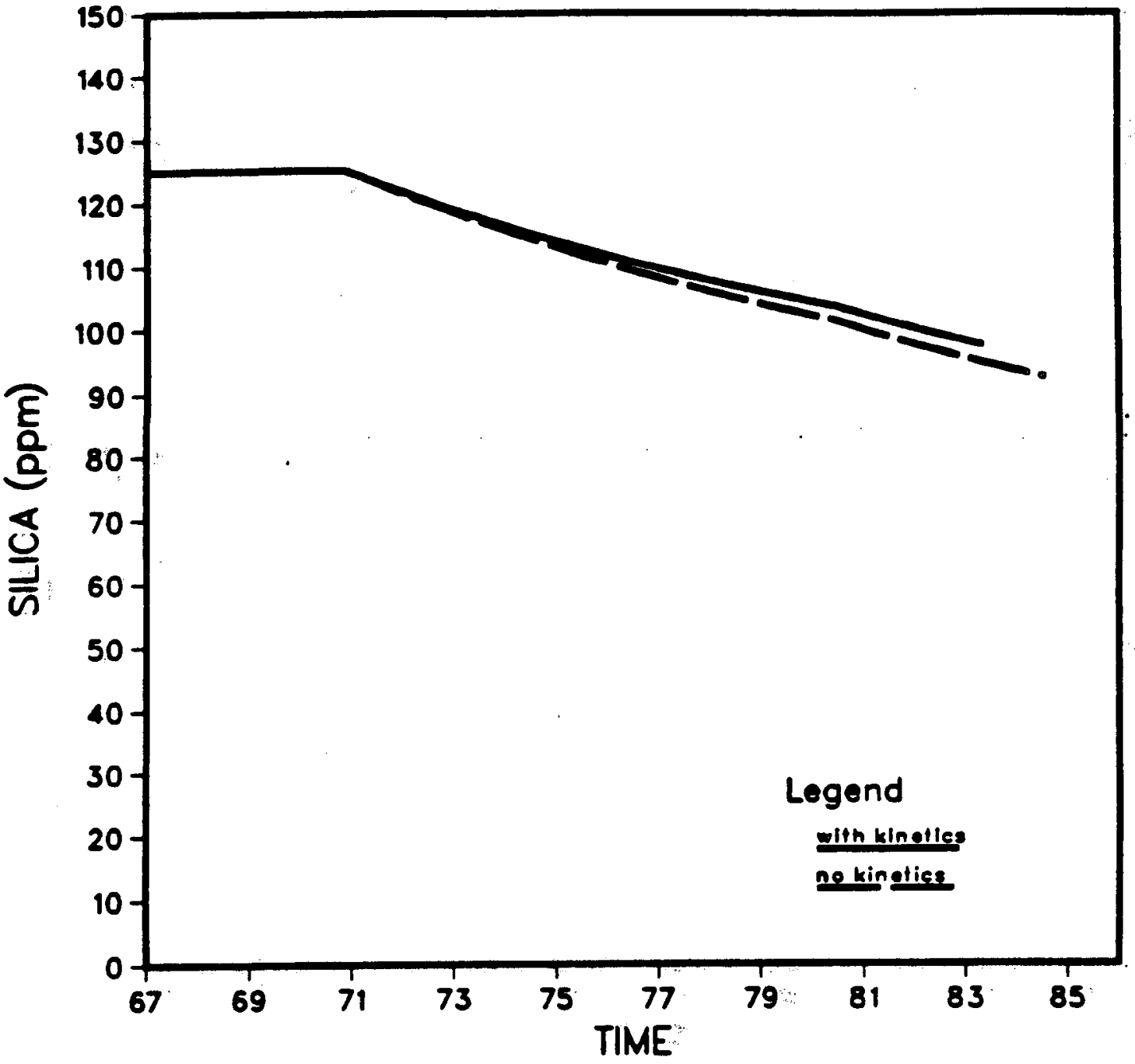

Figure 46. Silica versus time with and without kinetic transport using the best model for Seltjarnarnes. 
SN-06 (see Figure 39). Well SN-01, considered to be outside the main field area, was located in a low permeability, low porosity $\left(k=1.0 \times 10^{-14} ; \phi=.07 \%\right)$ region. Surrounding the near well region was a be a moderate permeability, moderate porosity $\left(k=2.5 \times .10^{-14} ; \phi=4 \%\right)$ region covering an area of $4.1 \times 10^{7} \mathrm{~m}^{2}$. The outermost region represented by the large volume nodes was found to have a moderate permeability and high porosity $\left(k=2.5 \times 10^{-14}, \phi=15 \%\right)$. The volume and porosity of the main geothermal region were determined to be $8.3 \times 10^{8} \mathrm{~m}^{3}$ and $2 \%$, respectively. The close agreement of the results for the field region gained by a pressure and temperature data match with the results of the simple two-layer model gained by the chemical transport metch, lends support to the value of chemical transport modeling.

The finer meah deacribed above, along with the reaults of the temperature and presure match, and available chemical field data were employed to further atudy the Seltjarnarnes field. The initial conditions for the chemistry of the fluid in the well field. region were set by feld data obtained at the initiation of field production. Two different fluid chemistries were incorporated in the model, representing seawater and meteoric water. Table 0 linte the concentrations used for each fluid type for the four chemical components modeled. Since the results of the two previous studies performed on the Seltjarnarnes geothermal field were in close agreement, the chemistry match in this study was not aimed towards verifying field parameters such as the permeabilities, porosities, and reservoir volume. Rather, the purpose of the study was to define the boundaries of the seawater adjacent to the well field. 


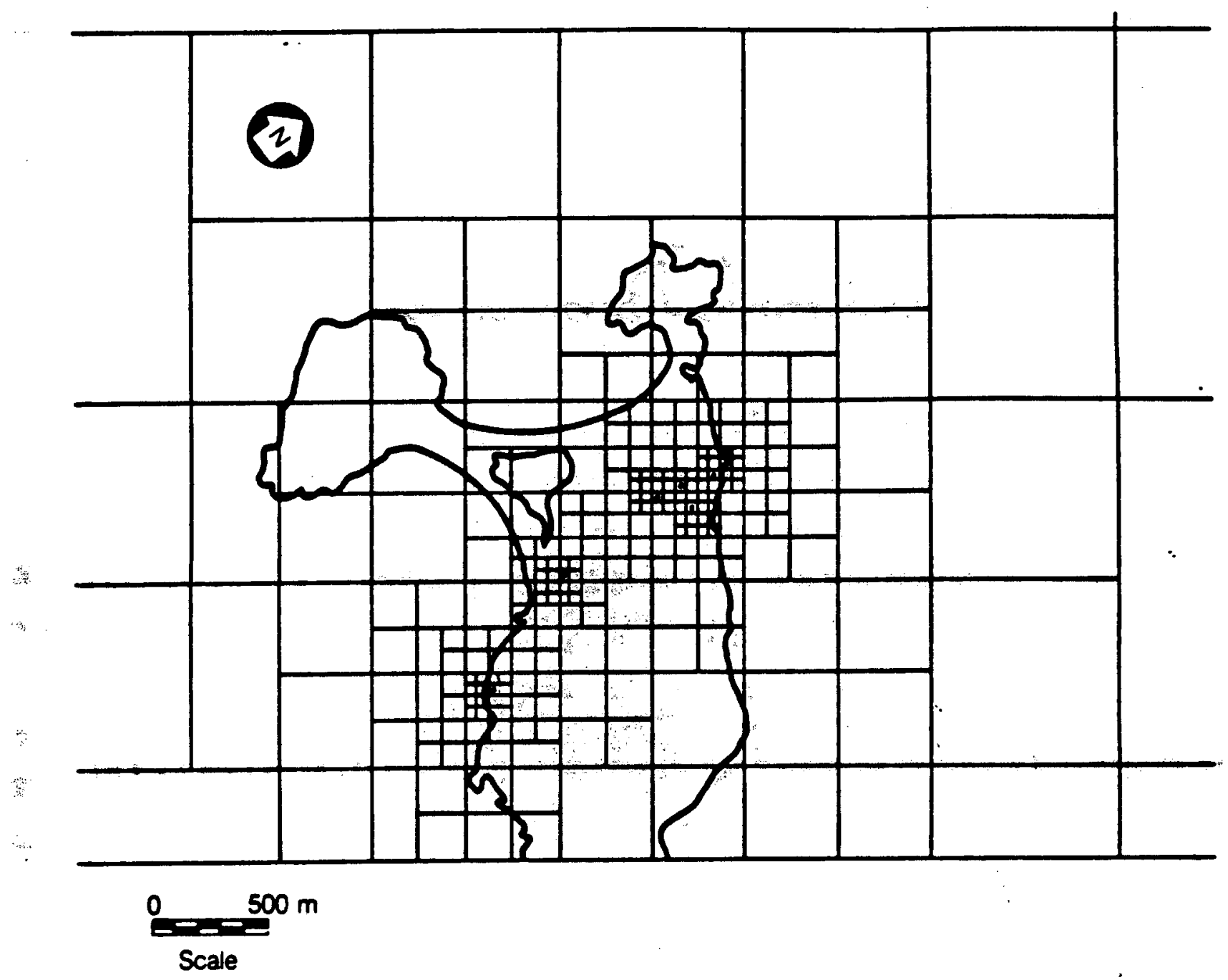

XBL $8612-12839$

Figure 47. The central section of the two-dimensional mesh designed to model the Seltjarnarnes geothermal Geld, Iceland (Tulinius et al., 1987). Small dots mark the well sites. 
TABLE 10. Values for the concentrations of the chemical species for the different fluids used in modeling the Seltjarnarnes geothermal field (Oxygen-18 in per mil, all other components in ppm).

\begin{tabular}{ccc}
\hline Component & Senwater & Meteoric Water \\
\hline Chlorine & 19,000 & 500 \\
Sodium & 10,500 & 300 \\
Oxygen-18 & 0.001 & -10.5 \\
Silica & 5 & 130.0 (at $\left.110^{\circ} \mathrm{C}\right)$ \\
& 5 & 80.0 (at $\left.75^{\circ} \mathrm{C}\right)$ \\
\hline
\end{tabular}

The results of the chemistry match are plotted for each well, for each chemical component; chloride, sodium, siliça and oxygen-18, respectively, in Figures 48 through 51. For the best match, the seawater boundary follows approximately to the land/sea boundary, surrounding the wells on three of four sides, and lying within 350 meters of wells SN-02 and SN-05 to the northeast. Figure 52 shows the suggested seawater/meteoric water boundary. The shaded region contains the meteoric water; the area outside this region contains seawater.

The results also raised several other points. The matches with the oxygen-18 data for the individual were not good; the numerical model showed a much more rapid increase in oxygen-18 than what the field data shows (see Figure 51). This infers that a three-dimensional model of the system is necessary, with fluid of a third chemical composition, of meteoric origin and containing a lower $(<-10.5$ per mil $)$ oxygen-18 content, entering the system. The reviews by Hettling (1984) of other geothermal systems nearby to the Seltjarnarnes geothermal field suggest that a third type of fluid with a lower oxygen-18 content recharges these systems at depth from an inland source, while seawater intrudes the fields at the shallower depths.

The match with sodium data was also not very good, indicating that the sodium ions in the system sustain significant ionic-exchange reactions, and are not truly 

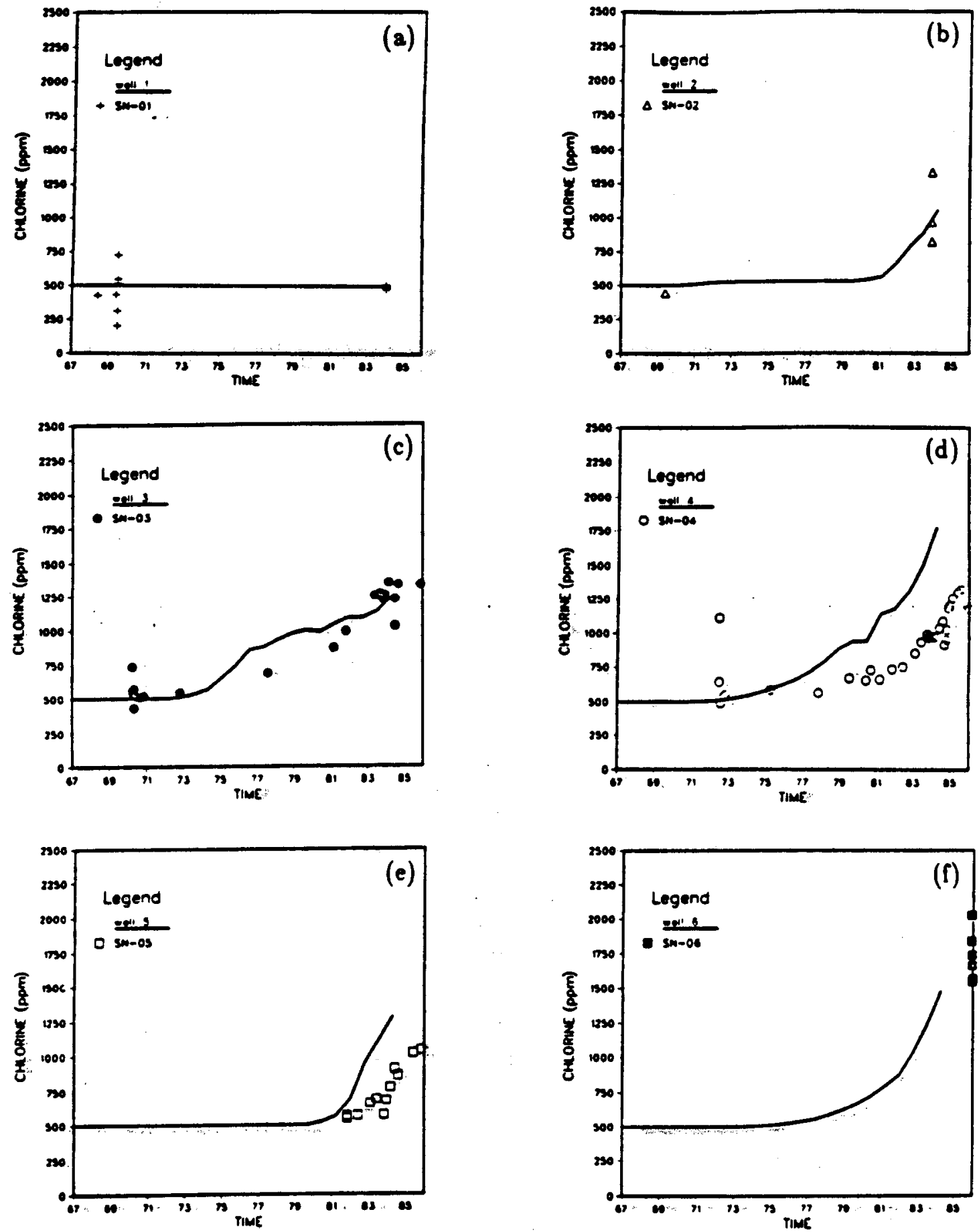

Figure 48. The chlorine transport match between the numerical model and field data for the Seltjarnarnes geothermal system for (a) well SN. 01; (b) well SN-02; (c) well SN-03; (d) well SN-04; (e) well SN-05; (f) well SN-06. 

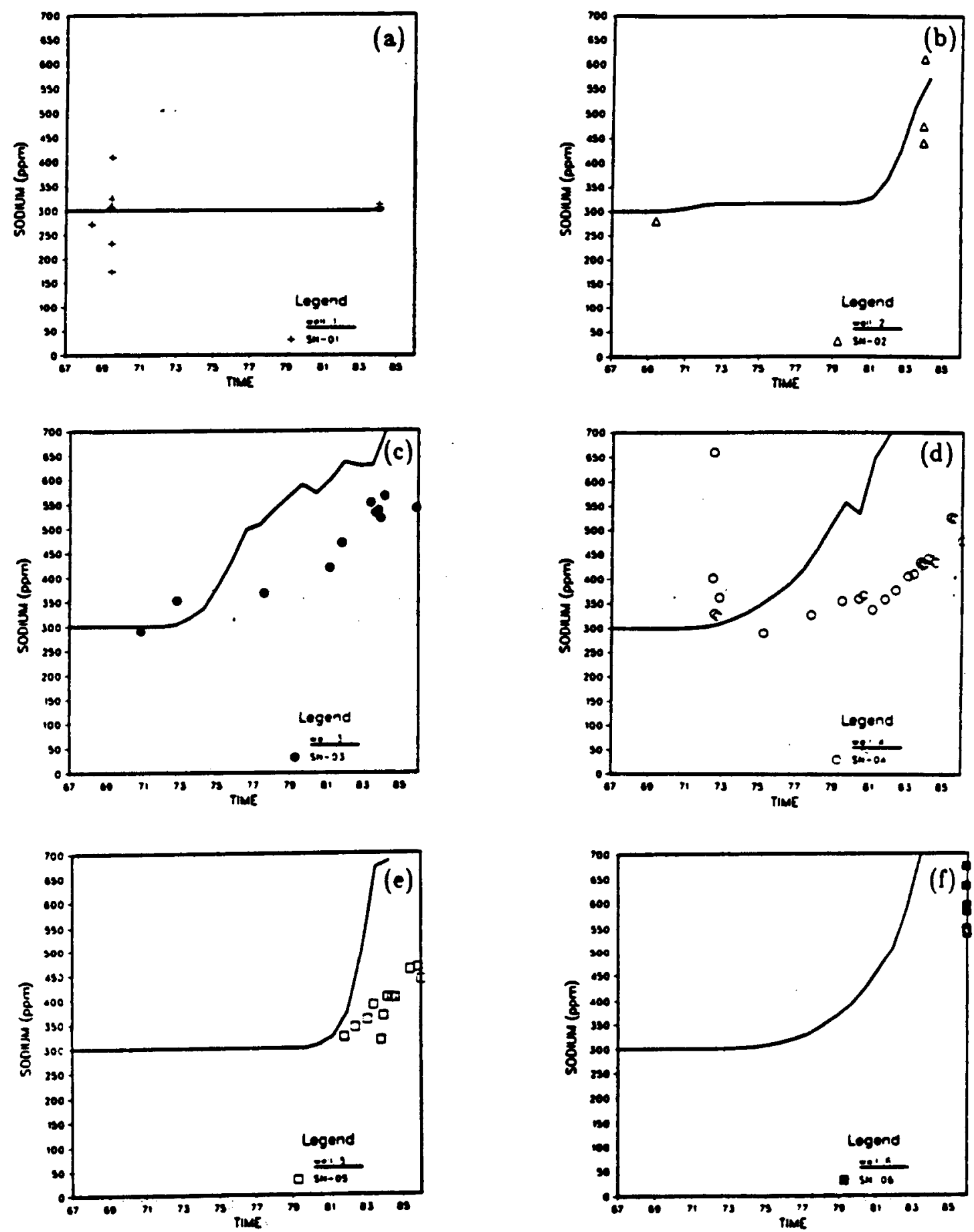

Figure 49. The sodium transport match between the numerical model and field data for the Seltjarnarnes geothermal system for (a) well SN01; (b) well SN-02; (c) well SN-03; (d) well SN-04; (e) well SN-05; (f) well SN-06. 

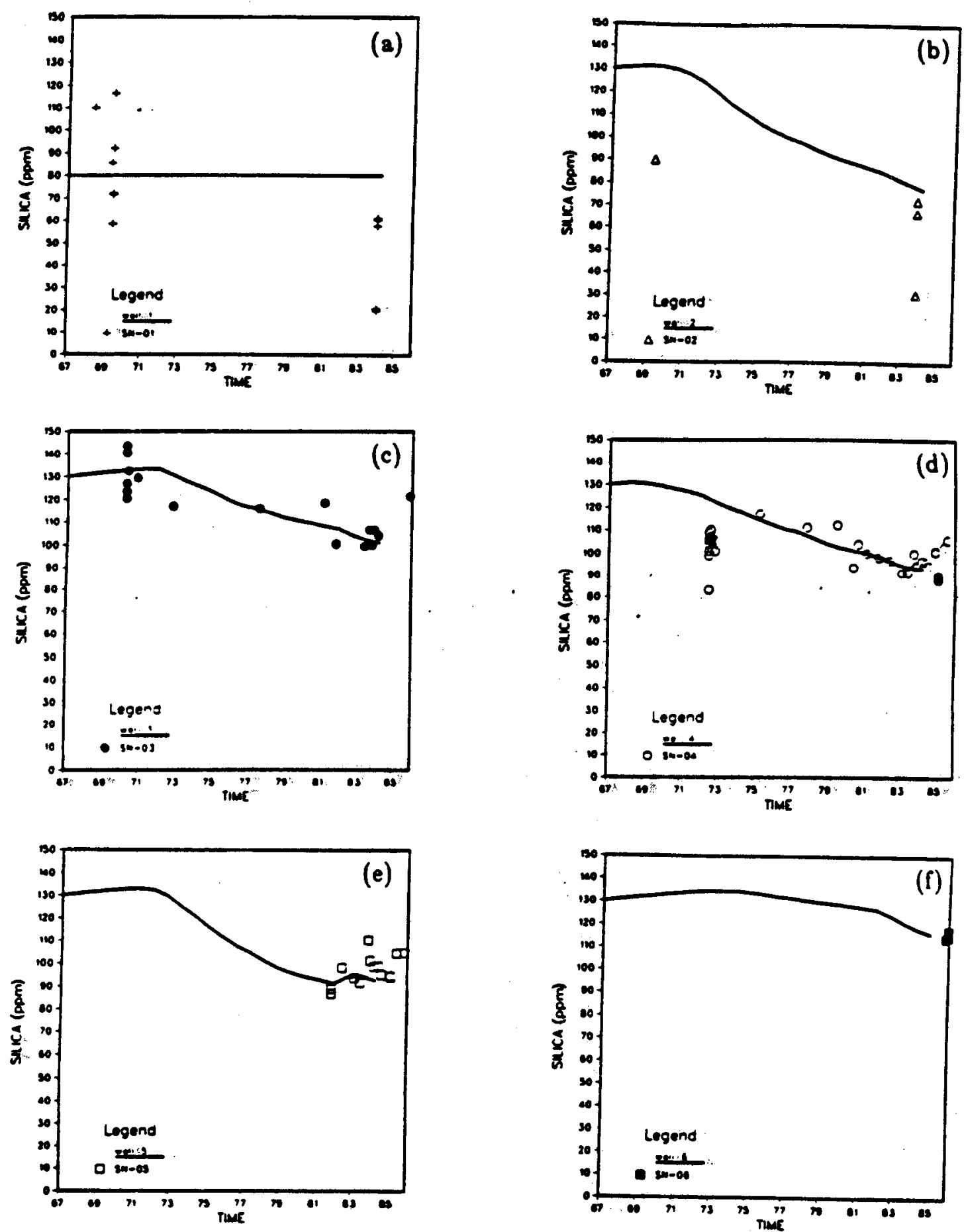

Figure 50. The silica transport match between the numerical model and field data for the Seltjarnarnes geothermal system for (a) well SN-01; (b) well SN-02; (c) well SN-03; (d) well SN-04; (e) well SN-05; (f) well SN-06. 

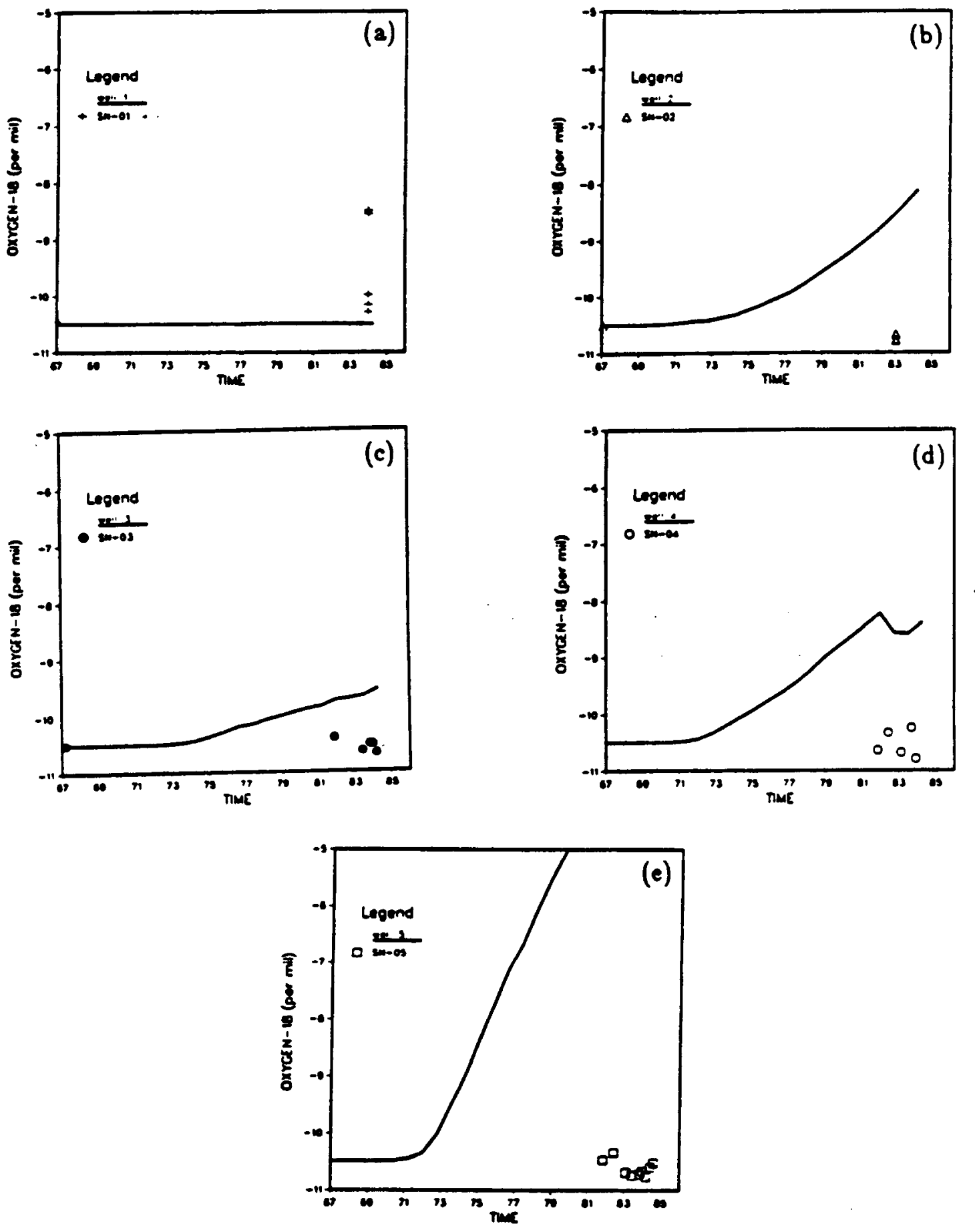

Figure 51. The oxygen-18 transport match between the numerical model and field data for the Seltjarnarnes geothermal system for (a) well SN01; (b) well SN-02; (c) well SN-03; (d) well SN-04; (e) well SN-05; (f) well SN-06. 


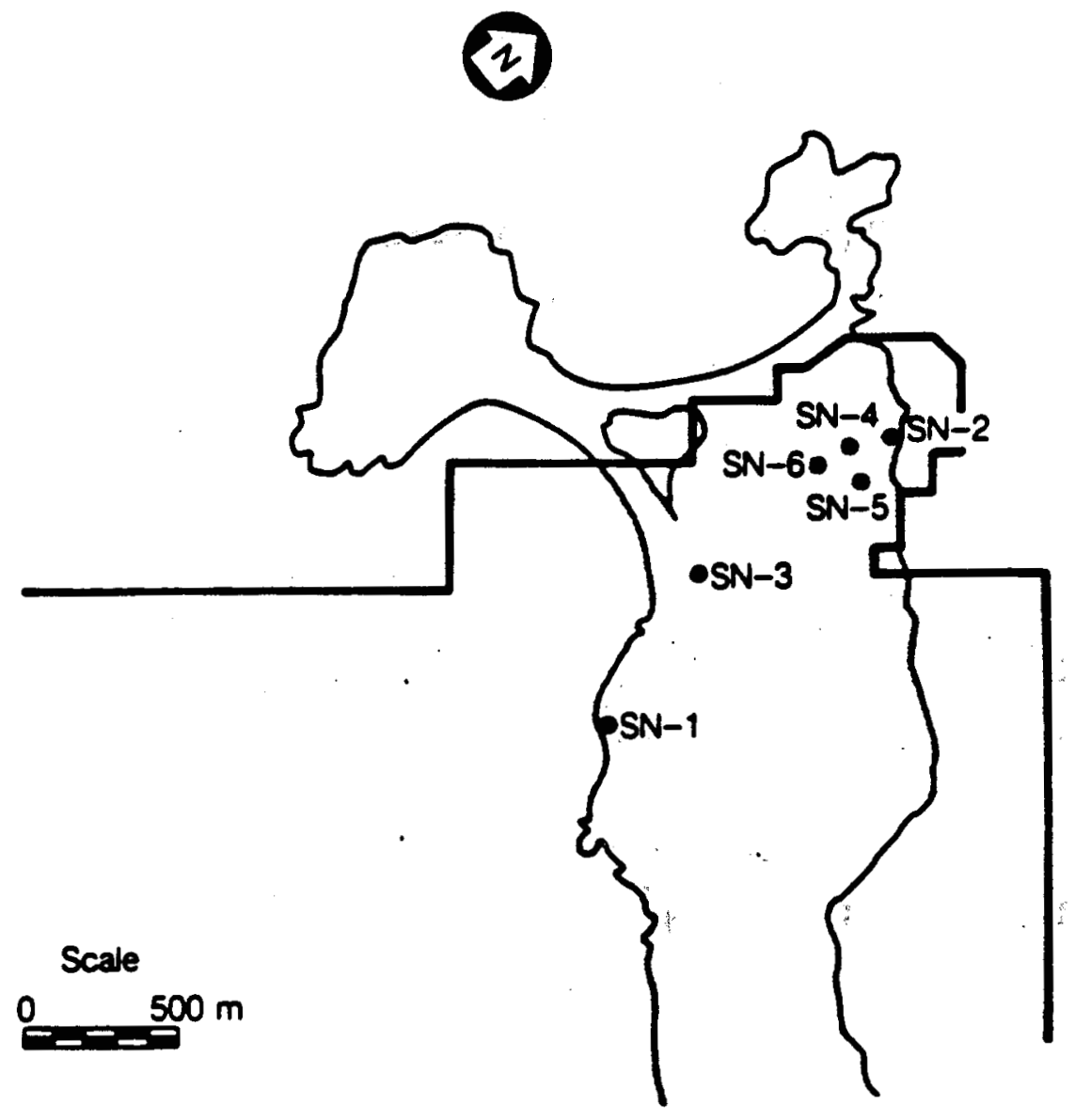

XBL 8612.12846

Figure 52. Sketch showing the suggested boundary between seawater and meteoric water at the Seltjarnarnes geothermal field, Iceland. 
conservative as assumed in the present model. The matches with the chloride are much better, as shown in Figure 48.

The results of the silica match suggest that kinetic reactions do play a role in the transport of silica in the Seltjarnarnes system, in opposition with the results obtained with the simple, two-layer chemistry match. Before the start of production, the silica concentration was approximately $130 \mathrm{ppm}$ at a temperature of $110^{\circ} \mathrm{C}$, in the well field region. Comparison of this concentration to equilibrium concentrations for each form of silics at $110^{\circ} \mathrm{C}$ (see Figure 23), indicates that the form of silica in the system is most likely a-cristobalite. However, at this temperature the true equilibrium value for a-criatobalite would be $150 \mathrm{ppm}$, indicating that there may also some $\beta$-cristobalite mixed with the a-cristobslite, lowering the equilibrium value.

To achieve the best match for silica, the $A / V$ value was set at 25.0. Referring back to Figure 17 which shows the effect of $A / V$ on the rinetic reactions of silica, it can be seen that a value of 25.0 indicates moderately rapid kinetic reactions. The silica match would probably improve if a three-dimensional model with a third type of luid of meteoric origin is used as suggested by the oxygen-18 modeling.

Although the chemistry modeling bas identified some stortcomings of the twodimensional model, the model can be used to roughly predict the future influence of the seawater on the system. Thus, an estimate of the amount of influx of seawater into the field over the next fifteen or twenty years could be obtained. From this information, the potential corrosion problems in the future may be identified and the necessary steps taken to minimize or alleviate these problems. 


\subsection{THEORETICAL STUDY}

As a final application of the multi-component, mass and heat transfer code, a theoretical study of an evolving geothermal system was performed. The system was modeled after the characterization given by White (1963) of a typical geothermal system. Geothermal systems, as described by White, consist of at least one permeable aquifer with a low-permeable cap, surface recharge and a heat source at depth. Warm surface springs of ten develop as the system heats and the expanding fluid flows out through fractures in the rock matrix: The hypothetical system developed in the present study includes two permeable aquifers separated by a three hundred meter layer of low-permeability rock. The ahallow aquifer is overlain by a low-permeability rock layer one bundred metere thick, extending to the ground surface. Both of the low-permeability layers extend a distance of ten kilometers. Beyond the ten kilometers there is a ten kilometer stretch of a permeable rock spanning from the surface to the bottom of the aystem. The total depth of the system is 1800 meters; the upper aquifer is 400 meters thick, while the lower aquifer is 1000 meters thick. Cool rainwater (at $\left.10^{\circ} \mathrm{C}\right)$ percolates in acrose the ten kilometers of permeable ground surface. $A$ warm spring initiating from a fracture underlying the lowsermeable cap layer results due to the warming. Figure 53 shows a sketch of the hypothetical model.

At the start of the problem, the system is in hydrostatic equilibrium and the temperature profile is governed by the local geothermal gradient. Both silica and oxygen18 are in equilibrium with the temperature, throughout the system. A deep heat source begins to warm the system, releasing $1.3 \times 10^{10}$ watts per square meter, across a distance of five kilometers, in to the system at the depth of 1800 meters. The system is allowed to heat for 100,000 years before the heat plume dies out and the system begins to cool with rainwater continuing to percolate in at the surface.

After beating for 3,200 years, the portion of the system directly above the heat source begins to warm up, but the effects do not spread far. The temperatures of the right-hand side of the system still reflect the geothermal gradient. By 32,000 years, 


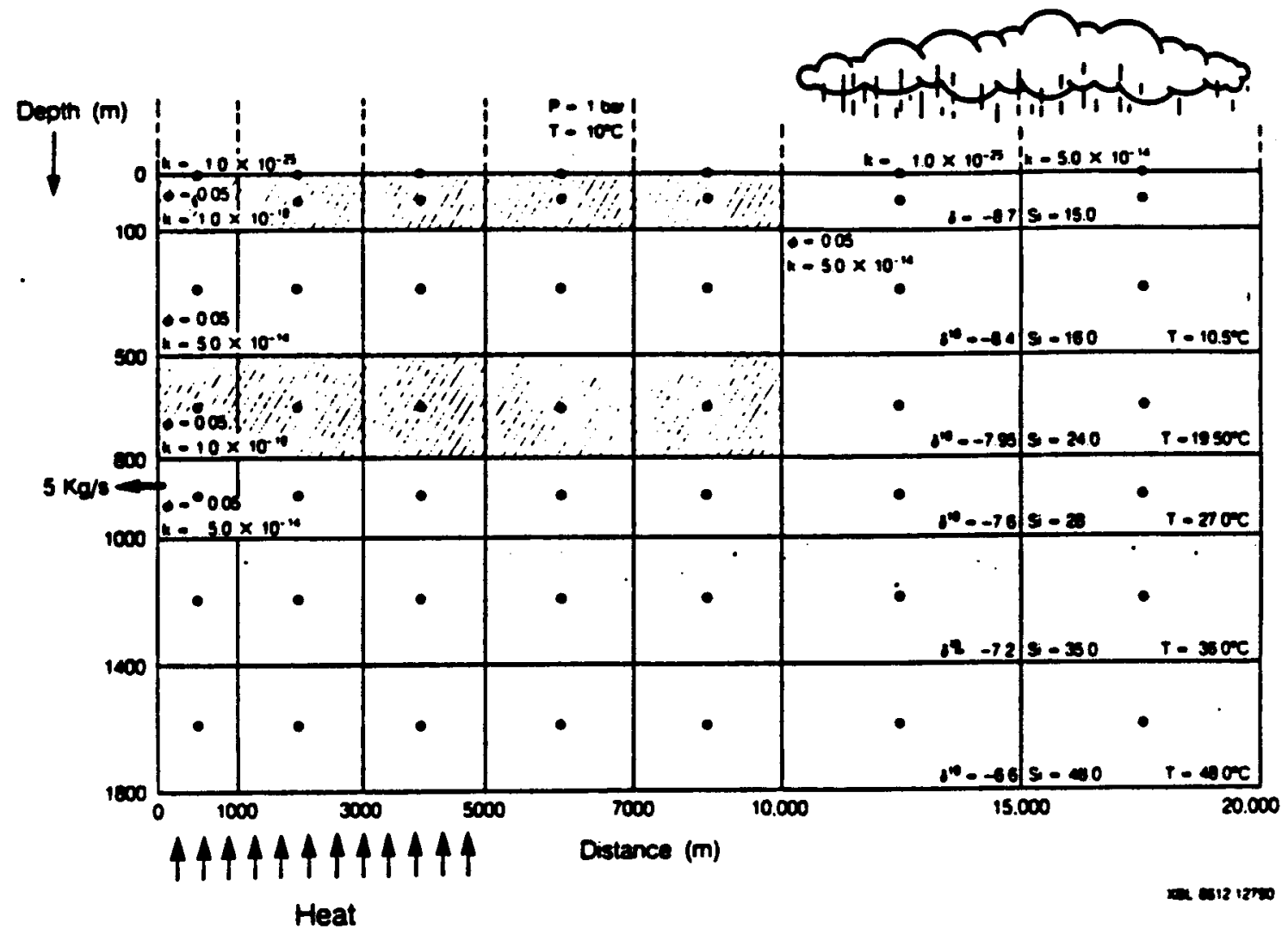

Figure 53. A simple hypothetical model of a typical geothermal system. 
the two influences on the system, the incoming heat and the infiltration of cool water, show up clearly on the temperature profile (Figure 54). Directly above the heat plume, exists an overall thermal gradient of approximately $130^{\circ} \mathrm{C} / \mathrm{km}$, while the right-hand side is influenced completely by the influx of cool rainwater and the geothermal gradient.

After 100,000 years of heating, the system has reached a quasi-steady condition between the influx of heat and cool water. The only region to be heated has remained the portion directly above the heat plume. The pattern of flow through the system indicates that most of the cool fluid mass descends quickly to the bottom of the system. As it moves horizontally acroes the bottom of the deep aquifer, the fluid is warmed and quickly begins to rise. The warming decreases away from the heat source. Below the lower cap layer, the warmed fuid mixes with cool fluid, as both are moving to exit the system from the spring conduit. This decreases the thermal gradient, keeping the majority of the temperature rise in the system confined to the lower depths. It is also evident from the mass fux (see Figure 55), that the heating of the system is due to conduction not convection, as the fux above the heat plume is nearly zero. This helps to explain why the system warms only above the heat plume.

The quasi-steady condition indicates that although the thermodynamic changes within the system are small, the balance of energy into the system and energy out of the system is not equal. Considering that the average temperature change over the last 70,000 years of heating was an increase of about $30^{\circ} \mathrm{C}$ in the warmed region, and the change necessary to reach equilibrium between the inflowing and outflowing heat needs" to be about another $120^{\circ} \mathrm{C}$, it will probably take the system an additional 600,000 years to reach a true steady state. For the purpose of this study, it is not necesary to continue heating until the system reaches steady state.

After the system bas reached a quasi-steady condition, the heat plume "dies out" and the system is cooled by the infiltration of cool rainwater. The effects of the cooling are slow initially but after 32,000 years, the effect of the cool influx of water is felt over the entire system, lowering the temperature by over $100^{\circ} \mathrm{C}$ in the previously 


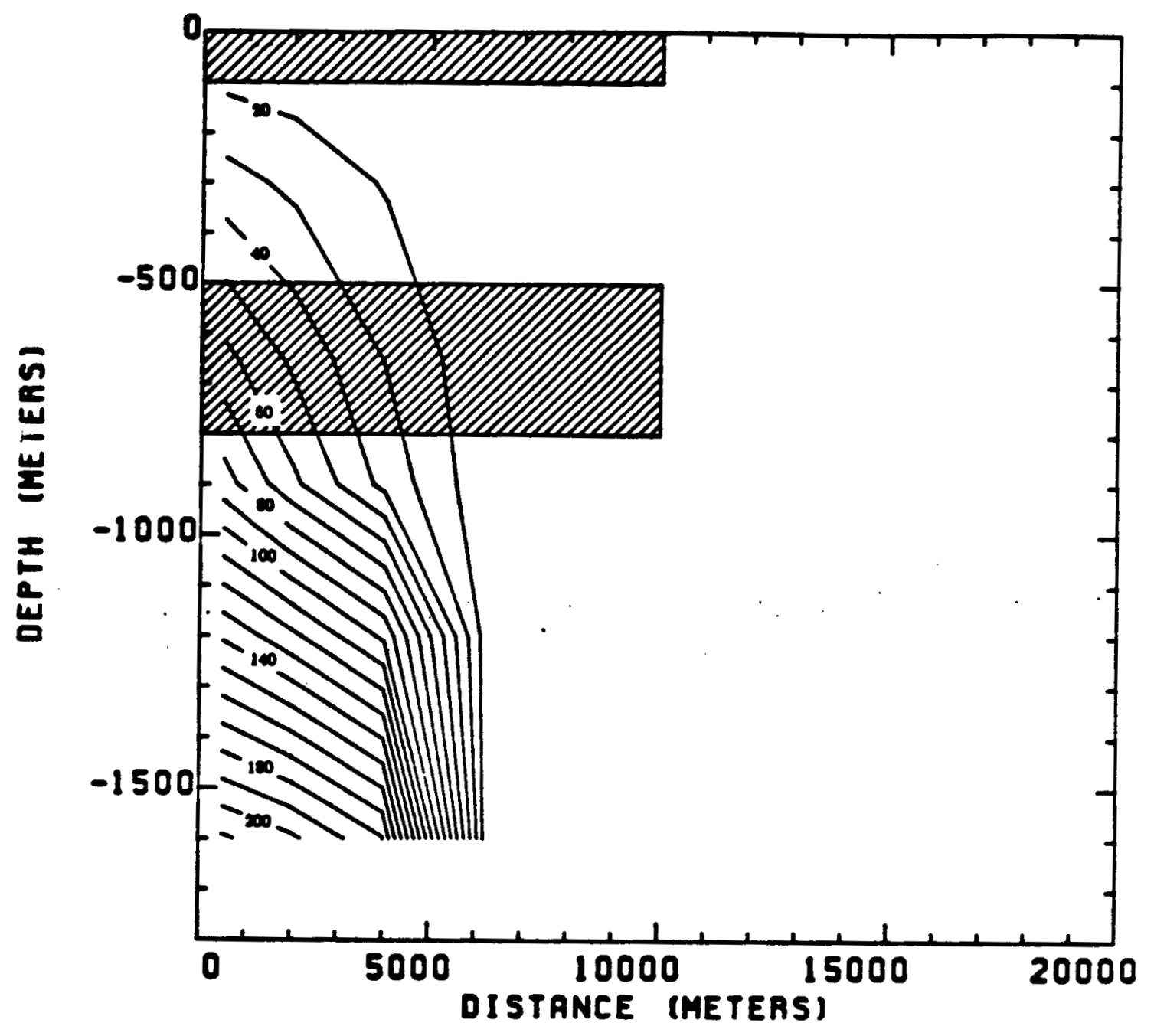

Figure 54. Temperature contours for the system evolving under the influence of a heat source for 100,000 years. Contour units are in ${ }^{\circ} \mathrm{C}$. 


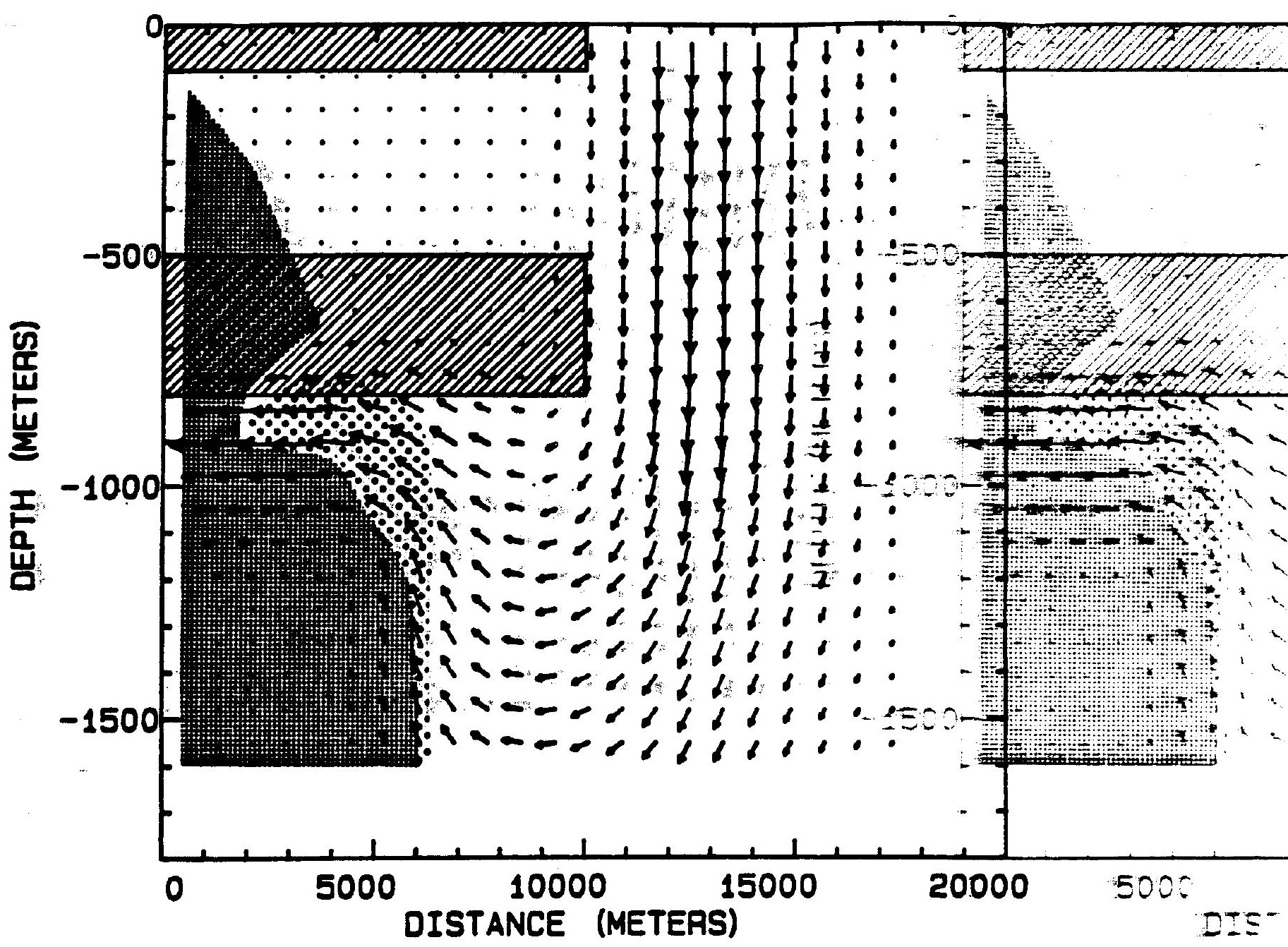

Figure 55.

The pattern of fluid flow and of the silica precipitation/dissolution for the system evolving under the influence of a heat source. The relative sizes of the arrows corresponds to the amount of fluid flow: The light shading represents the area of precipitation; the dark shading corresponds to the area of dissolution: 
warm region. The temperature drop is enough to lower the pressure head under the lower cap and cause the warm spring to stop flowing. After the beat source has been extinct for 100,000 years, the system is entirely cooled and the temperature profile is once again governed by the geothermal gradient.

The influence of the heat plume on the silica concentration is primarily controlled by the kinetic transport. This is due to the fact that in the regions where the fluid is moving significantly, the temperature is low and nearly constant. Thus the amount of silica to be transported by the fluid is small. The dissolution and precipitation of silica directly follows the changes in temperature. During the first 3,200 years, silica is ateadily dissolved from the country rock sbove the hest plume, rapidly increasing the porcoity. No silica was precipitated out of the fuid in the outer regions during this time, due to the slow initial affect of the infltration cool rainwater. When aignificant mixing of warm and cool waters begins to take place, precipitation of silica out of the fuid occurs beneath the lower cap layer (referring back' to Figure 55, the areas of precipitation are shaded lightly, and the areas of dissolution are shaded more darkly), and the porosity of the under the lower cap is decreased.

Although the program does not calculate the change in permeabilities due to the dissolution/precipitation of silica, it is likely that the permeability above the beat plume is increased due to silica dissolution and decreased under the lower cap, due to silica precipitation. This should cause the flow patterns within the system to change continuously, moving more fuid through the areas of increased permeability and less Guid through the areas of decreased permeability. The pattern of the precipitation/dissolution within the system should remain approximately the same, but the amounts would likely be greater had the effects of the permeability change been accounted for. A greater amount of fluid would be flowing nearer to the plume to be heated. More silica would be dissolved from the bwer portion of the system and consequently more silica would be re-precipitated under the cap.

The pattern of silica dissolution/precipitation during the 100,000 years of cooling is in reverse of the 100,000 years of heating. As the warm region cools, silica 
precipitates out of the fluid. By the time the system has completely cooled, the previously dissolved silica has been re-precipitated. As mentioned above, the model cannot calculate the changes in the permesbilities of the system. Even though most of the dissolved silica has been re-deposited, the permeability of the system will not necessarily be the same for two reasons. First, the silica will not be re-deposited exactly as it was originally positioned. Second, some silica was lost from the system through the spring outlet.

Also of interest in the theoretical evolution of a lowttemperature geothermal sys: tem, is the behavior of the oxygen-18. As with the silica transport, the oxygen-18 transport is governed primarily by the kinetic reactions, throughout both the heating and cooling periods of the system. Although the kinetic rates of the oxygen-18 are not as rapid as those of the silics within the the oystem, the oxygen-18 contents still follows closely to the temperatures developing in the system. During the heating of the system, the oxygen-18 within the warm region slowly begins to increase due to kinetic transport (Figure 56). When the system cools; the oxygen-18 content slowly returns to the original lower:values.

The most interesting result seen during the beating of the system is the very high content of oxygen-18 evolving in the heated region of the system. By the end of 3,200 years of heating, the average value of the oxygen-18 content in the warmed area is -4.0 per mil. After 100,000 years of heating, the value of the oxygen-18 has increased to -1.0 per mil (see Figure 56). In most real low-temperature geothermal systems, the oxygen18 content within the system is much lower than either of these values, usually falling in a range of -7.0 to -11.0 per, mil. But, all of the oxygen-18 data reviewed by the author prior to the present study was taken several years after the initiation of production. Either the oxygen-18 content in many systems is not in isotopic equilibrium due to a very transient flow regime or the oxygen-18 is decreasing during production due to recharge from cooler waters lower in oxygen-18. Both explanations are plausible, and a choice between the two is not necessary to try to explain the behavior of every system. However, the latter explanation does lend support to the oxygen-18 content estimated previously for the Ellidaar geothermal field prior to production (see section 


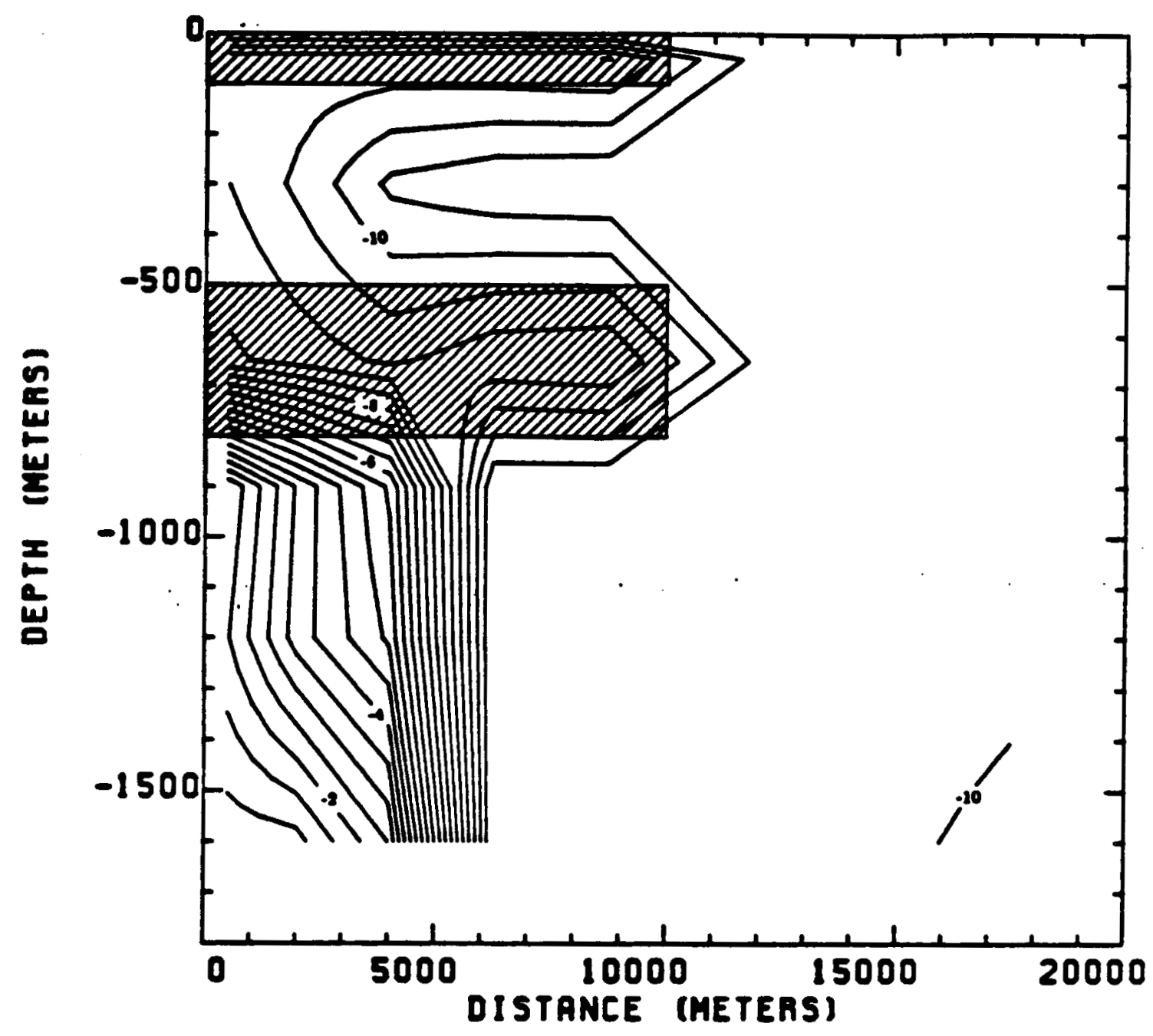

Figure 56. Oxygen-18 contours for the evolving system after 100,000 of heating. Contour units are in per mil. 
3.3).

A thorough review of the results from the theoretical studies of the plausible evolution of low-temperature systems can help to answer many questions. The areal extent of a.low-temperature system appears to be directly governed by the size of the heat source, covering only the portion directly above the incoming heat flux. Conduction appears to play a major role in heating even a permeable system, with convection being confined to the outer regions of the plume. This causes the cool water, as it nears the heat plume region at depth; to be warmed quickly and rises bouyantly, before it can travel far enough horizontally to mix with the waters directly above the plume. Without the mixing of cool and warm waters above the plume, the disolution of silica becomes significant in this region.

Also, a review of the reaults can reveal important topics for further investigation. One interesting idea arising from the study that should be pursued, is just what could be the lasting effects of silica precipitation and disiolution on the porosity and permear bility of the system. It was theorized that the pattern of precipitation and discolution would be the same after the heating cycle, whether or not permeability changes were taken into account. But, at the end of the cooling cycle, it would seem doubtful that the permeabilities within the system would remain unchanged from the original values. Another idea to pursue could be to study how much of the importance of the conductivity seen in the above study is actual, and how much is due to the design of the grid. By studying the unanswered questions such as these, important areas for further study can be sketched. 


\subsection{CONCLUSION}

The main objective of the present study was to develop a method to reliably estimate the cooling rate of a low-temperature geothermal field. To achieve this goal, the various methods of modeling geosiermal felds including hydrological methods, geochemical methods and numerical methods were carefully reviewed. Through the review, it became clear that work on modeling geothermal systems by integrating all the available data including preasure, temperature and chemical, was lacking. The present work was based on the idea that utilizing all available data on a geothermal system would enable the most reliable determinations of field parameters as well as the most detailed understanding of the system. A clear understanding of the system, its flow patterns and areas of recharge, would enable the determination of the rate of cooling of the system. Once this has been eatablished, it can be decided whether a geothermal project will be economical or not, subsequently decreasing the risk involved.in developing low-temperature geothermal systems.

To successfully integrate chemical transport into heat and mass transport modeling, a thorough background on the behavior of the chemical components common to low-temperature systems was essential. First, the chemical components found in natural waters were reviewed. Components which could not be modeled conservatively were listed and recommended to be excluded from a modeling scheme. It was found that silica and the stable isotope oxygen-18 could not be modeled conservatively, but information existed on their kinetic reactions within natural systems Their behavior was examined in greater detail so they could be incorporated into a modeling scheme which included kinetic reactions.

The next step in achieving the objective of this study involved a careful review of the equations governing mass, heat and chemical transport. The equations were then transferred into numerical form. The existing codes, PT, capable of modeling mass and heat transport and PTC, the version of PT modified previously to include silica transport, were examined. Additions made in the present study to incorporate multicomponent chemical transport were described and the performance of the new code 
tested.

Before applying the code to a field example, the sensitivity of the convective transport of components as well as the kinetic transport of silica and oxy gen-18 to various field parameters (e.g. porosity, field volume, temperature, surface area per volume, average grain radius) was examined. Next, the governing equation for chemical transport was simplified and non-dimensionalized, defining several dimensionless groups. Although an analytical solution to the equation was still not possible, the dimensionleas groups aided in reducing the number of parameters affecting the chemical transport. Further sensitivity studies were performed and their assistance in modeling: geothermal aystems was demonstrated by matching feld data from the Ellidaar geothermal field, in Iceland.

The background attained through the literature review and chemical reviews and the sensitivity studies was then applied to two field examples. The first involved the modeling of the Ellidaar geothermal field using a simple two-layer mesh. The field had been modeled previously, so the results of the present work could be compared to the results of the previous study to test the applicability of the new code. The comparison was very good, and belped to indicate the strengths of integrated multi-component, heat and mase transport modeling. The second feld example involved the Seltjarnarnes geothermal area in Iceland. Several points were demonstrated by modeling this feld. As a first step, a simple, two-layer model was chosen. By matching the temperar ture and chemistry data, eatimates for the feld volume, porosity and the amount of recharge from the cooler, more saline top relative to the side were determined. As a second step, pressure and temperature data were matched numerically, using a much finer mesh, to eatimate the permeability porosity and field volume: After confirming the results of the simpler mesh by comparison with those of the more complex model; chemical transport was added to the complex model. With the aid of chemical data the boundary between the meteoric water and seawater near the well field region was established. From the example, it was seen that chemical transport data could aid in determining field parameters, amounts and zones of recharge as well as the amount of influx into the field of waters with potentially damaging chemical constituents. 
As a final application of the code, the evolution of a hypothetical geothermal system influenced by a heat source at depth and surface infiltration of cool rainwater was examined. The theoretical example provided helpful insight into low-temperature systems. The system was allowed to evolve under the influence of the beat source to an approximate steady condition. The effects of the heat migrating in to the system combined with the percolating cool surface waters on the silica and oxygen-18 contents of the fluid were documented. Zones of silica precipitation and dissolution were determined and reviewed along with the possible effects this might have on the permeability and fow pattern of a system. It was seen that the incoming heat rapidly increased the amount of oxygen-18 in the fuid to a level greater than normally seen in most systems, ouggeating that many geothermal aystems are not in isotopic equilibrium and are much more transient than the hypothetical system modeled.

Although the main objective of the present work to develop a method of reliably predicting the cooling rate in low-temperature geothermal systems was achieved, there are some drawbacks that must be understood. A major drawback involves the kinetic reactions of silica and oxygen-18. The kinetic reactions are governed significantly by the value of the surface area per volume $(A / V)$, or in the case of oxygen-18, the average grain radius $(\omega)$. It is very difficult to measure either of these values in the field. From the results documented on the field examples in section 4.3, $\omega$ appears to be an effective average grain radius, characterized by the size of the blocks within the system surrounded by fluid flow and not the size of the actual grains. The method of using the kinetic information gained on one component to determine the kinetic data on the other by using Eq. 50 alleviates this problem, if data on both oxygen-18 and silica are available. However, the field data available to teat the theory relating the $(A / V)$ and ( $\omega)$ ralues was not sufficient to demonstrate that the theory was firmly established.

A second drawback also concerns kinetic reactions. In both of the field examples investigated, the role of the kinetic transport of oxygen-18 was insignificant when compared to the convective transport. This suggests that oxygen-18 could be considered a conservative species. In general, modeling more than two conservative species will be redundant. The more components that are available with quantitative information on 
their kinetic behavior, the more information that can be gained on a system being studied. If oxygen-18 behaves essentially as a conservative species within low-temperature geothermal systems, it will not be as significant an aid in modeling. The conservative species are modeled on the basis of a mass balance determined by the fluid in minus the tuid out of a particular node. Thus, the rate of change for all conservative species will be the same, and no new information will be gained: However, as a side note, it is good practice to model two conservative species, as it is unknown bow significantly a species will enter in to ionic-exchange or other reactions. By modeling two species, effects of reactivity on either species can be averaged out.

There are exceptions to the statement that modeling more than two conservative apecies will give redundant reaults. If the field date on the chemistry of a oystem indicates that several species show different or opposing patterns of change with time, it is most likely due to separate zones of recharge containing luids of differing concentran tions. In this case, to achieve the most accurate simulation, all components exhibiting differing behavior should be included in the modeling scheme. An example of this is the change with time in the oxygen-18 content of Seltjarnarnes as compared to the change with time in the chloride content. The kinetic transport of oxygen-18 in the Seltjarnarnes field is insignificant relative to the convective transport, thus could be considered in this case a conservative species. Although the chloride in the system increased rapidly due to the influx of seawater into the system, the oxygen-18 content showed a slight decrease with time even though the seawater had a much higher oxygen-18 content than that of the meteoric water. This is a clear indication that there must be another source of water recharging the field; containing a lower oxygen-18 content than the water originally in the system.

The problem then encountered is how to model this new source of recharge. In order to best utilize chemical modeling, there must be information available on, not only the field area, but also on the fluids in the surrounding regions. This information is rarely available, thus the quality of the chemical modeling is lowered significantly. Where these data are available, the information gained by chemical modeling will be substantial as well as reliable. 
Understanding the shortcomings of chemical modeling is a necessary first step towards solving them. Future work should include a more extensive study of the kinetic behavior of silica and oxygen-18 to determine the connection, if any, between the values for $A / V$ and $\omega$. As the benefits of utilizing chemical data become more evident, the methods of gathering information on the chemistry of geothermal systems should be improved and extended. 
$-128$

APPENDIX A: EQUATION OF STATE FOR LIQUID WATER (SOURCE: BODVARSSON, 1982)

The. viscosity of liquid water is calculated based on the following

expression:

$$
u=d_{1} 10^{\left[\frac{d_{2}}{T+d_{3}}\right]}
$$

where $d_{1}=2.414 \times 10^{-5}, d_{2}=247.8$, and $d_{3}=133.15$. The fluid density is calculated as a function of pressure and temperature as follows (Buscheck, 1980):

$$
P(P, T)=A(T)+C(T) \cdot B(P)
$$

where

$$
\begin{aligned}
A(T)=a_{1} & +a_{2}\left(T-T_{\text {ref }}\right)+a_{3}\left(T-T_{\text {ref }}\right)^{2} \\
& +a_{4}\left(T-T_{\text {ref }}\right)^{3}+a_{5}\left(T-T_{\text {ref }}\right)^{4} \\
B(P)=b_{1} & +b_{2}\left(P-P_{\text {ref }}\right)+b_{3}\left(P-P_{\text {ref }}\right)^{2} \\
& +b_{4}\left(P-P_{\text {ref }}\right)^{3} \\
c(T)= & c_{1}+c_{2}\left(T-T_{\text {ref }}\right)+c_{3}\left(T-T_{\text {ref }}\right)^{2} \\
& +c_{4}\left(T-T_{\text {ref }}\right)^{3}+c_{5}\left(T-T_{\text {ref }}\right)^{4} \\
& +c_{6}\left(T-T_{\text {ref }}\right)^{5}+c_{7}\left(T-T_{\text {ref }}\right)^{6}
\end{aligned}
$$


The coefficients are:

$$
\begin{aligned}
& 0<T<199^{\circ} \mathrm{C}, T_{\text {ref }}=100^{\circ} \mathrm{C} \\
& a_{1}=.96628 \\
& a_{2}=-.70650 \times 10^{-3} \\
& a_{3}=-.28521 \times 10^{-5} \\
& a_{4}=.59365 \times 10^{-8} \\
& a_{5}=.32285 \times 10^{-10}
\end{aligned}
$$

$199<T<350^{\circ} \mathrm{C}, T_{\text {ref }}=260^{\circ} \mathrm{C}$

$$
\begin{aligned}
a_{1} & =.79829 \\
a_{2} & =-.14906 \times 10^{-2} \\
a_{3} & =-.57448 \times 10^{-5} \\
a_{4} & =.40265 \times 10^{-7} \\
a_{5} & =.17661 \times 10^{-9} \\
p<x_{1} & =70 \\
b_{1} & =-.12953 \times 10^{-2} \\
b_{2} & =.51594 \times 10^{-4} \\
b_{3} & =-.99714 \times 10^{-8} \\
b_{4} & =.10275 \times 10^{-9}
\end{aligned}
$$

$0<T<149^{\circ} \mathrm{C}, C(T)=1.0$ 


$$
\begin{aligned}
& 140<T<220^{\circ} \mathrm{C}, T_{\text {Ief }}=180^{\circ} \mathrm{C} \\
& c_{1}=1.2092 \\
& c_{2}=.70811 \times 10^{-2} \\
& c_{3}=.71415 \times 10^{-4} \\
& c_{4}=-.79423 \times 10^{-6} \\
& c_{5}=-.53925 \times 10^{-8} \\
& c_{6}=.5148 \times 10^{-9} \\
& c_{7}=-.54612 \times 10^{-11} \\
& 220<\mathrm{T}<350^{\circ} \mathrm{C}, T_{\text {ref }}=260^{\circ} \mathrm{C} \\
& c_{1}=.2 .2437 \\
& c_{2}=.23865 \times 10^{-1} \\
& c_{3}=.215671 \times 10^{-4} \\
& c_{4}=.81759 \times 10^{-7} \\
& c_{5}=.54541 \times 10^{-8} \\
& c_{6}=.36389 \times 10^{-8} \\
& c_{7}=.48355 \times 10^{-11}
\end{aligned}
$$


This density function is accurate to within 1 for $0<\mathrm{T}<300^{\circ} \mathrm{C}$, and 5, for $300<T<350^{\circ} \mathrm{C}$. The fluid compressibility and thermal expansivity are calculated from the density function on the basis of their definitions:

$$
\begin{aligned}
& B_{W}=\left[\frac{1}{\rho} \frac{d p}{d P}\right]_{T} \\
& \alpha_{W}=\left[\frac{1}{\rho} \frac{d \rho}{d T}\right]_{P}
\end{aligned}
$$




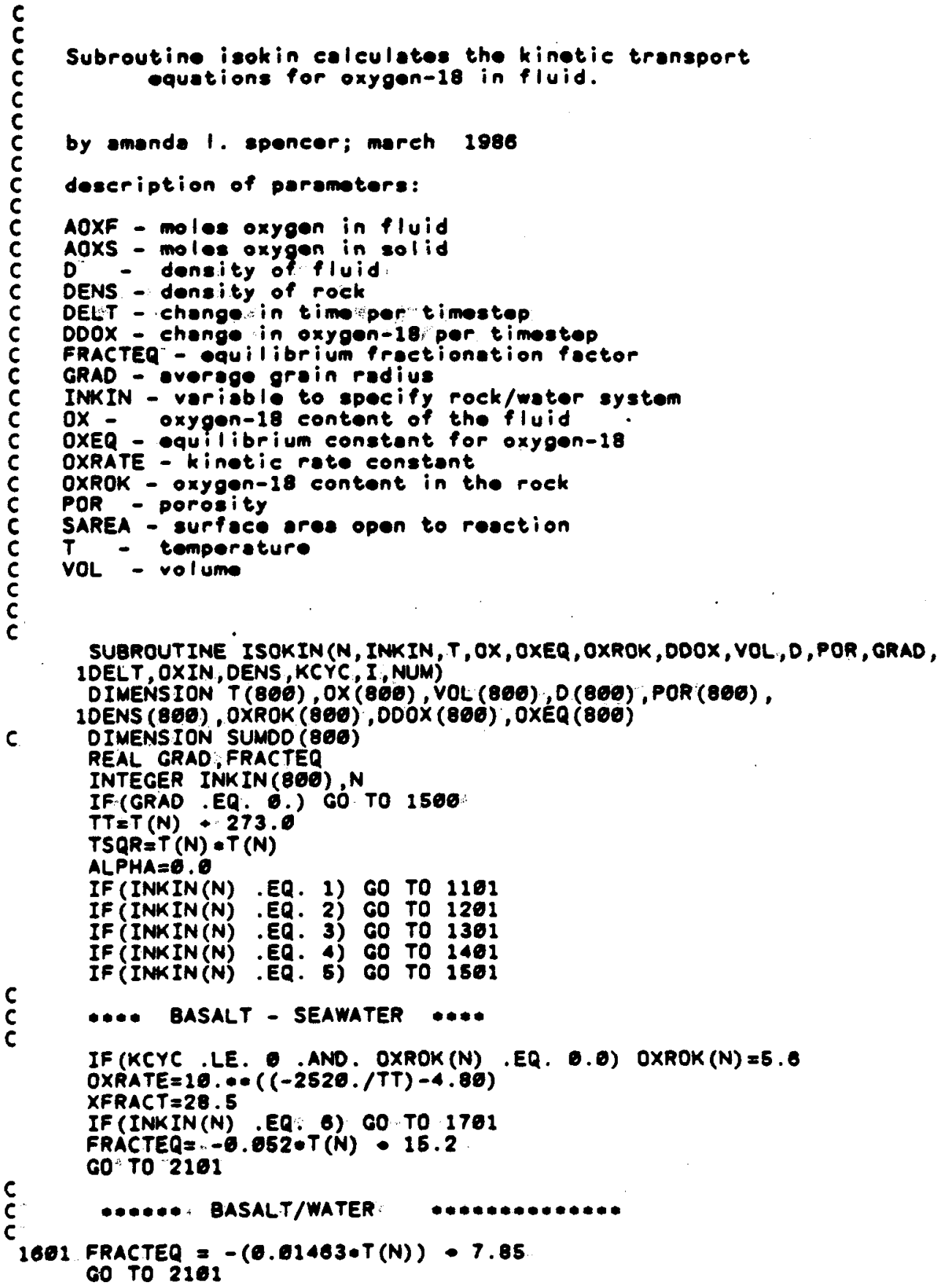




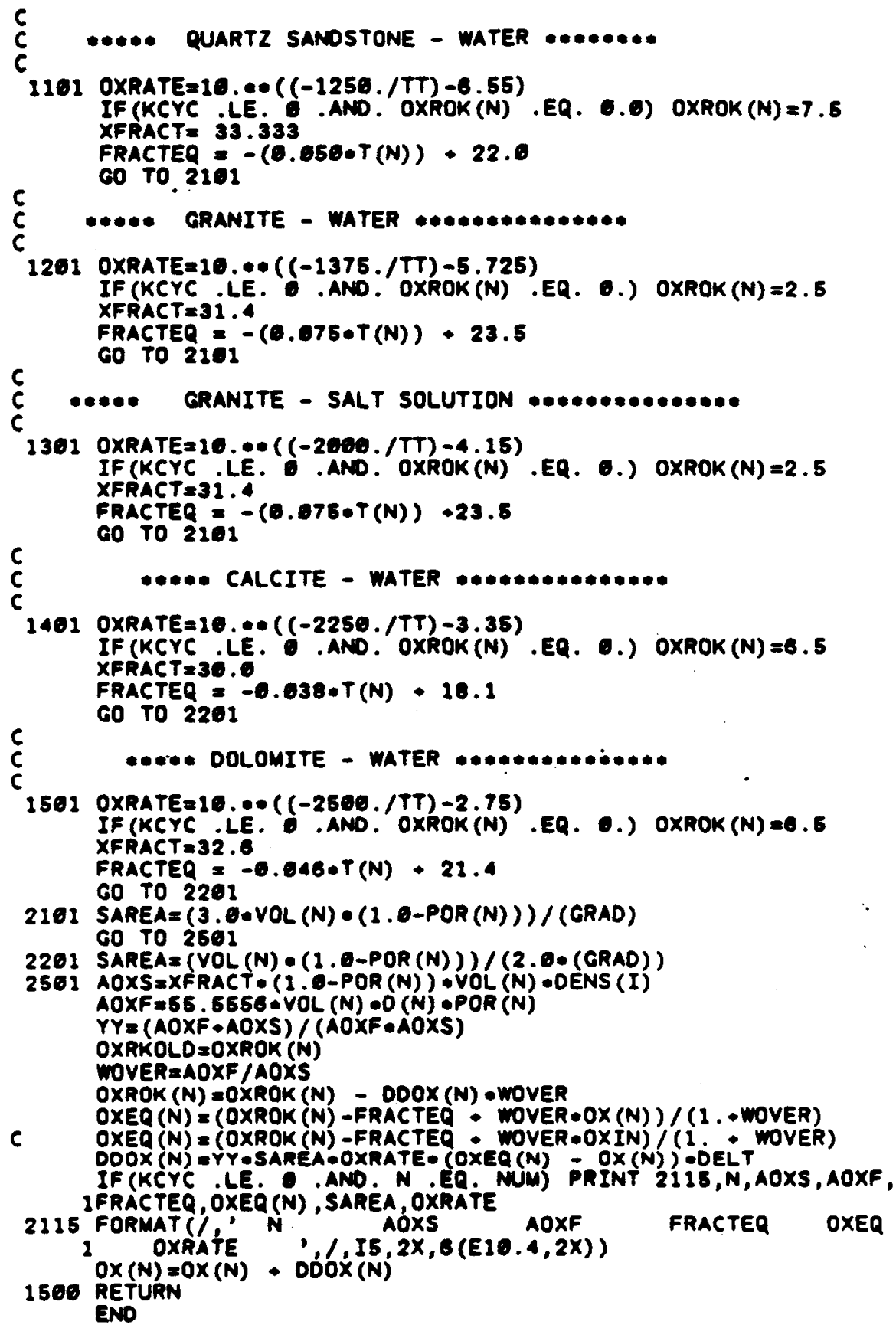




\section{REFERENCES}

ADAMS M.C. - Geochemistry of the Wendel-Amedee Geothermal Systems, California; Geothermal Resources Council, TRANSACTIONS, Vol. 8, August 1979 AIREY, P.L., G.E. CALF, P.E. HARTLEY - Use of Environmental Isotopes and Artificial Tracers to Study Recharge to Groundwater in the Burdekin Delta, Queenland; Isotope Hydrology, proceedings symposium, IAEA, 1974

ARP, J.J. - Analysis of Decline Curves; Transactions, AMME, 228, 1945

ARP, J.J. - Estimation of Primary Oil Reserves; Transactions, AME, 207, 1956

BENSON; S.M. - Well Test Data Analysis from a Naturally Fractured, Liquid-

Dominated System; Geothermal Resources Council, TRANSACTIONS; Vol.6, October 1982

BODVARSSON, G.S. - Mathematical Modeling of the Behavior of Geothermal Systems under Exploitation; PhD. Thesis, U.C. Berkeley, 1982

BOHLMANN, E.B., R.E. MESMER, P.BERLINSKI - Kinetics of Silica Deposition from Simulated Geothermal Brines; Oak Ridge National Laboratory; Dept. of Energy, 1980

BUSCHECK, E.B. - Equation of State for Liquid water; LBL-Internal Memo, Lawrence Berkeley Laboratory, Berkeley, California, 1980

CAPUANO, R.M. - Water Chemistry as an Aid in Reconnaissance Exploration for a Low-Temperature Geothermal System; Artesian City Area; Idaho; Geothermal. Resources Council, TRANSACTIONS, Vol. 5, October 1981

CATHLES, L.M. - An Analysis of the Cooling of Intrusives by Ground Water Convection which Includes Boiling; Economic Geology, Vol. 72, p.804-826, 1977 CHENG, P., K.C. YEUNG, K.H. LAU - Numerical Solutions for Steady Free Convection in Island Geothermal Reservoirs; from "Future Energy Production Systems", p.429-448, Hemisphere Publishing Corp., Washington D.C., 1976

CHENG, P. - Heat Transfer in Geothermal Systems; from "Advances in Heat Transfer", Vol. 14, copywright 1978, Academic Press

CLAYTON, R.N., J.R. O'NEIL, T.K. MAYEDA - Oxygen isotope exchange between quartz and water; J. Geophysical Research, Vol. 77, p.3057- 3067, 1972

COATS, K.H. - Geothermal Reservoir Modeling; paper presented at the SPE 52nd Annual Fall Technical Conference and Exhibition, Denver, Colo., SPE-6892, 1977

COLE, D.R., H. OHMOTO, A.D. LASAGA - Isotopic Exchange in Mineral-Fluid 
Systems. 1. Theoretical evaluation of Oxygen Isotopic Exchange Accompanying Surface Reactions and Diffusion.; Geochimica et Cosmochimica Acta, Vol. 47, No. 10, October 1983

COLE, D.R., M.T. MOTTL, H. OHMOTO - Isotopic Exchange in Mineral-Fluid Sys tems. 2. Oxygen and Hydrogen Isotopic Investigation of the Experimental Basalt/Seawater System.; submitted to Geochimica et Cosmochimica Acta, 1986 COLE, D.R. - Time Estimates for Oxygen Lotopic During Minerat-Fluid Interaction in Hydrothermal Systems; Geothermal Resources Council, TRANSACTIONS, Vol. 7, October 1983

COLELLA, P. - Multidimensional Upwind Methods for Hyperbolic Conservation Laws; LBL 17023, Lawrence Berkeley Laboratory, Berkeley, California, 1984

CRAIG, H. - The Isotopic Geochemistry of Water and Carbon in Geothermal Areas; in "Nuclear Geology in Geothermal Areas: Piea, Italy.", Consiglio Nazionale delle Laboratorio de Geologis Nuclear, p. 17-53, 1063

DOMaNGUEZ, B. A., M.J. LIPPMANN - Some Comments on the Le Primavera Geothermal Field, Mexico; Proceedings Ninth Workshop Geothermal Reservoir Engineering Stanford University, Stanford, Californis, December 1983

DUFF, I.S. - MA-28: A Set of Fortran Subroutines for Sparse Unsymmetric Linear Equations; AERE Harwell Report R 8730, July 1977

EDWARDS, A.L. - TRUMP: A Computer Program for Transient and Steady State Temperature Distribution in Multidimensional Systems; Lawrence Livermore Laboratory, Livermore, California, UCRL-14754, Rev. 3, 1972

ELDER, J.W. - Steady-Free Convection in a Porous Medium Heated from Below; J. Fluid Mechanics, 1967, Vol. 27, p.29-48

FAUST, C.R., J.W. MERCER - Geothermal Resevoir Simulation: Mathematical Models for Liquid- and Vapor-dominated Hydrothermal Systems; Water Resources Research, February 1979

FOUILlAC, C., G. MICHARD - Sodium/Lithium Ratio in Water Applied to the Geothermometry of Geothermal Waters; Geothermics, Vol. 10, p. 55.70, 1980 FOURNIER, R.O. - Chemical Geothermometers and Mixing Models for Geothermal Systems.; Geothermics, Vol. 5, p. 41-50, 1977

FOURNIER, R.O., R.W. POTTER- An Equation Correlating the Solubility of Quartz in Water from $25^{\circ} \mathrm{C}$ to $900^{\circ} \mathrm{C}$ at Pressures up to 10,000 bars; Geochimica et Cosmochimca Acta, Vol. 46, p. 1969-77, June 1982

FOURNIER, R.O., R.J. ROSENBAUER, J.L. BISCHOFF - The Solubility of Quartz in 
Aqueous Sodium Chloride Solution at $350^{\circ} \mathrm{C}$ and 180 to 500 bars.; Geochimica et Cosmochimica Acta, Vol. 46, p. 1975-1978, 1982

FOURNIER, R.O., A.H. TRUESDELL - An Emperical Na-K-Ca Geothermometer for

Natural Waters; Geochimica et Cosmochimica Acta, Vol. 37, p. 1255 -1275, 1973

FRIEDMAN, I., J.R. O'NEIL - Compilation of Stable Isotope Fractionation Factors of

Geochemical Interest; Geological Survey Profesaional Paper, 440-KK, 1977

GARG, S.K., J.W. PRITCHETT, D.H. BROWNELL - Transport and Energy in

Porous Media; Proceedings, Second U.N. Symposium on the Development and

Use of Geothermal Resources, San Franscisco, 3, p. 1651, 1975

GERTSCH, W:D., R.W. JUNCAL - Low to Moderate Temperature Direct Use Geoth-

ermal Projects in N. Eastern, California; Goothermal Resources Council, TRAN-

SACTION, Vol. 8, Aug. 1984

GIGENBACH, W.F., R. GONFLNTINI, B.L. JANGI, A.G. TRUESDELL - Isotopic and Chemical Componition of Parbati Valley Geothermal Discharges, NorthWest Himalaya, India; Geothermics, Vol. 12, p. 199-222, 1983

GILLETI, B.J., T.F. ANDERSON - Studies in Diffusion-II. Oxy gen in phlogopite Mica; Earth Planet Science Letters, Vol. 28, p. 225-233, 1975

GILLETI, B.J., M.P. SEMET, R.A. YUND - Studies in Diffusion-III. Oxygen in Feldspars: an Ion Microprobe Determination; Geochimica et Cosmochimica Acta, Vol. 42, p. 45-47, 1978

GUDMUNDSON, J.S., G. PALMASON - World Survey of Low Temperature Geothermal Energy Utilization; LAE Report, p. 148, 1981

GUDMUNDSON, J.S., G. PALMASON - World Uses of Low Temperature $\left(<150^{\circ} \mathrm{C}\right)$ Geothermal Resources in 1980; Geothermal Resources Council, TRANSACTIONS, Vol. 6, October 1982

HALFMAN, S.E., M.J. LIPPMAN, R. ZELWER, J.H. HOWARD - Identification of Fluid Flow Paths in the Cerro Prieto Geothermal Field; Geothermal Resources Council, TRANSACTIONS, Vol. 6, October 1982

HEM, J.D. - Study and Interpretation of the Chemical Characteristics of Natural Water; Geological Survey Water Supply Paper 1473, 1970

HETTLING, H.K. - The Chemical and Isotopic Changes in the Low-Temperture Areas of Laugarnes, Ellidaar and Reykir.; UNU Geothermal Training Programme, Iceland, Report 1984-3, 1984

HENLEY, R.W., A.H. TRUESDELL, P.B. BARTON - "Fluid-Mineral Equilibria In Hydrothermal Systems.", reviews in Economic Geology, The Economic Geology 
Publishing Company, copywright 1984

HILFIKER, K., C. HANLEY, D. HODGE, P. MORGAN, J. MAXWELL, C.SWANBERG - Correlation of Silica Heat Flow and Temperature Gradients, Central and Western New York; Geothermal Resources Council, TRANSACTIONS, Vol. 4, September 1980

HOWARD, K. - Principal Conclusions of the Committee on the Challenges of Modern Society Non-electrical Applications Project; Proceedings, Second U.N. Symposium on the Development and Use of Geothermal Resources, San Franscisco, p 2127-2139, 1975

HULEN, J.H., D.L. NIELSON - Stratigraphic Permeability in the Baca Geothermal System, Redondo Creek Area, Valles Caldera, New Mexico;

ITOI, R., H. MAEKAWA, K. TATSUTA, M. FUKADA, K. JNNO, K. HATANAKA, T. YOKOYAMA - Experimental Study on the Silica Deposition in a Porous Medium; Geothermal Remources Council, TRANSACTIONS, Vol. 8, August 1984

ITOI, R., H. MAEKAWA, K. TATSUTA, M. FUKADA, K. JNNO, K. HATANAKA, S. NASAKI, T. YOKOYAMA - A Mathematical Model of Silica Deposition in a Porous Medium; Geothermal Resources Council, TRANSACTIONS, Vol. 9, August 1985

KANDARPA, V., O.J. VETTER - Prediction of Salt Pricipitations Due To Injecting Foreign Waters into Geothermal Reservoirs; Geothermal Resources Council, TRANSACTIONS, Vol. 5, October 1981

KANG, J.M., J.AHERN - Finite Element Analysis of a Thermal Flow Motion in Geothermal Chambers; Geothermal Resources Council, TRANSACTIONS, Vol. 8, August 1984

KEITH, L.A., P.T. DELANEY, D.E. MOORE - Permeability Reduction Due to Precipitation of Quartz Under Non-isothermal Conditions; Proceedings Ninth Workshop Geothermal Reservoir Engineering, Stanford University, Stanford, California; Dec. 1983

KONIKOW, L.F. - Modeling Chloride Movement in the Alluvial Aquifer at the Rocky Mountain Arsenal, Colorado; USGS Water Supply Paper \# 2049, 1977

KRISTMANNSDOTTIR, H. - Exploitation Induced Infiltration of Seawater into the Seltjarnarnes Geothermal Field, Geothermal Resources Council TRANSACTIONS, Vol. 9, August 1985

KRISTMANNSDOTTIR, H. - Geochemistry of the Seltjarnarnes Geothermal Field, 
Iceland National Energy Authority, Report OS-83106/JHD-19, 1983

LAI, C.H., G.S. BODVARSSON, P.A: WITHERSPOON - Numerical Studies of Silica Precipitation/Dissolution; Economic Geology, 1984

LAI, C.H. - Mathematical Models of Thermal and Chemical Transport in Geologic Medie; Ph.D. Thesis, U.C. Berkeley, Berkeley, California, December 1985

LASSETER, T.J., P.A. WITHERSPOON, M.J. LIPPMAN - Multiphase, Multidimensional Simulation of Geothermal Systems; Proceedings, Second U.N. Symposium on the Development and Use of Geothermal Resources; San Fransisco, California, 3, p1715-1723, 1975

LI, T.M.C. - Axisymmetric Numerical Simulation of Hydrothermal Systems Including Changes in Porosity and Permeability Due to Silica-Water Reactions; Pb.D. thesis, Penn. State University, 240 p., 1980

LIPPMANN, M.J., G.S. BODVARSSON - The Heber Geothermal Field, California: Natural State and Exploitation Modeling Studies; J. Geophysical Research, Vol. 90 , No. 131 , p. $745-58$, Jan. 1985

MERCER JR., J.W., G.F. PINDER, I.G. DONALDSON - A Galerkin Finite Element. Analysis to the Hydrothermal System at Wairakei, New Zealand; J. of Geophysical Research, Vol: 80, 17, p. 2608-2621.

MICHELS, D.E. - A Simple Formula for Saturation Temperature/Pressure of $\mathrm{NaCl}$ Solutions; Proceedings Ninth Workshop Geothermal Reservoir Engineering Stanford Universitb, Stenford,California, December 1983

MOENCH, A.F. - Steam Transport in Porous Media; Proceedings Second Workshop Geothermal Reservoir Engineering, Stanford University, Stanford, California, 1976

MOORE, D.E., C.A. MORROW, J.D. BYERLEE, - SiO2 Precipitation Accompanying Fluid Flow Through Granite Held in a Temperature Gradient; Proceedings, Seventh Workshop Geothermal Reservoir Engineering, Stanford University, Stanford, California, 1981

NARASIMHAN, T.N., P.A. WITHERSPOON - An Integrated Finite-Difference Method for Analyzing Fluid Flow in Porous Media; Water Resources_Research, 12,1, p. $57-64,1976$

NORTHROP, D.A., R.N. CLAYTON - Oxygen lsotope Fractionation in Systems Containing Dolomite; J. Geology, Vol. 74, p.174-196, 1966

NORTON, D., H.P. TAYLOR - Quantitative Simulation of the Hydrotbermal Systems of Crystallizing Magmas on the Basis of Transport Theory and Oxygen Isotope 
Data: An Analysis of the Skaergaard Intrusion; J. Petrology, Vol. 20, part 3, p. 421-486, 1979

NORTON, D., J. KNIGHT - Transport Phenomena in Hydrothermal Systems: Cooling Plutops; Am. J. of Science, Vol 277, p.937-981, October 1977

O'NEIL, J.R., Y.K. KHARAKA - Hydrogen and Oxygen Isotope Exchange Reactions between Clay Minerals and Water; Geochimica et Cosmochimica Acta, Vol. 40, p.241-246, 1976

O'NEIL, J.R., H.P. TAYLOR JR. - Oxygen Isotope Equilibrium between Muscovite and Water; J. Geophysical Research, Vol. 74, p. 6012-6022, 1969

O'NEIL, J.R., R.N. CLAYTON, T.K. MAYEDA - Oxygen Isotope Fractionation in Divalent Metal Carbonstes; J. Chem. Phys., Vol. 51, p. 5547-5558, 1968

O'NEIL, J.R., H.P. TAYLOR JR. - The Oxygen lsotope and Cation Exchange Chemistry of Feldapar; Amer. Mineral., Vol. 52, p.1414-1437, 1967

O'NEIL, J.R. - Oxygen lootope Fractionation Studies in Mineral Systems; PhD. Thesis, University of Chicago, 1963; (unpublished)

PAYNE, B.R., Y.YURTSEVER - Environmental Isotopes as a Hydrologeological Tool in Nicargua; Lotope Hydrology, proceedings symposium at Vienna, LAEA, 1974

PARMENTIER, E.M. - Numerical Experiments on O-18 Depletion in Igneous Intrusion Cooling by Groundwater Convections; J. Geophysical Research, Vol. 86, No. 88, p. 7131-7144, August 1981

PANICHI, C., R. CELATI, P. NOTO, P. SQUARCI, L. TAVVI, E. TONGIORGI Oxygen and Hydrogen Isotope Studies of the Larderello (Italy) Geothermal System; Isotope Hydrology, proceedings symposium at Vienna, LAEA, 1973

PRUESS, K., J.M. ZERZAN, R.C. SCHROADER - Description of the ThreeDimensional Simulator SHAFT78 for Use in Geothermal Reservoir Studies; paper presented at the SPE Fifth Symposium on Reservoir Simulation, Denver, Colorado; SPE 7699, 1979

RANA, R., R.N. HORNE, P.CHENG - Natural Convection in a Multilayered Geothermal Reservoir; J. of Heat Transfer, Vol. 101, August 1979

RIMSTIDT, J.D., H.L.BARNES - The Kinetics of Silica-Water Reactions; Geochimica et Cosmochimica Acta, Vol. 44, p. $1683-991979$

ROBINSON B.A., - Quartz Dissolution and Silica Deposition in Hot Dry Rock Geothermal Systems, LA-9404-T, Los Almos Laboratory, July 1982

SOREY, M.L. - Numerical Modeling of Liquid Geothermal Systems; Ph.D. thesis, U.C. Berkeley, Berkeley, California, 1975 
TAYLOR JR., H.P. - Oxygen and Hydrogen Isotope Relationships in Hydrothermal Mineral Deposits; in "Geochemistry of Hydrothermal Ore Deposits", Second Edition, p. 356-377, 1979

THOMPSON, J.M., A.L. GRUNDER, W. HILDRETH - Selected Chemical Analysis and Geothermometry of Hot Spring Waters from the Calabozos Caldera, Central Chile; Geothermal Resources Council, TRANSACTIONS, Vol. 7, October 1983

TILLOTSON, P.M., D.R. NIELSEN- Scale Factors in Soil Science; Soil Science Society of America Journal, Vol. 48, no. 5, Sept.-Oct. 1984

TOMASSON, J., G.K. HALLDORSSON - The Cooling of the Selfoss Geothermal Area,

South Iceland; Geothermal Resources Council, TRANSACTIONS, Vol. 5, October 1981

TOMASSON, J. - The Selfoes Geothermal Area; Icelandic NEA Report, 1966 TONANI, F.B., M.A. TEILMAN - Geochemistry at Momotombo, Nicaragua: One Aspect in a Geothermal Field Case History; Geothermal Resources Council, TRANSACTIONS, Vol. 4, September 1980

TORONY, R.M., FAROUQ ALI - Twophse, Two-Dimensional Simulation of a Geothermal Reservoir and the Wellbore System; paper presented at the SPE $\$$ 50 sup th $\$$ Annual Fall Meeting, Dallas, Texas, SPE-5521, September 1975

TRUESDELL, A.H., F D'AMORE, D.NIEVA - The Effects of Localized Aquifer Boiling on Fluid Production at Cerro Prieto; Geothermal Resources Council, TRANSACTIONS, Vol. 8, August 1984

TULINIUS, H., G.S. BODVARRSON, A.L. SPENCER, H. KRISTMANNSDOTTIR, T. THORSTEINSSON - Reservoir Studies of the Seltjarnarnes, Iceland Geothermal Field.; Proceedings Twelfth Workshop Geothermal Reservoir Engineering, Stanford University, Stanford, California, January 1987

VAN LEER, B. - Towards the Ultimate Conservative Difference Scheme IV: A New. Approach to Numerical Convection; J. Comp. Physics, Vol. 23; p. 276-99; 1977

YUND, R.A., T.F. ANDERSON - The Effect of Fluid Pressure on Oxygen Isotope Exchange between Feldspar and Water; Geochimica et Cosmochimica Acta, Vol. 42, p. 235-239, 1978

YUND, R.A., T.F. ANDERSON - Oxygen Isotope Exchange between Potassium Feldspar and $\mathrm{KCl}$ Solutions; in "Geochemical Transport and Kinetics", Carnegie Institute, Washington Publishing (eds A.W. HOFMANN et al.), Vol. 634, p. 99-105,1974 
ZAIS, E.J., G. BODVARSSON - Production Decline Analysis; Geothermal Resources Council, TRANSACTIONS, Vol. 4, September 1980 